\title{
NEW ZEALAND SECONDARY SCHOOL TEACHERS' \\ PERCEPTIONS AND PRACTICES \\ TOWARD \\ CURRICULUM INTEGRATION
}

SUSAN ARROWSMITH

\author{
A thesis submitted to the \\ Victoria University of Wellington \\ in fulfilment of the requirements for the degree of \\ Master of Education
}

Victoria University of Wellington

2013 



\section{CONTENTS}

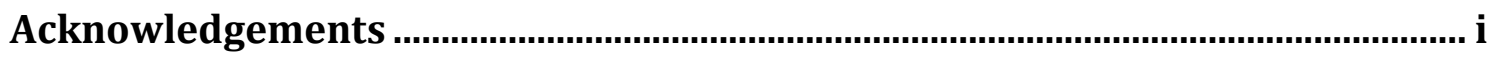

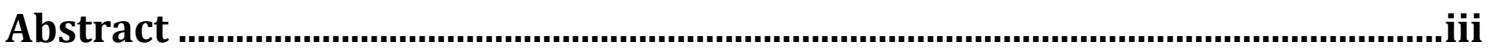

Chapter 1: INTRODUCTION

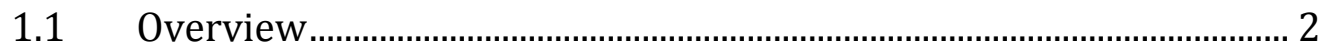

1.2 Contextual background to the research .............................................. 4

$1.3 \quad$ Research topic and questions................................................................ 5

1.4 Personal incentive for research ............................................................. 6

1.5 Thesis structure ....................................................................................... 7

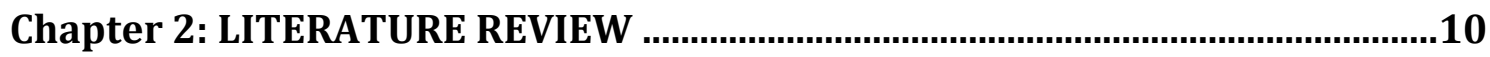

2.1 Chapter introduction ...........................................................................10

2.2 Descriptions and interpretations of curriculum integration ..........10

2.2.1 Trans-disciplinary integration .........................................................13

2.2.2 Inter-disciplinary integration ......................................................... 14

2.2.3 Multi-disciplinary integration ............................................................ 14

$2.3 \quad$ History of curriculum integration.............................................................16

2.4 Previous curriculum integration research .........................................18

2.5 Relevance of curriculum integration to education today ..................18

2.6 New Zealand Curriculum and curriculum integration ......................22

2.7 Theoretical frameworks of curriculum integration............................25

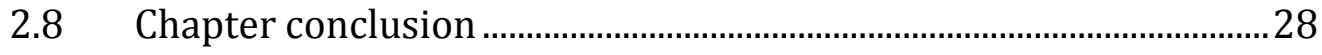

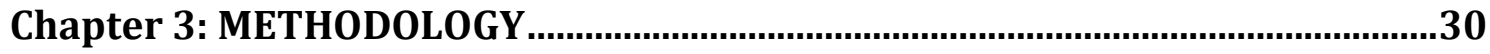

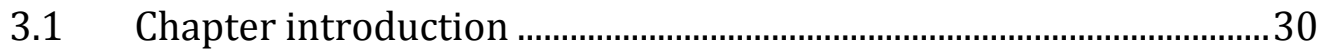

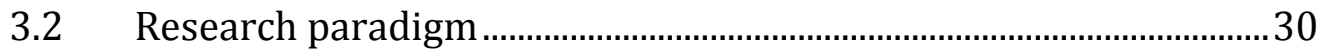

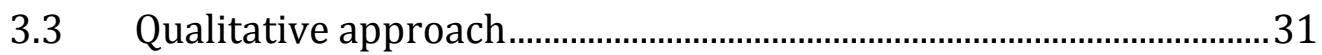

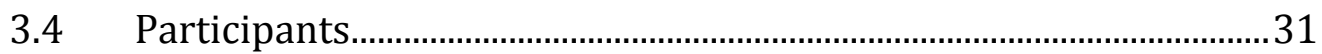

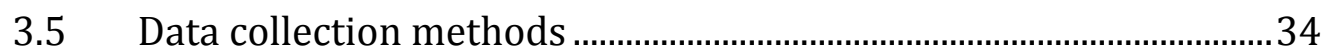

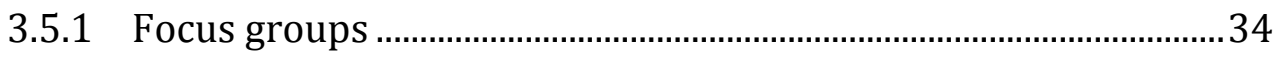

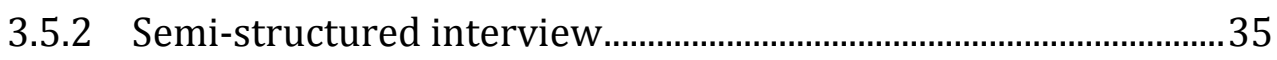

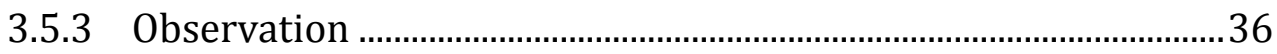

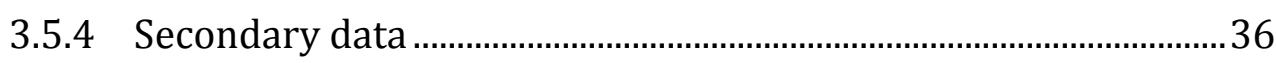

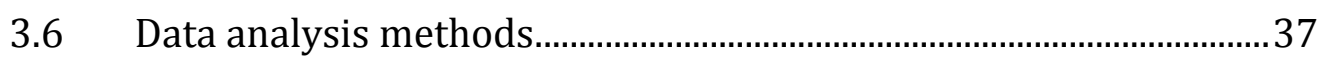




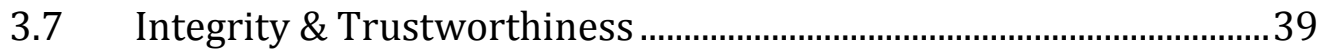

3.8 Ethical considerations ……………....................................................... 40

$3.9 \quad$ Limitations of study ................................................................................ 41

Chapter 4: SECONDARY SCHOOL TEACHERS' PERCEPTIONS TOWARD

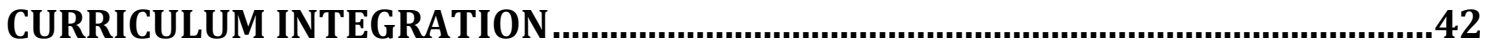

$4.1 \quad$ Chapter introduction ............................................................................ 42

4.2 Description of case study schools .........................................................42

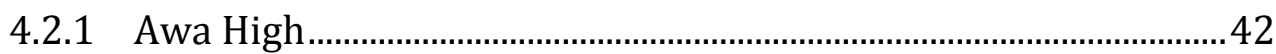

4.2.2 Pakirehua College ............................................................................... 45

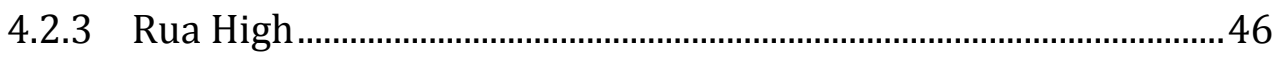

4.2.4 Niu College ................................................................................. 47

4.2.5 Description summary .....................................................................49

4.3 Why curriculum integration? ................................................................50

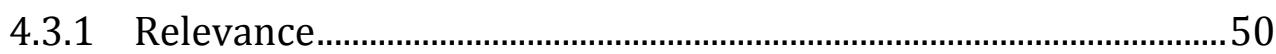

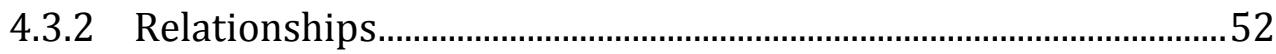

4.3.3 Knowledge and understanding ……..................................................53

4.3.4 New Zealand Curriculum....................................................................55

4.4 Teachers' discussions of the theoretical foundations of integration58

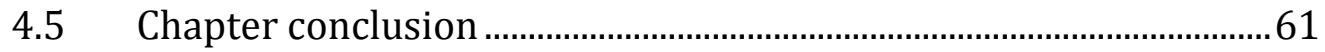

Chapter 5: SECONDARY SCHOOL TEACHERS' PRACTICES TOWARD CURRICULUM

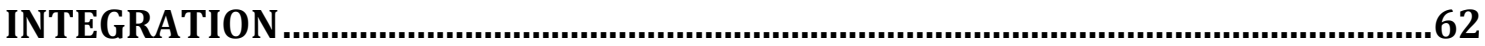

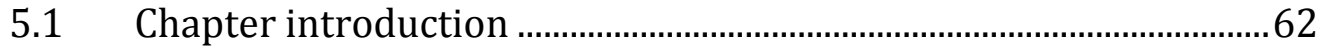

5.2 Types of curriculum integration: perceptions vs. practice ..............62

5.2.1 Trans-disciplinary integration ........................................................63

5.2.2 Multi-disciplinary and inter-disciplinary integration ...................67

5.2.3 Student-centeredness .......................................................................70

5.3 Support towards curriculum integration implementation...............72

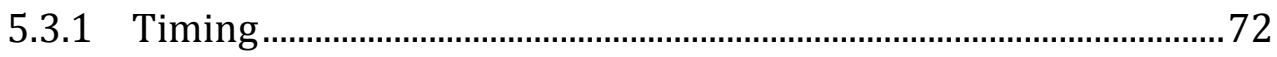

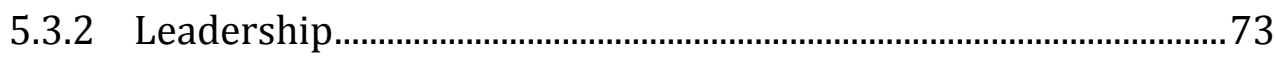

5.3.3 Support from senior management................................................... 73

5.3.4 Support from other colleagues......................................................... 75

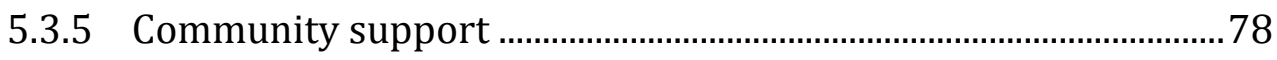

5.3.6 Professional Development........................................................... 79

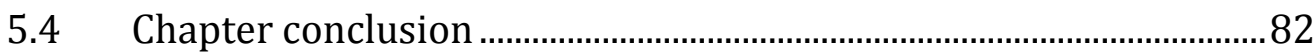




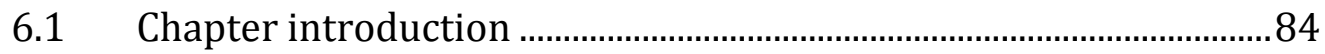

6.2 Factors enhancing and impeding curriculum integration................84

6.2.1 Whole school or trial beginnings........................................................ 85

6.2.2 Leadership \& Support........................................................................ 87

6.2.3 Impetus from the 2007 New Zealand Curriculum..........................90

6.3 Reasons for implementation: pragmatism or theoretical ................92

6.4 How perceptions aligned with practices...............................................94

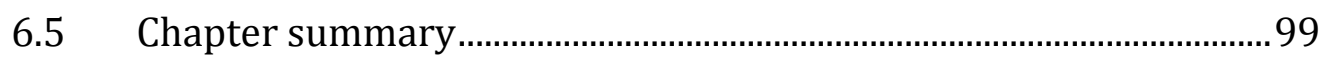

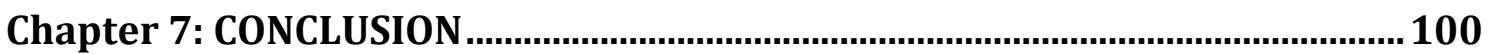

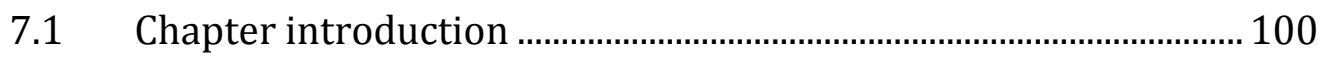

7.2 Revisiting the research questions.................................................... 100

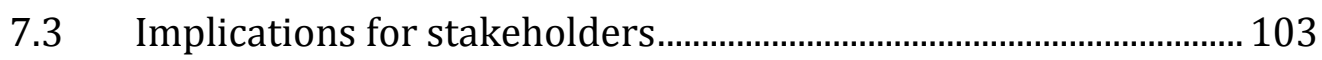

7.4 Further research in this area ............................................................... 104

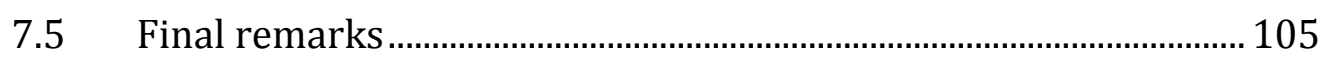

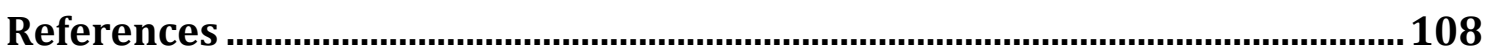

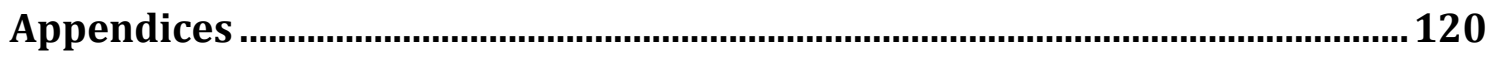

Appendix 1: Information sheet for schools ..................................................... 120

Appendix 2: Consent to participation in research - schools ........................ 122

Appendix 3: Information sheet for teachers .................................................... 123

Appendix 4: Consent to participation in research: teachers....................... 125

Appendix 5: Information sheet for Principals \& nominees .......................... 126

Appendix 6: Consent to participation in research: Principals .................... 128

Appendix 7: Demographic information ....................................................... 129

Appendix 8: Observation protocol..................................................................... 130 


\section{List of figures}

Figure 2.1: Curriculum integration as a continuum/ hierarchy ................................ 13

Figure 5.1: Schools' perceptions and practices of student-centered integration ....... 70

Figure 6.1: Participants' perceptions and practices towards the type of integration 95

\section{List of tables}

Table 2.1: Definitions for different forms of curriculum integration ........................ 12

Table 2.2: Dewey's model of thinking and Beane's model of integration ................... 26

Table 3.1: Profile comparison of case study schools................................................. 32

Table 3.2: Summary of participants at each of the case study schools ...................... 32

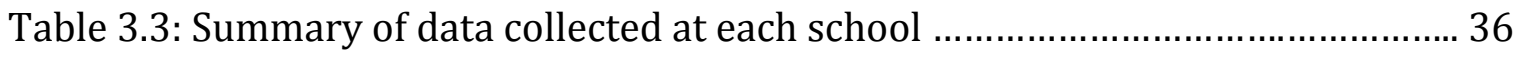

Table 4.1: Historical roots and nature of curriculum integration at each school ...... 49

Table 4.2: Summary of theorists \& authors linked to curriculum integration ........... 61

Table 5.1: Comparison of the perception and practices of the type of integration.... 63 


\section{Acknowledgements}

I would like to thank my supervisor, Bronwyn Wood, for her constant support and encouragement. I am extremely grateful for the time she has given to help me to develop my writing skills and critical reflection, I feel very fortunate to have had such a caring and thorough mentor.

I would like to thank the PPTA and Ministry of Education for the Teacher Study Award, which enabled me to take a significant break from teaching to carry out this study, and my school for allowing me to take study leave. I am grateful for the Victoria University of Wellington Faculty of Education Grant that helped towards the cost of field work and conference attendance.

My research would not have taken place were it not for the contribution of the participants of the four case study schools. I am particularly grateful to the teachers who took time out of their busy days to take part in the focus groups.

Thanks to my mum, from whom I inherited a love of learning and education, and my dad, who taught me determination and perseverance, for always encouraging and supporting me in everything I do, not least my Masters.

I would like to especially thank my husband, Rob, for his rationality, patience, cooking skills, proof-reading, and for being my most candid critic and biggest supporter. 


\section{Abstract}

Curriculum integration is an approach that aims to integrate teaching across traditional subject boundaries. Curriculum integration has received a growing level of interest in recent years in New Zealand, even from secondary schools that up until now have largely retained disciplinary boundaries. However, in spite of this recent popularity, curriculum integration remains a contested concept in terms of its definition, theoretical grounding, and practice, and we still know very little about how and why teachers are enacting this idea.

This study investigated New Zealand secondary school teachers' perceptions and practices pertaining to curriculum integration. Participants included 25 teachers and senior managers from four New Zealand secondary schools currently employing curriculum integration. A collective case study design was utilised, gathering qualitative data through focus group sessions, semi-structured interviews, classroom observations, and document analysis. The data was analysed thematically.

The findings indicated that teachers' theoretical understanding of integration was limited, and that most of the programmes were pragmatically founded. Factors that appeared to enhance the success of curriculum integration were the historical roots, whether the programme was initiated by teachers or senior managers, the type and degree of integration employed, if the programme ran as a special curriculum or across the whole school, the level of support received, and the timing of the programmes.

It was apparent that whilst curriculum integration has been advocated by the New Zealand Curriculum, there are still many challenges for secondary schools wishing to employ it. If this is indeed an area of future growth, then the Ministry of Education have a responsibility to provide a clear definition of, and professional development for, curriculum integration. This would help to strengthen the progressive, integrated curriculum espoused in the New Zealand Curriculum so that it is on far less shaky ground than at present. 


\section{CHAPTER 1: INTRODUCTION}

Curriculum integration is like a piece of rope with strands at each end. The strands are together during times of curriculum integration, otherwise the strands are separate.

(Teacher, Niu College)

\subsection{Overview}

The quote above is one of 22 metaphors for curriculum integration provided by individual participants of this study. I have used these metaphors at the beginning of each chapter, as I believe that they aptly draw attention to the frequent ambiguity, possibility, and challenges surrounding curriculum integration.

Curriculum integration is described by Beane (1997) as:

A curriculum design that is concerned with enhancing the possibilities for personal and social integration through the organisation of curriculum around significant problems and issues, collaboratively identified by educators and young people, without regard for subject-area boundaries. (p. 19)

However, curriculum integration has a wide range of definitions beyond this one provided by Beane (see for example, Drake \& Reid, 2010; Fogarty, 1991; Jacobs, 1991) and has been found to have multiple interpretations and enactments (Case, 1991; Chien, 2004; Fogarty, 1991; Kinsiz, 2010; Shriner, Schlee, \& Libler, 2010). Curriculum integration therefore is a highly contested idea, and one of the central challenges to research in this area has been attempting to pin down this elusive and ambiguous concept (Dowden, 2007, 2012; Fraser, 2000).

The origins of the educational philosophy of curriculum integration date back to the 1800s. Since then it has moved in and out of the educational limelight, reflecting various trends and philosophical positions toward education and its role in society. The American Progressive Movement and the British New Education Movement both brought curriculum integration back in to fashion from the beginning to the middle of the 20th century, and they also prompted the promotion of integration in the original document for mass secondary schooling in New Zealand - the 1943 Thomas Report (Dowden, 2007). Curriculum integration has experienced enduring popularity in primary schools and a much smaller number of more liberal and progressive secondary schools (Beane, 1993; Dowden, 2012). Curriculum integration has arguably been marginal to 
mainstream ideas of subject specialism in secondary schools, which could explain why it has been less widespread in this sector of education.

I argue that the launch of the 2007 New Zealand Curriculum has provided a stimulus for a renewed interest in curriculum integration in New Zealand. The 2007 curriculum has a new focus on its Vision, Values and Principles, alongside a traditional focus on the content and achievement objectives of the eight Essential learning areas (Begg, 2008; Hipkins, Cowie, Boyd, \& McGee, 2008). The Curriculum refers to and encourages curriculum integration, proposing that schools "may decide to organise their curriculum around central themes, integrating ... across a number of learning areas ... [and] wherever possible, schools should aim to design their curriculum so that learning crosses apparent boundaries" (Ministry of Education, 2007, p. 37-38). Moreover, an emphasis in the 2007 New Zealand Curriculum on Effective Pedagogy (p. 34) and collecting evidence in the Teaching as Inquiry model (p. 35) encourages a greater consideration of how to teach, as opposed to just what to teach. This has arguably encouraged teachers to reflect on their current teaching practice and consider new possibilities. The advocation of curriculum integration within the Curriculum document, as above, represents a fairly radical stance taken by the Ministry of Education on the direction of education in New Zealand.

As a result of this stance, several schools have used the New Zealand Curriculum as justification to employ curriculum integration (Hipkins, Cowie, Boyd \& McGee, 2008), although due to its relative infancy there is little empirical evidence to confirm this (Wood \& Sheehan, 2012). The ambiguity surrounding, and recent fascination with curriculum integration presents a timely opportunity to examine teachers' current perceptions and practices of integration, particularly in secondary schools where it is a less utilised methodology (Dowden, 2012). To date, few studies have explored New Zealand Secondary School teachers' perceptions and practices of curriculum integration.

In this chapter I will provide a contextual background to justify why my choice of curriculum integration in secondary schools is an important research topic in the current educational climate. I explain how my research questions were formed, and how they will help to deepen understanding in the area of curriculum integration in New Zealand secondary schools. My personal incentive for conducting this research is outlined, followed by a framework of the thesis. 


\subsection{Contextual background to the research}

In this section, I will discuss three key concepts that are influencing educational decision making and curriculum changes worldwide. These are:

1. the nature of knowledge

2. the OECD 2005 DeSeCo report

3. the disengagement of students.

I argue that these factors have contributed to the recently renewed interest in curriculum integration, particularly in secondary schools.

The changing nature of knowledge in recent times is argued to be a key reason why educators need to consider curriculum integration. Jane Gilbert (2005), a New Zealand academic who has written extensively in this area, asserts that new knowledge is "distinct from traditional philosophical understandings of knowledge" and is therefore a "major challenge to our education systems" (p. 4). Gilbert argues that in order to address this issue we must re-evaluate our view of what schools are for, what their aims are, and how to achieve them. This discussion, centering on what Gilbert refers to as the knowledge wave, has drawn attention to future focused educational literature signifying the importance of teaching students how to learn, rather than (just) what to learn. Gilbert argues that re-evaluating schools in light of this 'new' knowledge involves rethinking traditional subject boundaries and how these may restrict the types of knowledges required. Such ideas have been a key aspect of reviewing education that has encouraged teachers to return to the idea of curriculum integration.

A key document that has also influenced curriculum decision making worldwide is The Definition and Selection of Key Competencies (DeSeCo) (OECD, 2005). The focus of the DeSeCo report is on the competencies that students need to contribute to a successful life and a well-functioning society "by drawing on and mobilising psychosocial resources" (p. 4). The document describes how globalisation and modernisation are generating a diverse and interconnected world, where individuals will need to address shared challenges as a society, such as evaluating the benefit of economic growth against environmental sustainability, and prosperity versus social equity. It is argued that mastery of content through the traditional transmissive mode of teaching will not adequately prepare our students to meet such complex goals, not least due to the lack of engagement that it provokes (Gilbert, 2005; Kress, 2007). 
Students' disengagement, and the frequently associated lack of achievement, has been identified by many as a significant issue facing schools globally. Kress (2007) describes how students no longer judge school to be of relevance to the world as they experience it. One response by teachers has been to encourage looser boundaries between subject areas to encourage a more holistic approach to curricula in the hope that this will engage and motivate students toward improved educational outcomes. In New Zealand disengagement is particularly prevalent amongst Māori and Pacific Island students, which Bishop \& Berryman (2006) have attributed to a number of reasons, including negative relationships and an over-reliance on western teaching methodologies. They, along with Fraser \& Paraha (2002) and Fraser (1999), view curriculum integration as a culturally responsive pedagogy.

Evidence emerging from both quantitative and qualitative research, has endorsed curriculum integration as an important educational intervention. For example, studies have found that curriculum integration results in, increased relevance (Fraser, 1999; Locke, 2008; Murdoch, 1998), preparation for 21st century life (Godinho \& Imms, 2011; Parr, Edwards, \& Leising, 2009; Schultz, 2009), development of social skills, relationships, and greater collaboration (Beane, 1997; Fraser, 1999; Nolan, McKinnon, \& Owens, 1992; Russell \& Burton, 2000), advanced problem solving and critical-thinking skills (MacMath, Roberts, Wallace, \& Chi, 2010; Sharpe \& Breunig, 2009), heightened engagement (Parr et al., 2009; Thorburn \& Collins, 2006). and improved achievement (Dowden, 2007; Shriner et al., 2010). However, only a small number of these research studies have focused on secondary school curriculum integration (Locke, 2008; Nolan et al., 1992; Russell \& Burton, 2000; Sharpe \& Breunig, 2009) and few are based in New Zealand (Brough, 2008; Dowden, 2007; Fraser, 1999; Locke, 2008; Nolan et al., 1992).

\subsection{Research topic and questions}

In light of the emerging interest in curriculum integration in secondary schools in New Zealand it is timely to put in to place some research to examine how and why teachers are doing this. The need for teachers to operate as a community of educators in order to sustain curriculum integration pedagogy was proposed by Dowden (2007), rather than many teachers operating using different frameworks, which was suggested to be the case with curriculum integration in New Zealand by Fraser and Deane (2010). Therefore, I feel that it is important to explore this concept further. 
The purpose of my research is to ascertain the perceptions and practices of New Zealand secondary school teachers concerning curriculum integration. In doing so I intend to expose the nature of their conceptions, in particular to consider how their perceptions and practices have been formed. Previous research into curriculum integration and other innovative pedagogies has identified that more often than not, decisions are not grounded in theory (Fraser \& Deane, 2010; Fraser, 1999; Sharpe \& Breunig, 2009; Helen Timperley, 2008), and that support for curriculum integration is fundamental to its success (Inman, 2011; Wallace, Sheffield, Rennie, \& Venville, 2007). This knowledge helped to guide the formulation of my two key research questions and the three aligned sub-questions, as listed below.

\section{RQ1: What are New Zealand secondary school teachers' perceptions and practices of curriculum integration?}

- Are there differences between teachers' perceptions and practices of curriculum integration?

- What theoretical lens do teachers describe as the basis for their curriculum integration programmes?

- How is the curriculum integration programme supported by the senior management?

\section{RQ2: Why have teachers chosen to implement curriculum integration?}

\subsection{Personal incentive for research}

My interest in curriculum integration stems from my experience of teaching Science for several years in a secondary school in a low socio-economic area of the UK, where I worked predominantly with students from a large community of travellers who had settled in the local area. The students' caregivers had experienced negative encounters with, and had largely not finished compulsory schooling themselves. Both caregivers and students, therefore, saw little value in what I was teaching, and so I started to explore a more integrated style of teaching and learning, utilising greater student voice, and searching for more meaningful contexts through which to teach. I noticed a considerable improvement in both engagement and achievement with these students, which I attributed to the use of curriculum integration. 
I immigrated to New Zealand in 2007 and am currently the Head of Integrated Studies at a secondary school in the Wellington region. Within this role I have found that curriculum integration increased engagement and achievement across diverse groups of students, including various ability, ethnicity, gender and socio-economic groups. However, I have also discovered that the facilitation of integration varied considerably from class to class and from school to school.

In 2010 I established and led a Ministry of Education funded Network Learning Community (NLC) group to evaluate the curriculum integration programmes currently being offered in secondary schools in the Wellington region, as well as to offer support and guidance to the increasing number of schools starting integrated programmes. This experience within my department and the NLC led me to observe an increasingly diverse range of interpretations as to what curriculum integration entails, which triggered my curiosity as to what teachers perceive to be curriculum integration, as well as how and why they enact it. While I remain an advocate of curriculum integration, I entered this research with reflexivity; open to critical debate that I was aware would add to my insight into, and potentially shift my position on curriculum integration.

My intention is that the findings of this research will inform future professional development programmes and teacher training in the area of curriculum integration, so that the ambiguity surrounding it may be somewhat reduced.

\subsection{Thesis structure}

The literature review in Chapter Two begins with a number of descriptions of the different types of curriculum integration, followed by an outline of the ambiguity surrounding it. The history of curriculum integration is then examined to show its evolution over the last two centuries, leading to curriculum integration's position in New Zealand today. Section 2.5 describes the relevance of curriculum integration to contemporary education, both locally and globally, discussing two key paradigms of the changing nature of knowledge and the related notion of the changing nature of schools. The key part played by the 2007 New Zealand Curriculum in renewing interest in curriculum integration is examined, prior to an investigation of previous research in this area. Chapter Two concludes with an exploration of the theoretical lens used for this study. 
Chapter Three outlines the qualitative case study methodology used for this research. I recognised at the outset that the multiple definitions of curriculum integration and how it is implemented meant that I needed a broad spectrum of perceptions and practices towards curriculum integration. For this reason, my search for secondary schools considered to be using integrated curriculum programmes, included those that could be classified as trans-disciplinary, inter-disciplinary, and multi-disciplinary in nature. These definitions are described by Beane (1997), Drake (1998) and Jacobs (1989). Table 2.1 (pg. 10) contains definitions for reference. The use of purposeful maximal sampling to select participants is described, followed by a justification for the use of theoretical triangulation and the data collection techniques utilised, which included, focus groups, semi-structured interviews, observation, and the collection of secondary data. A description of the data analysis method is provided along with an explanation of how I worked to maintain integrity and trustworthiness throughout my research. The chapter finishes with a summary of the ethical considerations and the limitations of the study.

The findings of my research are provided in Chapters Four and Five. Chapter Four analyses teachers' perceptions of curriculum integration, providing a detailed description of each of the case study schools and their integration programmes. Chapter Four also specifically examines why teachers chose to utilise curriculum integration and the theoretical groundings of each of the programmes, if any. Chapter Five analyses teachers' practices towards curriculum integration, specifically the type of integration employed and the level of support received for integration.

The discussion in Chapter Six explores the key findings in greater depth. The three main themes identified were, the factors enhancing and impeding curriculum integration, the reasons for implementing curriculum integration, and, the level of alignment between teachers' perceptions and their practices.

The final chapter concludes the thesis with a reconsideration of the findings, providing several conclusions, along with suggestions for further research in the area of curriculum integration. 


\title{
CHAPTER 2: LITERATURE REVIEW
}

\author{
Curriculum integration is like the Olympic rings - \\ discrete learning areas joined by a common theme or pedagogy. \\ Some skills in the learning areas are the same, some unique. \\ (Rose, Awa High)
}

\subsection{Chapter introduction}

In this chapter I will provide a range of descriptions of curriculum integration as found in the literature, including an examination of the ambiguity surrounding curriculum integration. The history of curriculum integration is reviewed prior to a précis of previous research in this area. A description of the relevance of curriculum integration to education today precedes a discussion of the place of curriculum integration in the $2007 \mathrm{New}$ Zealand Curriculum. I conclude with a description of the theoretical framework guiding curriculum integration.

\subsection{Descriptions and interpretations of curriculum integration}

Over a century since Dewey first discussed the significance of experience based learning, there still remains confusion as to what constitutes curriculum integration (Field, n.d.; Whyte, 1999). This is despite its endorsement in several national and international documents (Godinho \& Imms, 2011; MacMath et al., 2010; Parr et al., 2009). Throughout its history there have been, and still are, multiple interpretations of curriculum integration. Drake (n.d.) believes that one of the issues surrounding an integrated curriculum is that "it can mean many things to different people" (para. 15).

Curriculum integration is a curriculum design that repositions subject content in order to increase its meaning and relevance to students, holding less regard for disciplinary boundaries than traditional didactical approaches (Beane, 1997). The aim of curriculum integration is for students to learn through collaboration and experience, while developing transferable skills across subject disciplines. Drake (1998) argues that curriculum integration is not just about connecting knowledge bases, but about a radically different approach to considering teaching and learning "shifting all aspects of curriculum design to align with what we know about the learning process" (p. 2). There are, however, multiple, varied and commonly ambiguous interpretations of curriculum integration as the examples below illustrate: 
The integrated model views the curriculum through a kaleidoscope: interdisciplinary topics are rearranged around overlapping concepts and emergent patterns and designs. (Fogarty, 1991, p. 62)

... to teach about topics that cut across or transcend ... subjects ... content drawn from one ... is used to enrich the teaching of another ... skills learned in one subject are used to process or apply information learned in another. (Brophy \& Alleman, 1991, p. 66)

To help students make sense out of the multitude of life's experiences and the bits and pieces of knowledge being taught in the typical splintered, overdepartmentalized school curriculum. (Vars, 1991, p.14)

... any intentional uniting or meshing of discrete elements or features ... new beliefs are filtered through and connected to the individual's prior beliefs. (Case, 1991, p. 215)

It is a way of thinking about what schools are for, about the sources of curriculum, and about the uses of knowledge ... the search for self- and social meaning. (Beane, 1995, p. 616)

Programmes in which students register for a 'package' of subjects, interdisciplinary investigation, theme, topic, or experience. (Sharpe \& Breunig, 2009), p. 300)

An emphasis on the conscious application of relevant personal and social perspectives coupled with the application of methodology and language from more than one discipline as the bases for the organization of curriculum. (Shriner, Schlee, \& Libler, 2010, p. 52)

The quotes above describing curriculum integration are a select few from the literature, and range from descriptions that are specific to the content and knowledge of a curriculum, to explanations that are more about generic learning and social skills. For secondary school teachers attempting to develop an integrated curriculum, with little or no prior knowledge, it is a complicated topic upon which to establish a clear understanding.

One of the sources of the ambiguity surrounding curriculum integration is that there are many different forms, described by Dowden (2007) as "a plethora of models" (p. ii). Curriculum integration is referred to by different authors as fusion, within one 
subject, multi-disciplinary, correlation, inter-disciplinary, harmonisation, insertion, transdisciplinary, core, and the integrative model (Drake, 1998; Erickson, 1995; Fogarty, 1991; Jacobs, 1991; Vars, 1991). Case (1991) examines four different types of integration (fusion, insertion, correlation, harmonization); four forms (content, skills-processes, school and self, underlying principles); four purposes (important issues, wider view of the subjects, seamless web of knowledge, reduced redundancy), and two dimensions (horizontal, vertical). Fogarty (1991) observes not four, but ten different models for integrating curriculum: fragmented, connected, nested, sequenced, shared, webbed, threaded, integrated, and immersed. Compounding the confusion is that descriptions of the specific types of integration listed above, vary from author to author. I have provided a table of the most common definitions in Table 2.1, which I will refer to throughout the course of this thesis.

\begin{tabular}{|c|c|c|}
\hline $\begin{array}{l}\text { Form of } \\
\text { curriculum } \\
\text { integration }\end{array}$ & Definition & $\begin{array}{l}\text { Key } \\
\text { author } \\
\text { linked to } \\
\text { definition }\end{array}$ \\
\hline $\begin{array}{l}\text { Fragmented } \\
\text { [Traditional] }\end{array}$ & $\begin{array}{l}\text { Content is taught via the lens of one learning area only, e.g. } \\
\text { Science, The Arts, the Languages, English, Social Sciences }\end{array}$ & $\begin{array}{l}\text { Fogarty, } \\
1991\end{array}$ \\
\hline Fusion & $\begin{array}{l}\text { A topic is infused into several subject areas, e.g. global } \\
\text { studies are infused into English, History, Geography, Music } \\
\text { and Art, OR, combining learning areas into a new course, } \\
\text { e.g. English \& Social Sciences becomes Humanities }\end{array}$ & $\begin{array}{l}\text { Case, } \\
1991\end{array}$ \\
\hline Insertion & $\begin{array}{l}\text { Absorbing one element of a learning area into another } \\
\text { learning area, e.g. interpreting the art of a historical period } \\
\text { into a Social Sciences topic }\end{array}$ & $\begin{array}{c}\text { Fogarty, } \\
1991\end{array}$ \\
\hline $\begin{array}{l}\text { Within one } \\
\text { subject or } \\
\text { Connected }\end{array}$ & $\begin{array}{l}\text { Sub-disciplines are integrated within one subject area, e.g. } \\
\text { History, Geography, Social Studies, and Economics, into } \\
\text { Social Sciences }\end{array}$ & $\begin{array}{c}\text { Drake, } \\
1998\end{array}$ \\
\hline $\begin{array}{c}\text { Multi-disciplinary } \\
\text { or Correlation }\end{array}$ & $\begin{array}{l}\text { Separate learning areas are linked through a theme, each } \\
\text { Area addressing the theme through their lens during the } \\
\text { same time frame, e.g. The Environment, or Belonging }\end{array}$ & $\begin{array}{l}\text { Drake, } \\
2007\end{array}$ \\
\hline $\begin{array}{l}\text { Inter-disciplinary } \\
\text { or Harmonisation } \\
\text { or Nested }\end{array}$ & $\begin{array}{l}\text { learning areas are connected more explicitly, inter- } \\
\text { disciplinary concepts or skills are emphasised across } \\
\text { learning areas rather than within them, e.g. critical } \\
\text { thinking or research skills are taught in a common way }\end{array}$ & $\begin{array}{c}\text { Jacobs, } \\
1989\end{array}$ \\
\hline $\begin{array}{c}\text { Trans- } \\
\text { disciplinary } \\
\text { or Integrative } \\
\text { model } \\
\text { or Core }\end{array}$ & $\begin{array}{l}\text { The focus is on a real life context that the learning areas } \\
\text { are then embedded in, with perceived relevance to the } \\
\text { students being the most important feature. Student inquiry } \\
\text { through research being the primary method }\end{array}$ & $\begin{array}{c}\text { Beane, } \\
1997\end{array}$ \\
\hline
\end{tabular}

Table 2.1: Definitions for different forms of curriculum integration 
A distinct divide exists among curriculum integration experts as to whether the different forms of curriculum integration can, or should, be placed on a continuum. Drake (1998), Fogarty (1991) and Jacobs (1989) represent integration as a continuum along which progressively more links are formed, as depicted in Figure 2.1. These authors believe that progress along the continuum is evolutionary in nature. Erickson (1995) views multi-disciplinary integration as a less complex form with which teachers tend to start integration, with trans-disciplinary integration being a more complex form

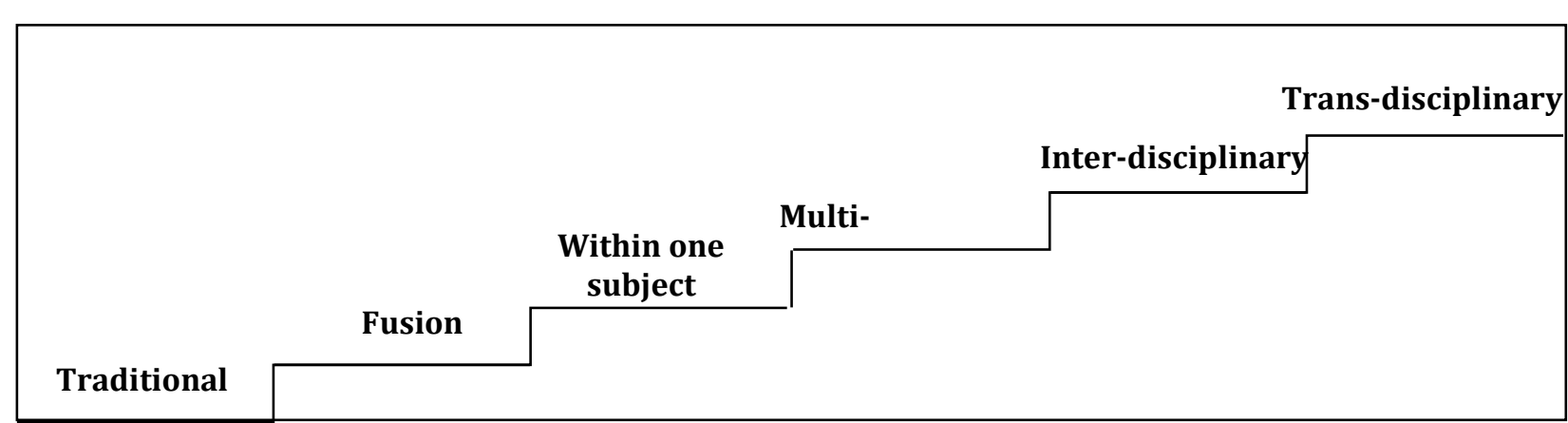

Figure 2.1: Curriculum integration as a continuum/ hierarchy (Drake, 2007, p. 27)

that teachers progress towards over time. Hargreaves, Earl, \& Ryan (1996) warn against using a continuum due to the implicit values embodied, suggesting that advancement along the continuum implies growth and progression, which is not the intention. Beane (1997) believes that there is only one authentic type of curriculum integration, referred to as the integrative model (Table 2.1). Brophy \& Alleman (1991) argue that "just because an activity crosses subject-matter lines does not make it worthwhile" (p. 66).

For the purposes of this thesis, I selected schools that utilised trans-disciplinary, multi-disciplinary, and inter-disciplinary integration (defined below). These three types of integration are the last three described in Table 2.1 and are located on the final three steps of Drake's (2007) continuum in Figure 2.1.

\subsubsection{Trans-disciplinary integration}

Proponents of the trans-disciplinary, student-centered approach to curriculum integration favoured by Beane (1997) describe it as a process that offers a holistic style of teaching and learning. Beane argues that participatory planning, contextual knowledge, real-life issues, and unified organisation provide extensive access to knowledge for diverse students, affording success to an increased number of learners. Beane identifies four aspects to student-centered curriculum integration: Integration of experiences, social integration, integration of knowledge, and, integration as curriculum 
design. Learning is centered on an issue of interest to the students, with learning area content incorporated when natural links arise. The student-centered approach of transdisciplinary integration is thought by some to reduce important subject-specific skills and knowledge (McGaw, in Schultz, 2009), while advocates believe that it creates more meaningful learning.

\subsubsection{Inter-disciplinary integration}

The inter-disciplinary subject-centred approach distinguishes the discipline boundaries (Drake, 2007), but the learning areas are connected more explicitly through the association of common skills than with multi-disciplinary integration. Interdisciplinary integration highlights the concepts and techniques that are shared by more than one learning area, such as, research skills for inquiry learning; data analysis techniques; presentation skills; cooperative learning techniques; critical thinking; communication skills etc. (Fogarty, 1991; Jacobs, 1989).

\subsubsection{Multi-disciplinary integration}

The multi-disciplinary approach is also subject-centered, where the learning areas are taught separately. Co-construction with students is a lesser feature, with the topic or theme generally selected by the teacher(s) according to the content that best corresponds from each subject. As a result, discipline specific skills are retained and the 'official' knowledge contained within curriculum documents is delivered (Jacobs, 1991). Beane feels that the opportunity to build on individual students' prior knowledge is diminished with this model (1997).

One of the enduring challenges in the area of curriculum integration is the ambiguous nature of how teachers have interpreted and enacted it. Beane (1997) states that the definition of curriculum integration has become eroded and less grounded in theory over time, to the point where it can be "used to describe arrangements that amount to little more than rearranging existing lesson plans" (p. x), a view endorsed by several others, such as, Brough (2008), Dowden (2007), MacMath et al. (2010),

Thorburn \& Collins (2006). Case (1991) echoes this view, stating that despite the ubiquity of integration, the debate surrounding it remains contentious due to the "ambiguous and loose conceptions of what is intended" (p. 215). New Zealand academic, Deborah Fraser (2000), commented that "curriculum integration is one of the most confused topics in education ... the term [is used] to mean a raft of things, some of which have nothing to do with curriculum integration at all" (p. 34). Rather than being uniform, 
Betts (in Thornley \& Graham, 1999), states that, “...each person's mental model of an integrated curriculum is virtually unique" (p. 2). Chien (2004) chose to focus his research on curriculum integration in America, because "there appeared to be no clear definition of integration nor a consensus on what constituted good integration" (p. i). Drake (2007) noted perceptible variations in the philosophy and methods used by educators to develop curricula. She concluded that "one position is not superior to another; rather different approaches are more appropriate than others according to the context in which they are developed" (p. 19). This highlights the necessity for a clear understanding of curriculum integration to ensure that teachers select the most appropriate form for their students.

Teachers' unfamiliarity with curriculum integration models and an understanding of the theory in which it is grounded is often absent when integration programmes are established, implemented and maintained (Beane, 1997; Fraser, 2000; Shriner et al., 2010). Many teachers desire a handbook of how to 'do it', which is at odds with the individualised and evolving nature of curriculum integration, and it is argued that this can lead to ineffective facilitation. The theories that underpin curriculum integration remain contested and the method through which teachers enact curriculum integration continues to vary. This draws attention to the need to examine teachers' perceptions of curriculum integration in relation to their current practice with a specific focus on curriculum integration theory.

As a result of the prevalent ambiguity surrounding curriculum integration I have created my own definition that incorporates elements of trans-, inter-, and multidisciplinary integration:

Curriculum integration is a means through which links can be made to connect the specialist knowledge of subject disciplines and students' lives, developing transferrable skills to grow independent, critical thinkers. 


\subsection{History of curriculum integration}

Ideas relating to the progressive education movement in which curriculum integration is positioned, can be traced back to Socrates who believed that "true understanding was developed in a pupil by using a question method that allowed students to find their own truth" (Hayes, 2007, p. 1). Since then, many other philosophers, educationalists, and politicians have influenced the thinking behind progressivism. John Locke in the 17th century considered that schools should do more than just pass on knowledge and should provide concrete experience tailored to the individual needs of students. Jean-Jacques Rousseau in the 18th century was against subordinate education and memorisation. In the 19th century Johan Pestalozzi advocated learning through direct experience with objects, and believed that the natural instincts of learners should be the source of motivation for learning. Horace Mann believed that teachers must have "common methods for common minds but with peculiar methods for pupils of peculiar dispositions" (Poole, n.d., para. 6).

The origins of curriculum integration date back to the 1800s with the work of John Dewey. At this time educators were grappling with a number of concerns similar to those that we are encountering today, resulting in discussions around the benefits and costs of integration (Drake, n.d.). Drake lists three fundamental issues raised then, which are also pertinent and highly topical now:

- What should be taught, given the vast increase in available knowledge?

- What should be taught, given the greater number of students who now need to be educated?

- How can schools be responsible for developing moral character unless the curriculum is connected to real life? (para. 40)

Although discussion was at the theoretical level in the late $1800 \mathrm{~s}$, the resistance to integration was again concurrent with contemporary opponents, listed by Drake as:

- varying definitions for varying degrees of integration, ranging from simple connections between subjects to integrating students' experience with the larger world;

- the importance of making the school experience applicable to life;

- the domination of the disciplines as an obstacle to integration (para. 41). 
In the early 1900s, experiential learning was promoted by John Dewey (1900), who made the claim that if school work was related more closely to students' lives, then all learning would naturally be correlated. Kilpatrick's (1926) attempt to create a more student-centered curriculum in the US was influenced by Dewey, and has also influenced the shape of curriculum integration. Despite its early conception, curriculum integration has moved in and out of the educational limelight over the last two centuries.

The British New Education and the American progressive movements both advocated curriculum integration. Their aim was to develop a democratic society, to shift the subject-centered dominated curriculum towards a more student-centered, integrative notion of curriculum. The American progressives developed two curriculum design plans - Experience, where the experiences of the student determined the nature of the content, and Core, where teachers and students plan collaboratively around the student's personal and social issues, drawing on disciplinary content where applicable. The British progressives presented their movement as a pedagogy, which Dowden (2007) maintains helped it to last longer than the American's.

Curriculum integration had a resurgence in Britain during the 1960s and 1970s, but again, its rationale and meaning were unclear and the discourses surrounding it were more subject-centered than the student-centered discussions in America. In 1937, the term integration and its theoretical development were first formally described by Hopkins in the book Integration: Its Meaning and Application (Dowden, 2007). Since then, particularly in the late 20th century, several theorists and authors have written about curriculum integration, such as Beane (1997), Drake (1998), Fogarty (1991), and Jacobs (1989).

Curriculum integration is not a new idea in New Zealand (Dowden, 2007). It was promoted by The Thomas Report (a 1943 Department of Education manuscript responsible for the direction of mass secondary schooling in New Zealand), which was influenced by both the British New Education and the American progressive movements. The Thomas Report used findings from the Eight-Year Study conducted in the USA to support its promotion of curriculum integration in New Zealand high schools. The Eight Year Study, supported the benefits of Core, advocated that curriculum should balance personal and social issues, and it demonstrated that teachers and students could effectively plan together. The Currie Report in 1962 also recommended the use of curriculum integration in New Zealand (Matangi-Hulls, 2010), which stimulated the 
establishment of several innovative schools around New Zealand. The longest running, and arguably the most documented integration project in New Zealand, is the Freyburg Integrated Studies Project (Nolan et al, 1992), established in 1987, which utilised several different models of integration, including inter-disciplinary and multi-disciplinary.

\subsection{Previous curriculum integration research}

There is a long tradition of curriculum integration in primary and intermediate schools (Boyd \& Hipkins, 2012; Fraser \& Deane, 2010; Fraser, 1999; Rennie, Venville, \& Wallace, 2011), but this approach has been less common in New Zealand's secondary schools (Dowden, 2012). Consequently most of the current research around curriculum integration in New Zealand and globally is situated in the middle years (Whyte, 1999). However, over the last 10 years an increasing number of New Zealand secondary schools have embraced curriculum integration (Ward \& Henderson, 2011). Despite this renewed interest, even at the middle level of schooling, there are relatively few studies on integration and the type of learning involved (Chien, 2004).

In the literature, several themes have been identified endorsing curriculum integration as an important educational intervention. Vars (1997) documented over 200 empirical studies examining the impact of curriculum integration, which have shown that students in integrated programmes perform at least as well as their peers in nonintegrated programmes, academically and socially. The main themes advocating curriculum integration in the literature are: relevance; 21st century preparation; its transformative power; social skills, relationships, and collaboration; problem solving and critical-thinking; engagement; achievement; and time allocation.

However, only a small number of studies have examined teachers' perceptions and practices in relation to curriculum integration (Leung, 2006; Shriner et al., 2010). Even fewer studies have been carried out into curriculum integration in New Zealand secondary schools (Fraser \& Paraha, 2002; Fraser, 1999; McKinnon et al., 1991; Whyte, 1999). Due to the limited amount of current research into curriculum integration in New Zealand Secondary Schools this will be the focus of my research, which was suggested by Dowden (2007) as a constructive area for future research.

\subsection{Relevance of curriculum integration to education today}

Curriculum integration has gained popularity in the early 21st century, and has been viewed by many educators as a solution towards addressing several of the issues 
faced in education today. These issues include the disengagement and underachievement of particular groups of students, and the inadequacy of the current education system's outdated model to prepare young people for life in the $21^{\text {st }}$ century (Gilbert, 2005; Kress, 2007; Mutch, 2010). Two key propositions situate curriculum integration as a significant 21 st century pedagogy. These are:

- $\quad$ the changing nature of knowledge and the world in the 21st century

- $\quad$ a requirement for schools to evolve to meet these changing times.

I will explore these ideas in this section, which I contend have led to a renewed interest in curriculum integration in recent years. First, I will discuss the part that neoliberal political agendas have played in the rekindled interest in integration.

Neoliberalism, which became the dominant political discourse in the 1980s in many western societies, has had a big impact on global education. Neoliberals support economic liberalisation, free trade, privatisation, and deregulation. They could therefore be argued to favour curriculum integration due to the Neoliberal agenda for education to become a free market, making individual schools responsible for many of their own decisions, including those concerning the curriculum, which is reflected in the New Zealand Curriculum (Ministry of Education, 2007). However, it could conversely be argued that neoliberals reject integration due to its student-centered nature. Some proponents of neoliberal reforms eschew child-centered pedagogies, such as curriculum integration, viewing them as the reason for the lack of discipline and achievement in today's progressive schools. Michael Apple (2009) discusses how neoliberalism has contributed to the radical reshaping of the common-sense of society and the way we evaluate our institutions, as well as our public and private lives. This view is mirrored by Davies \& Bansel (2007) who believe that neoliberalism, juxtaposed with globalisation, has played a part in the reworking of schools' and individual subjects' discourses and identities.

Western nations are currently experiencing a shift away from egalitarianism, as their economic, educational and societal problems are attributed to too much cultural and political equality (Apple, 2009). This shift poses a threat to a democratic education system, with education becoming an economical commodity, where students are viewed as human capital and education as a product for consumption. Apple argues that discourse around recent educational policies has largely centered on neoliberal agendas, 
such as markets, national standards and high stakes testing, which often serve to intensify existing inequalities between different ethnic and socio-economic groups of students, benefitting those already favoured.

The traditional education system is argued to favour the dominant socioeconomic group, in part through the transmission of a limited selection of 'official knowledge' (Apple, 2007; Gilbert, 2005; Kress, 2007), which is seen by many to be outdated and inappropriate for today's learners. Kress (2007) stresses the unsuitability of the traditional system for adolescents, describing how:

A significant proportion of the young are alienated from school - they no longer judge school to be of relevance to ... the world as they experience it ... what the school actually offers is...no longer of interest to these young people. (p. 259)

A leading motive for utilising curriculum integration is the potential that it holds to address the disparity of engagement and achievement between diverse groups of students, not typically catered for through the traditional curriculum. In New Zealand it has been a national priority for several years to address the difference in educational outcomes between Māori and Pacific Island students, and students of other ethnic groups (Ministry of Education, n.d.), a disparity that is also reflected in general social statistics (Bainbridge, 2005; Peterson \& Williams, 2000). This inequality has been attributed to a number of causes including, deficit theorising, cultural exclusion, low expectations, negative relationships, and lack of recognition (Bishop \& Berryman, 2006). Curriculum integration has been advocated as a culturally inclusive pedagogy (Fraser \& Paraha, 2002; Fraser, 1999), which could provide a pathway to begin addressing the traditional western, hegemonic school system.

The changing nature of what is valued as knowledge is described by Locke (2008), who argues that expert knowledge, while still important, has been supplanted by new knowledge, which is being developed by students with rather than by teachers. Curriculum integration encourages the co-construction of knowledge by students and teachers, which perhaps makes it a fitting pedagogy for current times. Numerous authors have written about the changing nature of knowledge including, in New Zealand, Jane Gilbert (2005). Gilbert argues the case for 'new' approaches to knowledge. She discusses how disciplinary boundaries will dissolve as 'old' knowledge is organised to pursue 'performativity', described as the ability to combine elements from different 
knowledge systems to generate new knowledge. Knowledge is viewed as intellectual capital and the key driver of future economic growth. In order for 21st century learners to contribute to this global economy, it is suggested that they will need to be accomplished in thinking across disciplines. Drake (1998) argues that contemporary education is located in a constantly changing context in which it is virtually impossible to teach everything in the current "information explosion" (p. 11). She argues that curriculum integration assists teachers to cope with the inherent complexity of the world, which may explain the renewed interest in curriculum integration.

However, ideas about integrating curriculum are highly contested. In his article, Knowledge, Learning and the Curriculum of the Future, Young (1999) views the curriculum,

As a way of asking questions about how ideas about knowledge and learning are linked to particular educational purposes and more broadly to ideas about society and the kind of citizens and parents we want our young people to become (p. 463)

Young is a critic of curriculum integration, believing that any attempt to integrate subjects will naturally reduce the status of such subjects, therefore gaining little favour amongst subject specialists. Curriculum integration is critiqued by Young and Muller (2010) in their proposal of three educational scenarios for the future:

Future 1 - Boundaries are given and fixed - the 'Future' is associated with a naturalised or 'under-socialised' concept of knowledge;

Future 2 - The end of boundaries - the 'Future' is associated with an 'oversocialised' concept of knowledge;

Future 3 - Boundary maintenance as prior to boundary crossing. In this 'Future' it is the variable relation between the two that is the condition for the creation and acquisition of new knowledge (p. 16).

Young and Muller argue that integrating curriculum is a feature of Future 2 schooling, and has the potential to undermine the nature of how knowledge develops within disciplinary areas. They also argue that less able students miss out on learning to negotiate the boundaries of disciplines and how disciplines operate to form a level of rigour within them. The promotion of learning through people's lives and a focus on participation, both of which are key elements of curriculum integration, are referred to 
by Young (2009) as possible weaknesses of a Future 2 curriculum. Young argues that new divisions and disparities may be constructed through the polarisation of new learning opportunities. He claims that a participatory focus can inhibit the access of students to specialist knowledge communities by overlooking the relationship between tacit and explicit knowledge. Young believes that powerful knowledge is accessed at school by some students who do not have access to such knowledge at home. He argues that this knowledge is not localised, but generalisable, and that learners lack the prior knowledge to make choices which will enable them to access this specialist knowledge, which positions Young as an adversary of curriculum integration.

There is a significant divide amongst educationalists regarding the retention of specialised subjects and their boundaries, particularly in secondary schools (Brough, 2008; Dowden, 2012). This debate is often at the heart of critiques surrounding curriculum integration. Kinsiz (2010) argues that "educational theory and practice must recognise the value and pressing existence of [the] multi-disciplinary and interdisciplinary nature of life in today's world" (p. 123). Several other authors are in agreement that the focus of students' learning should not be defined by particular disciplines (Beane, 1997; Brady, 1995), which aligns with Young \& Muller's (2010) Future 2. Conversely, others align with the traditional, transmissive view of education (Future 1), where knowledge as a known body of ideas, skills, and information is to be transferred by an expert from one generation to the next (McGaw, in Schultz, 2009). Jacobs (1989) sits in the middle of the discipline - boundary-less continuum, suggesting that we should make the disciplines so explicit that students may understand and use the perspective of each one, valuing the different approach each brings to our social world. She believes that once the disciplines have been grasped, we can confidently integrate them (Future 3).

The information outlined above would suggest that it is a critical time to examine teachers' perceptions and practices surrounding curriculum integration to help determine whether it really is a fitting pedagogy for 21st century education.

\subsection{New Zealand Curriculum and curriculum integration}

The 2007 New Zealand Curriculum advocates curriculum integration (Boyd \& Hipkins, 2012; Brough, 2008; Fraser, Aitken, Price, \& Whyte, 2012; Hipkins et al., 2008), suggesting that schools have the option to integrate "values, key competencies, 
knowledge, and skills across a number of learning areas" (Ministry of Education, 2007, p. 37-38). This offers a convincing reason as to why many schools have shown a resurgence of interest in curriculum integration, and should also be an important consideration when examining how curriculum integration has been interpreted by schools. Therefore, a review of the origins and content of the 2007 curriculum linked to curriculum integration is appropriate in this literature review.

A number of authors have pointed to the significance of the OECD DeSeCo Report in 2005 (OECD, 2005) as a key driver for many of the features of the 2007 New Zealand Curriculum (Samu, 2011; Wood \& Sheehan, 2012). This report names key competencies that are fundamental for the personal and social development of citizens in contemporary, multifaceted societies. It highlights the benefits to both individuals and societies of investment in human capital and outlines a conceptual framework for the evaluation of education systems (Samu, 2011). This publication has stimulated the inclusion of key competencies in recently revised curriculum documents in many countries, for example in Australia, the UK, and Singapore (Australian Curriculum, Assessment and Reporting Authority, 2008; Department for Education, 2012; Hodge, n.d.). Some of these curriculum documents encourage the use of integration as a way of embracing the key competencies. The DeSeCo report was pivotal to repositioning debates about the nature of knowledge, particularly concerning the consideration of skills as opposed to competencies, and subject as opposed to inquiry knowledge (Dede, 2009). The DeSeCo report's discussions have clearly infiltrated the New Zealand Curriculum, which encourages the development of key competencies in social contexts, acknowledging that practices are "shaped by interactions with people, places, ideas, and things. Students need to be challenged and supported to develop them in contexts that are increasingly wide-ranging and complex" (Ministry of Education, 2007, p. 12).

The development of creative, actively involved, critical thinking, and lifelong learners is a focus of the Curriculum, as well as the need to provide for a diverse range of students (Ministry of Education, 2007). The New Zealand Curriculum places a strong emphasis on the pedagogy used to teach the eight Essential learning areas, stating that "knowledge and skills that students will need for addressing real-life situations are rarely confined to one part of the curriculum. Wherever possible, schools should aim to design their curriculum so that learning crosses apparent boundaries" (p. 38). Page 34 of the New Zealand Curriculum is entitled Effective Pedagogy: Teacher actions promoting 
student learning. The Curriculum lists the conditions beneficial to promoting positive outcomes for students, according to empirical evidence. The conditions listed align closely with curriculum integration, and are summarised as:

- $\quad$ create a supportive learning environment

- $\quad$ encourage reflective thought and action

- $\quad$ enhance the relevance of new learning

- $\quad$ facilitate shared learning

- $\quad$ make connections to prior learning and experience

- $\quad$ provide sufficient opportunities to learn

- $\quad$ inquire into the teaching-learning relationship.

Hipkins (2008) draws attention to the fact that the 2007 New Zealand Curriculum allows teachers to see the connections that can be made between learning areas more clearly. She points out that the Curriculum is all contained in one document, rather than the previous versions that have had separate documents for each subject area. Correspondingly, Wood \& Sheehan (2012) remark on how the Curriculum has shifted from being content to process driven, with the five key competencies having replaced the previous curriculum's eight essential skills. They also note the encouragement of integration between learning areas, the promotion of individual and flexible pathways, and the emphasis on lifelong learning throughout the curriculum document. Wood and Sheehan are, however, concerned that the moderation of knowledge in the Curriculum could have stark repercussions for underprivileged and marginalised learners "by failing to provide them with the conditions by which they can acquire the foundations for powerful, intellectual work" (p. 18).

Contrastingly, Begg (2008) argues that despite the new front end of the Curriculum, which refers to the vision, values, principles, effective pedagogy and teaching as inquiry, there is still a large weighting towards the learning areas and their subject specific achievement objectives. This leads to confusion as to whether the curriculum is advocating integration or still promoting separate subject learning, and is very much up to individual schools to interpret. This also signals a tension between new and old approaches, which could result in confusion around the Curriculum's intentions.

Some argue that the subtle and not so subtle modifications of the 2007 New Zealand Curriculum, outlined above, signal a repositioning away from the 'what' of 
learning towards the 'how' of learning. In order to implement such a change, a pedagogical alternative to the traditional transmissive mode of teaching must be employed, which has, in part, justified the use of curriculum integration. The increasing interest in curriculum integration is also reflected in the inclusion of three articles in the latest New Zealand Council for Education Research's journal SET (Boyd \& Hipkins, 2012; Dowden, 2012; Fraser et al., 2012), published a number of weeks prior to this thesis being submitted. All three articles offer practical suggestions for incorporating integration into schools' curriculums, and indicate a renewed interest in this area.

\subsection{Theoretical frameworks of curriculum integration}

Curriculum integration's theoretical origins stem from Dewey's (1900, 1916, 1949) theoretical framework of progressive and experiential learning, and more recently from Beane's (1997) curriculum integration framework (Godinho \& Imms, 2011; Parr et al., 2009). Dewey (1900) argued in his book, The school and society, the child and the curriculum, that the true centre of correlation of the school is within the child's own social actions, rather than the subject disciplines. This view aligns with the philosophy of curriculum integration, particularly the trans-disciplinary model, which situates all learning around issues of interest to its students.

Individual teachers and schools embracing curriculum integration do so in order to make learning more meaningful and engaging, as noted previously, with less emphasis on the learning areas as a result. In this way, students are active participants in their own learning, rather than passive recipients of disciplinary knowledge. Dewey (1916) believed that learning and knowledge were constructed through action and experience, and that no learning takes place without action. These ideals are the foundation of an integrated curriculum, with students experiencing learning that is personalised and relevant. While there is flexibility of context within curriculum integration, the process of progressing through the inquiry of choice is structured, teaching students valuable, non-discipline specific skills, such as thinking, questioning, and reflection (Beane, 1997). This mirrors Dewey's belief that education must be viewed as a continual reconstruction of experience, and that the process of education is tantamount.

Dewey's (1949) progressive model of thinking incorporates three steps, which Beane (1997) has linked into his model of integration, as illustrated in Table 2.2 below: 


\begin{tabular}{|c|l|l|}
\hline \multicolumn{2}{|c|}{ Dewey's model of thinking } & Beane's model of curriculum integration \\
\hline $\mathbf{1}$ & $\begin{array}{l}\text { A student encounters } a \\
\text { problem in action }\end{array}$ & $\begin{array}{l}\text { Curriculum integration is often initiated } \\
\text { through questions that students have about } \\
\text { themselves \& their world. }\end{array}$ \\
\hline $\mathbf{2}$ & $\begin{array}{l}\text { The problem is interpreted } \\
\text { drawing on prior experience } \\
\text { and knowledge }\end{array}$ & $\begin{array}{l}\text { Students are encouraged to establish themes } \\
\text { within their questions drawing from their } \\
\text { current knowledge and understanding. }\end{array}$ \\
\hline $\mathbf{3}$ & $\begin{array}{l}\text { A solution to the problem is } \\
\text { experimented with }\end{array}$ & $\begin{array}{l}\text { Students attempt to answer their questions } \\
\text { through the activities they have co-constructed } \\
\text { with each other and their teacher. }\end{array}$ \\
\hline
\end{tabular}

Table 2.2: Dewey's model of thinking and Beane's model of curriculum integration

Schools are shared spaces in which students and teachers gather to create new opportunities and shape new futures. Constructivism views that experience, learning, language and meaning are based on the constructive and creative actions of individuals who come together in a social environment (Sutinen, 2008). Curriculum integration arguably offers a greater opportunity, than traditional methods, to collaborate and learn in a communal setting, to add to students' prior understandings of various concepts, nurturing their social skills and therefore their understanding of others' viewpoints.

Advocates of curriculum integration argue that it is responsive to the way students learn, due to the fact that the brain seeks patterns between new details, and learning happens more readily when presented in a meaningful context. Kaskey-Roush (2008) explains that:

The constructivist view of learning views the learner as the creator of meanings and learning as an active process ... an inter-disciplinary approach is in line with this view of learning and teaching. The theme and subsequent activities used in an integrated curriculum come from the students thoughts and concerns. Students concentrate on using their own skills and knowledge to answer their questions and construct their own meaning. (p. 7)

Reich (2009) illustrates the parallels between curriculum integration and constructivism in this regard, maintaining that "the more numerous and varied the consciously shared interests within a constructivist interpretive community, the more development and growth we may expect" (p. 61).

Curriculum integration is evolutionary in nature, as learning changes according to the prior experience, interests, and diversity of its learners. This notion of curriculum integration mirrors Bickhard's (1997) belief that a pragmatic model imposes an 
evolutionary epistemology that is essential for the understanding and planning of education. John Dewey was a major contributor to the theory of pragmatism, which is based on transactional constructivism. Pragmatism considers that “...the knowledge constructed by an individual emerges in the transaction between the individual's activity and the environment for action" (Sutinen, 2008, p.2), a view that is concurrent with curriculum integration. Students choose an issue to investigate and then the learning and knowledge follow. Educators are continuously constructing knowledge with students as their needs are interpreted, providing them with assistance to construct solutions to problems for which they cannot produce their own solutions.

James (2012) described pragmatismas a philosophical tradition that was centered on the coupling of theory and practice. He viewed pragmatism as a process that extracted theory from practice, followed by a reapplication of the resultant theory back to practice. Teachers are often viewed as pragmatists, so by using the lens of pragmatism to view curriculum integration I will be better equipped to observe whether the teachers' practice is theoretically or pragmatically grounded.

Many contemporary learning theorists such as Jerome Bruner, Jean Lave, and Etienne Wenger have expanded on Dewey's socially constructed learning theory. Bruner (2009) states that "learning and thinking are always situated in a cultural setting" (p. 161), Lave (2009) believes that situated activity involving changes in knowledge and action are central to learning, that "de-contextualised learning activity is a contradiction in terms" (p. 202), and Wenger's (2009) social theory of learning also has a primary focus on learning as social participation. Links can be made between curriculum integration and all of these theories in the following ways: integration builds upon individuals' prior socially and culturally constructed knowledge; integrated learning is always situated and contextual due to co-construction between students and teachers; that students tend to collaborate throughout integration.

The co-construction of learning, which is a central feature of trans-disciplinary integration, is an example of communicative action, a critical theory developed by Habermas (Prasad, 2005). This theory supports consensus through agreement, and understanding via communication (as opposed to manipulation, and intimidation). Throughout my research I used the notion of curriculum integration as a form of critical pedagogy to discern the level of student-centered integration at each school. Critical pedagogy considers a student's place in the world, rather than removing them from their 
context (Hofstede, 2011). Habermas viewed that "societies are created and maintained by the coordinated activities of its members" (Prasad, 2005, p. 147). This concept is termed an ideal speech community and is reflected in curriculum integration through the contribution that students make to the planning of their learning. Hidden agendas and the preclusion of authentic interaction leads to what Habermas terms systematically distorted communication, which can be the case via more traditional, transmissive methods. Such systematic distortion, where old ideas are reproduced, as opposed to the production of new discourse, could be viewed as concurrent with the reproduction of knowledge contained in the curriculum, as discussed in section 2.5. These theoretical frameworks have therefore shaped the approach to curriculum integration in this research.

\subsection{Chapter conclusion}

This chapter has highlighted the many different types, descriptions, models, and methods that have led to the current ambiguity surrounding curriculum integration. I have given a brief history of integration, from its inception by Dewey in the 1800s, to present, with a particular focus on its development in New Zealand, followed by a summary of previous curriculum integration research. The political, societal, and educational influences that have stimulated a renewed interest in curriculum integration in recent times have been considered, concluding with an outline of the theoretical paradigms of progressivism, pragmatic constructivism, and Habermas' critical theory of communicative action, in which curriculum integration is situated. 


\title{
CHAPTER 3: METHODOLOGY
}

\author{
Curriculum integration is like a fern frond - All different areas of learning contributing to one \\ beautiful understanding of the world we live in. \\ (Lily, Awa High)
}

\subsection{Chapter introduction}

This chapter describes the methodology that I employed to explore teacher's multiple perceptions and practices towards curriculum integration. The nature of my research is descriptive, and so I have utilised a qualitative methodology to address my research questions.

I begin this chapter with an overview of the constructivist theoretical paradigm underpinning my methodological approach. I will explain why constructivism is a fitting paradigm for this study, particularly in terms of case study research. The process by which participants were invited to take part in the research is described, followed by an outline and justification for the data collection methodologies adopted. I have provided a detailed portrayal of the analysis process, as well as an account of how I worked towards enhancing the integrity and trustworthiness of my research. Ethical considerations of working with teachers, as well as those specific to this study are described, followed by the study's limitations.

\subsection{Research paradigm}

Teachers' perceptions and practices are multiple, and are often shared among individuals through complex social constructions. Therefore the research paradigm that guides this qualitative inquiry is constructivism. Guba \& Lincoln (2001) believe that constructivism holds a subjectivist ontology that describes realities as locally and specifically constructed, and so the transactional epistemology of qualitative constructivism provides a fitting worldview for this study. In particular, socially constructed learning theory fits well with the methodology of this research, as I will be investigating the detailed construction of curriculum integration at four case study schools, where specific aspects of their settings have influenced their current views and actions of curriculum integration.

The lack of a clear definition, description, or model of curriculum integration has, in my experience, led to teachers collectively, or sometimes individually, constructing their own descriptions and models of integration. In particular if the curriculum 
integration programme is 'opt in', rather than mainstream, and therefore smaller in size, the teacher community involved with the programme's construction draw on their prior knowledge and previous experience, to construct their own meanings around integration. Teachers in a small learning community will draw on their own values and beliefs about what they think curriculum integration should look like, and for this reason I have chosen a constructivist paradigm to carry out my research to examine how each case study schools' teachers' perceptions and practices have been fostered.

\subsection{Qualitative approach}

This research has been conducted using a qualitative approach, a methodology that is used to collect unquantifiable facts, allowing the researcher to share the understandings and perceptions of people and how they give meaning to their existence (Berg, 2009). As described in Chapters One and Two, teachers maintain varied interpretations of curriculum integration. Qualitative research allows the inclusion of multiple perspectives, showing that the world can be viewed and understood in diverse ways (N.I.U., n.d.). Qualitative research is interpretive in nature, allowing depth of perspective and so is an appropriate choice of methodology for this inquiry.

The qualitative methodology that I have employed is case study research, described by Creswell (2007) as a methodology used to explore a bounded system or systems. Case study research allows an in-depth understanding of the cases in the bounded system through multiple sources of data collection. I have specifically utilised the approach of collective case study (N.I.U., n.d.). This refers to a study involving more than one case. I chose this method so that I could examine the issue of teacher's perceptions and practices regarding curriculum integration through diverse conditions and attitudes in four New Zealand secondary schools.

\subsection{Participants}

I used purposive maximal sampling to select four secondary schools in New Zealand that currently offer a curriculum integration programme. This selection process provided cases that would offer slightly different perspectives on the issue of teachers' perceptions and practices surrounding curriculum integration (Creswell, 2007). In order to consider whether the length of time each school had been practicing curriculum integration had effected teachers' perceptions and practice toward it, I have included schools in New Zealand that are at different stages on their curriculum integration 
journey. I also wished to investigate whether the whole school or 'opt-in' nature of the programmes affected perceptions and practices, and so I invited schools representing both. The other factor that I wished to examine in terms of teachers' perceptions and practices was whether they were using curriculum integration voluntarily or not, therefore the schools that I invited to participate also reflected diversity in this area.

I invited schools to participate in the research by sending the Principal a letter of invitation, which outlined the nature and intention of my research (appendix one). The schools I invited were either known to me prior to the research, or had been recommended as possible participants by colleagues, as there is currently no database listing New Zealand schools employing curriculum integration. One school that I invited to participate in the research declined due to accommodating two other groups of researchers at the time of my study. Another school that I planned to include had discontinued their integration programme at the end of the year prior to my research commencing. Principals who were willing for their schools to take part in the research filled in a consent form (appendix two) and nominated a contact person to liaise with regarding potential participant teachers who taught within each school's curriculum integration program. One of the participating schools is my own. A summary of the profiles of the case study schools is provided in Table 3.1 below, with each school having been given a pseudonym.

\begin{tabular}{|l|c|c|c|c|}
\hline SCHO0L & $\begin{array}{c}\text { AWA } \\
\text { HIGH }\end{array}$ & $\begin{array}{c}\text { PAKIREHUA } \\
\text { COLLEGE }\end{array}$ & $\begin{array}{c}\text { RUA } \\
\text { HIGH }\end{array}$ & $\begin{array}{c}\text { NIU } \\
\text { COLLEGE }\end{array}$ \\
\hline Recile & 8 & 6 & 9 & 5 \\
\hline Authority & 1567 & 1767 & 942 & 604 \\
\hline Nature & State & State & State & State \\
\hline $\begin{array}{l}\text { Type } \\
\text { YYears) }\end{array}$ & $\begin{array}{c}\text { Secondary } \\
(9-13)\end{array}$ & $\begin{array}{c}\text { Secondary } \\
(9-13)\end{array}$ & $\begin{array}{c}\text { Secondary } \\
(9-13)\end{array}$ & $\begin{array}{c}\text { Intermediate \& } \\
\text { Secondary (7-13) }\end{array}$ \\
\hline Founded & 1926 & 1958 & 1886 & 2011 \\
\hline CI founded & 2000 & 2007 & 2008 & 2011 \\
\hline
\end{tabular}

Table 3.1: Profile comparison of case study schools

All teachers involved in the curriculum integration programs at each school were asked if they would like to participate in the research. At Awa High School six out of 15 curriculum integration teachers participated. At Pakirehua College there were only two 
curriculum integration teachers, who both took part. As all of the year nine and ten teachers at Rua High School and Niu College taught within their integration programs, the lead teachers asked a range of teachers with eight participating at Rua and six at Niu. Potential participants were given an information letter (teachers, appendix three and Principals, appendix five), which contained example questions to be asked in the focus group and interview, to allow them to make an informed decision as to whether to partake in the research. If they were willing to participate then they completed a consent form (teachers, appendix four and Principals, appendix six). The letter advised potential participants that they could ask questions prior to giving consent if desired. A teacher at my own school declined to participate due to work pressures and family commitments, which I believe reflected the fact that no participants felt coerced in to taking part. Participants' age, gender, ethnicity, teaching qualifications, teaching subjects and teaching experience were sought via a demographic sheet (appendix seven) to provide personal data about the participants. The information was not used as participant selection criteria. Table 3.2 below summarises this information for each school.

\begin{tabular}{|c|c|c|c|c|}
\hline $\begin{array}{ll}\text { SCHOOL } & \text { PARTICIPANTS }\end{array}$ & $\begin{array}{l}\text { AWA } \\
\text { HIGH }\end{array}$ & $\begin{array}{l}\text { PAKIREHU } \\
\text { A COLLEGE }\end{array}$ & $\begin{array}{l}\text { RUA } \\
\text { HIGH }\end{array}$ & $\begin{array}{l}\text { NIU } \\
\text { COLLEGE }\end{array}$ \\
\hline Total number & 7 & 3 & 11 & 8 \\
\hline Number of teachers & 6 & 2 & 8 & 6 \\
\hline Number of senior admin & 1 & 1 & 3 & 2 \\
\hline Male & 2 & 3 & 5 & 3 \\
\hline Female & 5 & 0 & 6 & 5 \\
\hline $\begin{array}{l}\text { LEARNING AREAS } \\
\text { TAUGHT WITHIN } \\
\end{array}$ & \multicolumn{4}{|c|}{ NUMBER OF TEACHERS } \\
\hline Just English & 0 & 0 & 1 & 2 \\
\hline Just Maths & 0 & 0 & 1 & 1 \\
\hline Just Science & 1 & 0 & 3 & 1 \\
\hline Just Social Sciences & 0 & 0 & 2 & 1 \\
\hline English \& Social Sciences & 3 & 1 & 1 & 0 \\
\hline Maths \& Science & 1 & 1 & 0 & 1 \\
\hline Maths \& English & 1 & 0 & 0 & 0 \\
\hline
\end{tabular}

Table 3.2: Summary of participants at each of the case study schools 


\subsection{Data collection methods}

Information was gathered through the use of multiple collection techniques to gather data on the same phenomenon. Berg (2009) explains that "by combining several lines of sight, researchers obtain a better, more substantive picture of reality; a richer, more complete array of symbols and theoretical concepts; and a means of verifying many of these elements" (p. 5). Employing multiple methods of data collection is also a characteristic of case study research, as the use of several pieces of data from a variety of sources assists in uncovering convergent lines of inquiry. Case study findings are strengthened in this way by providing several measures of equal phenomena (Yin, 2002). The data collection procedures I used were focus groups, semi-structured interviews, observation, and analysis of documents.

\subsubsection{Focus groups}

This technique was especially useful in drawing out teachers' perceptions of curriculum integration due to the stimulation of discussion between members. Focus groups are small group discussions led by a facilitator to elicit information regarding the "conscious, semiconscious, and unconscious psychological and sociocultural characteristics and processes among various groups" (Berg, 2009, p. 144). This method of interviewing specifically utilises the interaction of the group as a tool for gathering data regarding a topic of interest to the group and the researcher that could generate differing perspectives and viewpoints. Berg supports focus groups as a practice that generates a much larger number of ideas and issues than individual discussion. I used a digital recording device to document the focus group sessions and interviews, that I later transcribed myself.

All teachers carried out a mind-mapping activity immediately prior to the focus group commencing. The mind map took the form of a 'SWOT' analysis listing the strengths, weaknesses, opportunities, and threats of curriculum integration. This was performed in pairs before the larger group discussion took place in order to stimulate thoughts and ideas around curriculum integration, and as a way of encouraging an even greater contribution across all focus group participants. This activity also addressed the critique that focus groups are often dominated by one or two outspoken members. The SWOT analysis also generated useful information that I used in the data analysis to build a bigger picture at each school. 
Six to eight teachers formed the focus groups at Awa High, Niu College and Rua High, which Berg (2009) suggests is an ideal number to effectively elicit a suitable breadth of responses while also allowing the transcriber to identify participants. Pakirehua College's focus group comprised two teachers as this was the sum of teachers facilitating the curriculum integration programme there. The lead teachers at each school invited teachers that represented a mix of ages, genders, and experience to ensure a range of views. The teachers represented views of curriculum integration from different subject areas in each school.

At each of the schools we ran out of time before all of the focus group questions were answered. After the first focus group session, I decided to maintain consistency by asking all school's participants to complete the last three questions individually by email. I made it clear to all participants that this was voluntary; however, all but one participant completed a response.

\subsubsection{Semi-structured interview}

I conducted a semi-structured interview with the Principal or Deputy Principal at each school. The perspective of senior management was part of my research interest and one of the research sub-questions. In my experience, senior management support is pivotal to the success or struggle of curriculum integration initiatives, and so it was important to explore their contributions. Semi-structured interviewing is utilised to acquire in-depth information about the interviewee's "thoughts, beliefs, knowledge, reasoning, motivations and feelings about a topic" (Johnson \& Christensen, 2008, p. 207). Semi-structured interview questions are predetermined, open ended and their order is flexible (N.I.U., n.d.). I used the same questions for the Principals' interviews as I did in the focus group interviews, with slight amendments where appropriate to the roles. This flexibility allowed additional questions that arose to be addressed, as well as allowing the participants to pursue areas that spontaneously surfaced (Berg, 2009). The Principals' perceptions of curriculum integration provided an important contribution to the data. However, including the Principal in the focus group interview could have influenced the nature and depth of the teachers' participation, which is why I conducted individual interviews with each Principal or Deputy Principal.

The research questions asked during the focus groups and semi-structured interviews are summarised in section 1.3 (pg. 6) 


\subsubsection{Observation}

I included observations in my methodology to address the research questions regarding teachers' practice towards curriculum integration. Johnson \& Christensen (2008) state that qualitative observation requires the examination of all relevant phenomena, recording extensive field notes to be analysed at a later date. The observations were naturalistic, undertaken in teachers' classrooms, and no effort was made to manipulate variables or control activities (N.I.U., n.d.).

It is impossible to watch and hear everything that is going on in the observed environment, and so Berg (2009) suggests that researchers should pinpoint specific observable activities. Creswell (2007) advocates the use of a protocol to record information during observations, so I designed and used a template (appendix eight).

In-class observations of two to four teachers from each school were carried out. In the schools where the subjects are taught separately, the observations were conducted across a range of subjects. Following the focus group, participants were invited to volunteer their class for observation. Several teachers at each school offered to be observed, so I conducted as many observations as time allowed (see table 3.3).

\subsubsection{Secondary data}

To obtain a more detailed picture of both perceptions and practices of curriculum integration at each school I collected secondary data. Secondary data is that which existed prior to the research being instigated and can include personal documents, official documents, physical data and archived research data (Johnson \& Christensen, 2008). I collected data from curriculum integration planning documents, websites and blog links, lesson plans, professional development plans and presentations, and, teaching and learning guidelines or handbooks, as summarised in table 3.3 below.

\begin{tabular}{|l|c|c|c|c|}
\hline \multicolumn{1}{|c|}{ SCHOOL } & AWA & PAKIREHUA & RUA & NIU \\
COLLEGE & HIGH & COLLEGE \\
\hline Observations & $\mathbf{4}$ & $\mathbf{2}$ & $\mathbf{3}$ & $\mathbf{4}$ \\
\hline Planning docs & $\checkmark$ & $\checkmark$ & $\checkmark$ & $\checkmark$ \\
\hline Websites \& blogs & $\checkmark$ & & $\checkmark$ & $\checkmark$ \\
\hline Lesson plans & $\checkmark$ & $\checkmark$ & $\checkmark$ & $\checkmark$ \\
\hline PD plans & $\checkmark$ & & $\checkmark$ & $\checkmark$ \\
\hline T\&L guides & $\checkmark$ & $\checkmark$ & & \\
\hline
\end{tabular}

Table 3.3: Number of observations and types of secondary data collected at each school 


\subsection{Data analysis methods}

Qualitative data analysis is often inductive and seeks patterns emerging from the data. It is shaped by the research questions, which guide the focus of the data, yet qualitative analysis can be messy and confounding. Yin (2002) states that analysing case study evidence is difficult as the strategies and techniques are not clearly defined. He advises that much practice, starting modestly and working thoroughly, is necessary in order to produce powerful analysis and compelling case studies.

I commenced data analysis while still gathering data from other schools. Johnson \& Christensen (2008) report that the process of data collection and analysis occur simultaneously, with data analysis beginning early in qualitative research. They describe it as a cyclical process of gathering and analysing data, referred to as interim analysis. Creswell (2007) lists three main steps involved in the data analysis of qualitative research:

1. preparing and organising the data

2. condensing the data into themes

3. representing the data.

Once I had begun organising the data I embarked on searching for themes. I developed a provisional coding frame soon after the focus groups and discussions had taken place, as suggested by Barbour (2008), noting the main themes and grouping them under initial subcategories. I then transcribed all of the interview data verbatim, followed by a description of each of the cases and their contexts. Barbour notes the importance of avoiding the quantitative approach of pre-determining coding categories prior to data collection and analysis. This can lead to over-reliance on themes stimulated by the focus-group and interview questions, rather than allowing flexibility to incorporate themes introduced by the participants and other data collection methods. She also advises the analyst to question their disciplinary assumptions in order that they do not distort analysis. Biases in the researcher's analysis, for example having a preconceived idea of the findings due to expertise in the research area, can influence the themes identified. Barbour also highlights the importance of being alert to the language, sentence structure and rhetorical styles, noting any tensions and expression of beliefs as polarities or continua. An important distinction is made by Burton, Brundrett, \& Jones (2008) between a priori codes (themes anticipated prior to data collection) and in-vivo 
codes (less obvious themes likely to require exposition and clarification by the researcher, and notably developed in focus group data), which I was deliberately mindful of throughout my data analysis. Once several detailed codes were identified, categorical aggregation ensued to establish themes or patterns. Barbour (2008) describes how some people like to go from very detailed codes, which they then group into broader themes, whereas others prefer to conceptualise in broad themes followed by separation into narrower codes - I have employed the first preference.

In order to avoid impressionistic evaluations in my analysis I generated a grid using the themes and codes to frame patterns in the data, which enabled me to identify more closely the features of the data that provided the greatest insights for my research questions, which in turn helped to identify the themes. As I identified subcategories it became apparent that some of them were appearing under multiple themes. For example, professional development was a subcategory under support from senior management, barriers to integration, and teaching as inquiry. The New Zealand Curriculum emerged under history, and reasons for implementing integration. The relatedness of subcategories grouped under different broad themes is viewed by Barbour as unproblematic and a reflection of the complex and inclusive nature of qualitative data. She suggests the production of coding diagrams of broad themes to show how subcategories are related, helping to develop a deeper understanding of the means through which participants' viewpoints and shared identities are formed.

The intention of employing focus groups is to portray such shared identities, through the interaction between the participants, summarised by Barbour (2008):

Rather than simply extracting the comments made by individuals, huge dividends can be gained by paying due attention to what is happening during a piece of interaction, as the whole can be infinitely greater than the sum of the parts. (p.130)

Barbour warns of the overemphasis of concurrence in focus groups and to guard against attributing apparent group consensus to individuals' opinions, as well as imparting an over-simplified representation of complex discussions. Systematic application of constant comparison requires focus on inter- and intra-group variation, so I have analysed the focus group data at both group and individual levels to ascertain the collectivity of perspectives and to avoid giving simply a descriptive report. 
Once I had analysed the focus group data for each case study school, I incorporated the observation data and documentation from each school to explore whether the perceptions of the teachers were also evident in their practice. The combination of different data sources requires engagement in critical analysis in order to understand and explain underlying reasons for particular phenomena (Burton et al., 2008). Throughout the data analysis I continued to connect with the literature surrounding the topic to enhance the validity of the resulting codes and to ensure that all relevant codes were included.

I have presented my data with my analysis, rather than separately, as well as using my research questions as a structural device to support the analytic process, as advocated by Burton et al. (2008). Creswell (2007) suggests that with multiple cases it is common to give a detailed description and themes of each, called within-case analysis and then follow with a cross-case analysis of themes across the cases including assertions (interpretation of meanings). Chapter Four is largely a within-case analysis of each school, with a cross-case analysis offered in Chapter Five.

\subsection{Integrity \& Trustworthiness}

The reliability of qualitative research is often critiqued on the degree of integrity, which refers to how dependable the findings are (Johnson \& Christensen, 2008). Through the use of multiple case studies, low inference descriptors, participant feedback, and detailed descriptions of the methods used, the findings of this research study are consistent and reliable. A description of how I addressed five forms of validity is outlined below.

Researcher bias is a major threat to validity (Johnson \& Christensen, 2008; N.I.U., n.d.) due to selective observation and recording, and the influence of personal perspectives on interpretation. As a teacher at one of the case study schools, researcher bias was an important consideration. I was also aware that my status as a researcher and experienced teacher of integration could result in participants saying what they thought I wanted to hear. In order to avoid this I explained to all participants that my aim was to find out their own perceptions of curriculum integration. Gilgun (2010) highlights the importance of qualitative researchers considering reflexivity, and that it is well recognised that researchers and the research process are reciprocally influential, in both qualitative and quantitative research. Gilgun describes how "researchers are 
reflexive when they are aware of the multiple influences they have on research processes and on how research processes affect them" (p. 1). Acknowledging that my presence influenced the data is another way that I have recognised researcher bias.

Descriptive validity (the factual accuracy of the findings), and interpretive validity (accurate portrayal of participants' meanings) were promoted through the use of participant feedback to attempt to address misinterpretations or lack of clarity. Interpretive validity was also upheld by using direct quotations where possible.

Theoretical validity (how well a theoretical explanation fits the data) was increased through peer review. I discussed my interpretations and conclusions with my peers (colleagues, and Masters and PhD students), at a conference presentation, and with my supervisor, as a process to clarify and sharpen the theoretical implications of my research, and to refine the analytical value of the selected theoretical framework.

Internal validity (justification for concluding a cause-effect relationship) was maximised by using data triangulation (N.I.U., n.d.). As discussed earlier, I collected data through several different methods, to collect detailed information, leading to a better understanding of curriculum integration.

External validity (level of generalisability), although not a key focus of qualitative research, by providing detail the reader can determine the relevance to their own setting. External validity was increased by the use of multiple case study approaches (Merriam, 2001). This led to replication logic, or findings which are found to hold true across multiple settings. In my research, the findings in one school were frequently replicated across many or all four schools, which increased my level of confidence in the robustness of the research findings.

\subsection{Ethical considerations}

An application for ethical approval was lodged with and approved by the Victoria University Wellington Faculty of Education Ethics Committee (19339). This investigation observed the ethical guidelines of the New Zealand Association for Research in Education (NZARE).

Informed consent was obtained from each of the participants, as outlined previously. Participants were given a copy of the transcripts of the thesis to check that 
the correct meaning was communicated. Two participants emailed me from two different schools, both to correct the name of authors that they had referenced.

As one of the case study schools was my own, I was careful not to apply pressure on the staff to participate. Although I made every effort to ensure that participants gave open and sincere contributions I acknowledge that my connection could have impacted data from this school.

The identity of participants has been protected throughout the study and all participants and schools have been given pseudonyms (which are Awa High, Rua High, Pakirehua College, and Niu College). Each school was offered a copy of the completed thesis and advised that the thesis will be stored in the Victoria University Library.

\subsection{Limitations of study}

This was a small scale explorative study in keeping with the time constraints and limitations of a one year Master's research thesis. Therefore the findings are not generalisable, but could be useful in establishing frameworks for future research and generating theory.

In keeping with the nature of qualitative research in schools, there was some unevenness to the number of participants in each school. At one of the schools there were only two teachers in the focus group, due to there being only two teachers in the integration programme. This changed the dynamics and contribution of the data as there was a smaller breadth and greater depth of opinion than at the other schools.

Another limitation was linked to the complex nature of working in a school setting, and in particular finding time for busy teachers to meet. I would have liked for the focus groups to be longer in duration as, at times, it felt rushed. The meetings were variable in length, but had to meet the needs of the teachers. At one school we met during their normal professional development time to conduct the focus group, and then reconvened at lunchtime, where one participant was unable to attend, due to duty. I was also unable to observe all of the participants teaching due to time constraints.

Chapters Four and Five offer the analysed findings of the research. Key themes have been identified via analysis of the data under the two broad ideas of teachers' perceptions (Chapter Four) and their practices (Chapter Five) toward curriculum integration. 


\section{CHAPTER 4: SECONDARY SCHOOL TEACHERS' PERCEPTIONS TOWARD CURRICULUM INTEGRATION}

Curriculum integration is like white light - a combination of all the different colours of the learning spectrum. These colours are useful and have their place individually, mix a couple together to make new understanding and all together in equal parts to produce the overall white light. White light is what you use to see clearly, an uneven mix will just eventually hurt your eyes.

(Misty, Rua High)

\subsection{Chapter introduction}

The primary focus of this chapter is to present teachers' perceptions towards curriculum integration. The chapter begins with a description of each of the case study schools to offer historical, background and contextual information. Section 4.3 examines the theoretical grounding of each programme, as perceived by the teachers, and the final section of this chapter considers the teachers' perceived benefits of utilising curriculum integration.

\subsection{Description of case study schools}

The four case study schools and the nature of their curriculum integration are described below. The schools are described in order from the school with the longest integration experience (Awa High - 12 years), to the least (Niu College - two years). The four schools participating in the research are all New Zealand state secondary schools, and three of the schools are co-educational, with Pakirehua College being the only single sex school. Table 3.1, in the previous chapter, compares the profiles of the four case study schools for reference.

In this section, I review the historical roots of curriculum integration in each school, how curriculum integration currently operates, and where each school intends to head in the future. A tabular summary is provided in Table 4.1 at the end of this section.

\subsubsection{Awa High}

Awa High is a decile 8, co-educational school in the Wellington Region, founded in 1926. In 1998, a nearby local college was closed down by the Ministry of Education, and its students were integrated into Awa High. Awa High had the use of the other college's site for a period of five years after its closure and so Awa's Principal decided to trial an innovative programme for the teaching and learning of junior students there. The curriculum integration programme was designed and facilitated by two teachers with a 
strong interest in progressive pedagogy. The resulting curriculum integration programme was established in 2000, and continues through to today on the main school site. Since the programme's induction, three different Principals have led the school, all of whom have chosen to maintain the programme.

Prospective Year Nine students opt into Awa High's programme by ticking a box on their enrolment form. Not all interested students gain entry to the programme, so the selection process ensures that the students reflect the same demographic makeup as the mainstream classes. Between 2000 and 2002, the programme operated in Years Nine and Ten, with two classes at each year level. In 2003, the programme moved to the main school site where the number of classes grew to three at both Years Nine and Ten. In 2010, a Year 11 curriculum integration class was trialled, but didn't continue the following year due to timetabling issues and resistance from individual heads of department (field notes, June 2012). In 2012, there were eight integrated classes at Years Nine and Ten.

In 2010, Awa High's senior leadership team decided to incorporate relational, but not curricular, aspects of the curriculum integration programme's methodology across the whole junior school. Professional learning groups comprising the English, Maths, Science, Social Studies, and Physical Education teachers of each junior class were established to facilitate discussion around the pastoral needs of the students, and to develop common strategies for addressing such needs. Rose, a teacher at Awa, explained that "we've got these new structures this year for teachers to meet and talk about the needs of students they have in common, so that would be a natural way to promote integration." The groups have evolved to incorporate teaching and learning strategies into their discussions, which is intended to develop in 2013.

The curriculum integration programme incorporates the learning areas of English, Maths, Science, and Social Studies. In the original programme, one of the two teachers taught Maths, Science, and Health to each class, and the other teacher taught English and Social Studies. The programme has undergone some changes since then, and most teachers now teach within one learning area. This is due to some teachers not wanting to teach across two learning areas, and also a strong preference by one particular head of department for his staff not to teach across learning areas (field notes, June 2012). In the past, the curriculum integration programme at Awa High has been thematic, but is less so now. The curriculum integration department is required to 
follow an increasingly prescribed whole school plan and set sequence for the Year Nine and Ten curricula in Maths and English, which has made it more difficult to link between all of the learning areas, as described by Angela, a teacher at Awa: "Because I teach English and Maths, it's harder ... some departments are too fixed in the way they want to do things, then it's harder to do the integration." In Science and Social Studies there is more flexibility around when and how topics are taught.

Rose, a teacher, shared how the integration at Awa High is based around using common teaching methodologies, chiefly cooperative learning, but also thinking and questioning skills, and multiple intelligences, amongst others: “[Awa's programme] was built on cooperative learning foundations ... the way that we teach, the integration of our pedagogy." Teachers plan together at a fortnightly meeting after school where the pastoral needs of each class are also discussed and links between learning areas are considered where appropriate.

The location of teachers and students was noted as influencing the programme. Some of the teachers in the curriculum integration programme share office space and felt that this aided their planning across learning areas and collaboration in general. Students move between different classrooms for all of their lessons in 50-60 minute blocks, which are taught in traditional classrooms. This movement and timeframe was viewed by the teachers at Awa High as reducing their ability to integrate. One of the four subject teachers is also the form teacher for a curriculum integration class that they teach.

Teachers described the intention to disband Awa High's curriculum integration programme in the future in order to spread its methodology across the whole junior school, rather than having it as a separate programme. The reason behind this decision, to extend the curriculum integration programme, is to offer an innovative approach to the delivery of the New Zealand Curriculum, which is anticipated to make students' learning more meaningful and to increase their engagement. Additionally, the last three ERO reports for Awa High indicated that teachers in the curriculum integration department were consistently using sound pedagogy, whereas this had not been reflected across the main school, which provided further stimulus for the programme's expansion. 


\subsubsection{Pakirehua College}

Pakirehua College is a decile 6, single sex boys' school in the Bay of Plenty, founded in 1958. The curriculum integration programme was started in 2009 by a Science teacher to trial inquiry learning with one class. Pakirehua's Principal stated that the programme was "set up to meet the needs of a group of boys", explaining that, "there is a particular group of parents that seek that sort of learning for their sons." Warren, a teacher at Pakirehua, explained that their inquiry learning is centered on an issue or problem that is co-constructed by the teachers and students, into which content from several disciplines is naturally drawn.

The students start the year with one week of separate learning area lessons in English, Maths, Science, and Social Studies, delivered by two teachers with a focus on learning the inquiry cycle that they will use throughout the year. This is followed by three weeks of problem based learning on topics that are chosen by the teachers to assist in ensuring effective curriculum coverage and integration as well as learning the process for inquiry (field notes, July 2012). Presentations of inquiries commence for approximately half a week, and then another learning area delivery week commences.

Students choose a question that they are researching on a topic selected by the teacher for the second three week inquiry of the term, and are responsible for the planning process, including the development of the research questions, and how they will acquire the information that they need. The final week of the term is spent on subject specific learning as students in the integration programme are still required to sit the same formative and summative assessments as other Year Nine and Ten students. In term two, students conduct two inquiries on topics of their own choice.

All students entering Year Nine can apply to join the inquiry programme prior to the start of the year. As at Awa High, students are selected to represent the same demographic makeup as the rest of the school (after two top streamed classes and one learning needs class have been formed). There are currently two curriculum integration classes at Pakirehua College, one at Year Nine and one at Year Ten, and two teachers within the programme. Students are in the same classroom, with one of the two teachers, for 16 hours a week. Pakirehua College has a vertical tutoring system and so the curriculum integration teachers are not the form teacher for most of their students. 
The Principal intends to spread the programme's methodology throughout the junior school over the next few years, with a slightly different model:

We're going to try and have one teacher who will be responsible for English and Social Studies and maybe PE, and the other teacher will teach Science and Mathematics. So we'll have a year 9 class we'll trial with interested teachers.

Warren, a teacher, explained how fortunate they were to have support from the Principal, and how he appreciated the fact that the Principal often asked him to come and share their recent progress, as well as suggestions for how they could spread the programme more widely.

\subsubsection{Rua High}

Rua High is a decile 9, co-educational school, also in the Wellington Region, founded in 1886. The curriculum integration programme at Rua High was launched in 2008 under the direction of the Principal. Motivation toward curriculum integration was described by the Principal as a way to address a number of issues pertaining to the secondary education sector such as:

The need for students to understand rather than merely gather knowledge; the requirement to better prepare students to fill future focused jobs and careers; the necessity to meet the needs of all learners, not just a select few; and the desire to cultivate life-long learners who learn how to learn.

Rua High's Principal did extensive research and concluded that curriculum integration was an apposite pathway to address such concerns (field notes, July 1012). An open invitation was given to all prospective Year Nine students to opt in to the programme, and two Year Nine classes were formed. Two teachers designed the initial trial programme that was deemed successful. The programme is now mainstream throughout all Year Nine and Ten classes. The Principal also expressed the potential to carry the curriculum integration through to Year 11 in the future.

A Deputy Principal, appointed in 2009, was given responsibility for developing the curriculum integration programme and spent time with the programme's two original teachers deciding how it should be implemented. She described how "we used to sit and think, OK, how do we take this very loose thing that we trialled last year to roll it out to the whole staff. You've actually got to give something that everyone feels comfortable doing." The result was a whole school programme comprising four teachers 
from the learning areas of English, Maths, Science, and Social Studies teaching two junior classes of the same year level, based in adjoining rooms. The curriculum integration programme is set up so the students spend one hour blocks on each learning area in the same classroom. At the discretion of the team of teachers, the students occasionally have double blocks on the same learning area. The two classes are divided up into four roopu (pastoral groups) and so each of the four teachers has pastoral responsibility for 12-13 students.

The learning in all four classes is intended to focus around a common theme, problem, or question chosen either by the teachers or co-constructed with the students. The extent of the linking to a common theme in each group varies largely depending on the experience and commitment of the individual teachers to the philosophy of the programme. The Deputy Principal fought to provide an extra hour in the timetable for the four teachers to discuss pastoral matters and to plan together around the common theme, which formed a way "to talk and collaborate ... [and] with that came more confidence". All teachers also meet for professional development twice a term to do group planning. Additionally one lesson a week was timetabled so that all four teachers could work with their class at the same time, ideally on inquiry learning. The four teachers then decided if and when additional periods from their learning area would be dedicated towards inquiry. A generic inquiry is timetabled once or twice a year for all Year Nine and Ten classes in collaboration with the school librarian.

\subsubsection{Niu College}

Niu College is a decile 5, co-educational school in the Bay of Plenty, that was built in 2010 to provide a combined intermediate and high school for one of the fastest growing populations in New Zealand. The school opened at the start of 2011 with Years Seven to Nine (which had grown to include Year Ten at the time of my research). Each subsequent year will gain a year level, until 2015, to include Years Seven to 13. Niu's Principal explained that the school has been designed with "the intention of supporting 21st century teaching and learning at a physical and a structural level."

Having been designed and built after the launch of the 2007 New Zealand Curriculum, the school's philosophy is founded on preparing students for life and work in the 21st century. One of the teachers described how during the recruitment process, "We were asked 'Are we 21st century educators?'” The Principal of Niu College wanted structures in place that made curriculum integration central to the learning, rather than 
something that had to fit around the traditional subject disciplines. He explained that he wanted to ensure that links were made across learning areas and with the local community, in order to provide authentic contexts for learning, as well as developing students' problem solving, group and individual skills, and Key Competencies. Both Deputy Principals appointed at Niu College had experience with curriculum integration, which became the focus for the development of the whole school curriculum and teacher recruitment.

In Years Seven and Eight all learning areas are taught together by one (typically primary trained) teacher using a problem based learning model, under a common school wide theme, chosen by the school's curriculum committee. It was decided at the end of 2010 by staff and senior management, that most of the primary trained teachers did not have the depth or breadth of knowledge needed in the separate learning areas required to prepare students for NCEA. Consequently, subject specialists were recruited in Years Nine and Ten, and each learning area is taught by specialist teachers using the schoolwide theme.

Niu College's learning spaces have also been designed and built to support the school's focus on curriculum integration. Instead of traditional classrooms there are commons. These are large open spaces that can accommodate up to 100 students at a time, each with two smaller break-out rooms. Four teachers teach their learning area in the same common, which can have one to four classes occupying it at one time. There are currently no senior classes at Niu College, therefore each Year Nine or Ten teacher teaches four classes of the same year level. These four classes comprise one pastoral group within the school. Each teacher has pastoral responsibility for one class of approximately 25 students in the common; however, students may choose to identify pastorally with any of the staff in the learning space.

The day is divided into three 100-minute blocks, which is the time spent on each learning area or inquiry at a time. There are three and a half timetabled inquiry blocks per six day cycle for Year Nine, and two blocks for Year Ten, which are taught by one of the four teachers. The students choose their inquiry focus around the school-wide theme, and the teachers guide and support the inquiry, spending a greater amount of time with individuals and pairs needing more support. All students also have one citizenship block where they work on an aspect of the local community. 
All Year Nine and Ten staff meet in week five of each term in learning area groups to brainstorm possible learning activities based on Achievement Objectives predetermined by the curriculum committee. This is followed up a week later by a meeting where the four commons teachers will plan collaboratively for their curriculum areas for the following term, discussing commonalities and opportunities to integrate across the curriculum. Each team of four teachers shares office space that is adjoining to the teaching common of their class. The four teachers meet once a week after school for pastoral and administrative duties. There is regular professional development each term focused on the learning needs of the staff specific to curriculum integration and inquiry learning. The intention at Niu College is to carry the curriculum integration programme right through to Year 13 as the school grows.

\subsubsection{Description summary}

There are similarities and differences across all four schools in regards to the establishment of their curriculum integration programmes, summarised in Table 4.1

\begin{tabular}{|c|c|c|c|c|}
\hline $\begin{array}{l}\text { SCHOOL } \\
\text { CI } \\
\text { programme }\end{array}$ & $\begin{array}{l}\text { AWA } \\
\text { HIGH }\end{array}$ & $\begin{array}{l}\text { PAKIREHUA } \\
\text { COLLEGE }\end{array}$ & $\begin{array}{l}\text { RUA } \\
\text { HIGH }\end{array}$ & $\begin{array}{c}\text { NIU } \\
\text { COLLEGE }\end{array}$ \\
\hline $\begin{array}{l}\text { \# of years } \\
\text { of CI }\end{array}$ & 12 & 4 & 5 & 2 \\
\hline Year levels & \multicolumn{2}{|c|}{$9 \& 10$} & \multicolumn{2}{|c|}{7 to 10} \\
\hline $\begin{array}{l}\text { Mainstream } \\
\text { or opt in }\end{array}$ & Opt in & Opt in & Mainstream & Mainstream \\
\hline $\begin{array}{l}\text { Future } \\
\text { intentions }\end{array}$ & $\begin{array}{l}\text { Mainstream } \\
\text { Years } 9 \& 10 \\
\end{array}$ & $\begin{array}{l}\text { Mainstream } \\
\text { Years } 9 \& 10 \\
\end{array}$ & $\begin{array}{c}\text { Mainstream } \\
\text { Years } 9,10 \& 11\end{array}$ & $\begin{array}{c}\text { Mainstream } \\
\text { Years } 7 \text { to } 13 \\
\end{array}$ \\
\hline $\begin{array}{l}\text { Learning } \\
\text { areas } \\
\text { integrated }\end{array}$ & \multicolumn{4}{|c|}{ English, Mathematics, Science, Social Sciences } \\
\hline $\begin{array}{l}\text { Teaching } \\
\text { across } \\
\text { learning } \\
\text { areas (LA) }\end{array}$ & $\begin{array}{l}\text { Most teach in } \\
\text { one LA, some } \\
\text { across two or } \\
\text { three LAs }\end{array}$ & $\begin{array}{l}\text { Two teachers } \\
\text { for all four LAs, } \\
\text { access to } \\
\text { specialists }\end{array}$ & All teach one LA & $\begin{array}{c}\text { Years } 7 \& 8 \text { - } \\
\text { one teacher for } \\
\text { all LAs } \\
9 \& 10 \text { - one for } \\
\text { each LA }\end{array}$ \\
\hline
\end{tabular}

Table 4.1: Historical roots and nature of curriculum integration at each school

As illustrated in Table 4.1, all of the schools' curriculum integration programmes incorporate the learning areas of English, Maths, Science and Social Sciences, at Years Nine and Ten, with Niu also including Years Seven and Eight. All schools either currently utilise, or intend to utilise, curriculum integration across the whole junior school, with Rua and Niu anticipating integration in their senior schools in the future. Rua, Awa, and 
Niu have separate subject specialists at Years Nine and Ten, whereas Pakirehua and some classes at Awa have one or two teachers for the four subjects, as does Niu at Years Seven and Eight. All of the schools perceive curriculum integration to be valuable, as they have, or intend to, spread their programmes school wide.

The next section outlines why schools choose to integrate, and the benefits of curriculum integration as perceived by the participants.

\subsection{Why curriculum integration?}

There was a high level of agreement and correspondence within and across all four case study schools about why participants had chosen to implement curriculum integration. In this section, I examine the four reasons that were most commonly raised by the participants. These were relevance, relationships, knowledge and understanding, which largely aligned with the benefits of integration as outlined in the literature (Fraser, 1999; Inman, 2011; Locke, 2008; Sharpe \& Breunig, 2009), and the New Zealand Curriculum which deserves specific examination (section 4.3.4).

\subsubsection{Relevance}

The factor that was repeatedly cited as a reason for utilising curriculum integration was its relevance to students' 'real life' outside of school, which participants often described as the 'real world'. All participants described how they perceived curriculum integration to be an invaluable tool for making learning relevant and authentic to the students and their lives, creating meaningful learning experiences, and preparing them for the lives they would be entering post education. Warren at Pakirehua provided a fitting metaphor of the benefits of integration related to relevance:

When students are involved in curriculum integration it's like [they're] viewing their world from above. They can see the big picture and make sense of where things are and how they fit together. It's real world, it's their world, and it's relevant ... On the ground they may come to a steep mountain and think that it's too hard to cross and not worth the effort. From above they can see a way through and that the rewards are worth the effort.

Several teachers at Rua reiterated these views:

Charlie: "This is a really good way of giving relevance to what we're doing." Misty: "Relating the content to the kids and their lives." 
Libra: "It's the real world that we're talking about [with] curriculum integration."

Deputy Principal Rua: "The co-construction makes sense ... it's more authentic because you've linked to something that's real and its happening ... you're not learning something that has no relevance to the kids."

The staff at Niu agreed that relevance was a key rationale for using curriculum integration:

Katy: "The advantage of curriculum integration is a real life context is used, or a problem in society or globally, which seems to capture the kids a bit more than just prescriptive stuff."

Sid: "If there's a real life scenario and they can relate to it, then suddenly they can see how this fits and why it's important and it suddenly becomes much more meaningful to them."

Deputy Principal Niu: "Meaningful integration, so you're actually drawing on other areas of the curriculum for some purpose."

Molly at Niu drew the same conclusion:

It gives a purpose to the learning ... having taught in that traditional model for so long I think ... it's like teachers are holding all the knowledge and they've just plucked this and that out of the air and the kids have no idea why we're doing what we're doing, it's just much more opportunity for the kids to own what they're learning.

The potential for curriculum integration to increase relevance is argued by a number of authors (Beane, 1997; Kain, 1993; Murdoch, 1998). Loepp (1999) agrees that "having the opportunity to utilise knowledge and skills from several disciplines does offer increased opportunities for making the curriculum relevant", but he also cautions that "just because a curriculum is integrated does not automatically mean that it is relevant" (para. 9).

Preparing students for life after education was also a recurring theme. Aroha, a teacher at Awa, felt that integration helped to "prepare these children to be adults who are going to be good citizens, but also good people in the world." Warren at Pakirehua agreed: 
What drives us is setting the boys up for the future ... to cope with the rapid sort of change in the way information is disseminated and how they get it and how they identify what they need and how they're going to interpret and make use of that information. I think that traditional pedagogy is a lazy out-dated factory model that does students a disservice by preparing them for a world that no longer exists.

Pakirehua's Principal concurred: "I think it mirrors the problem solving that we do as adults". Similarly, Rua's Deputy Principal stated that "anything that kids do when they leave school they don't just use skills from one discipline, they actually have to integrate all their learning. So to me it's much more about preparing them better for life." This is a point made by Gilbert (2005) in her critique of the current global education system still being structured to meet the needs of the industrial age rather than the knowledge society in which we now live. Gilbert believes that knowledge "can't be divided up into disciplines" and that learning "happens in real world, problem-based contexts" (p. 6).

A spin off of these connections through curriculum integration was perceived to be increased engagement, which is also noted by Stevens (2006). All participants felt that curriculum integration improved students' engagement compared to more traditional pedagogies:

Awa's Principal: “Student stimulation.”

Annabelle: “Engaged students, who are happy.” (Awa)

Russell: “Taking a real interest in a rounded way.” (Pakirehua)

Pakirehua's Principal: "Boys were really engaged.”

Molly: "Students are immersed in their work - interested and motivated." (Niu)

\subsubsection{Relationships}

All four schools reflected that curriculum integration supports the development of positive relationships between staff, students, caregivers, and the local community. The cultivation of affirmative, genuine relationships between students and teachers has been identified as one of the key contributors to positive outcomes for students (Bishop \& Berryman, 2006; Timperley, Wilson, Barrar, \& Fung, 2007). Teachers at Awa felt that teaching across two learning areas, especially in Year Nine, made the transition from intermediate to high school less challenging, due to the increased contact time, leading to relationships forming more quickly. Lily described her view that "it also builds 
relationships ... not just amongst staff, but hopefully between staff and students too, as you spend a lot more time with those kids." Vanessa from Rua expressed a similar opinion that "the primary transition's going to be better." The key benefit of the integration programme at Rua, as perceived by every teacher, was the increased relationships with, and knowledge of, the students: "pastorally it's very good" (Brendon); "the primary strength is the pastoral" (Sophie). This was also a motivation of the staff at Pakirehua, described by Warren: “[it] operates as a homeroom ... students will remain in one teaching space with predominantly one teacher for most of the school day."

Collegiality and increased communication between staff was another perceived outcome of integration at all four schools. Niu's Deputy Principal stressed that "the collegial professional development is certainly something that should never be underestimated." Sid, a teacher at Niu, described how staff are "always discussing what we're doing, why we're doing it and when we're doing it." Russell, a teacher at Pakirehua, agreed that "that sort of collegiality, they're the lessons that we have the most fun with." Similarly, Tom, a teacher at Rua, stated "integration really helps because you see what other teachers are doing and you have those discussions and it's built in rather than when you're teaching in your silo." Rua's Deputy Principal felt that "collaboration would be the biggest [benefit of integration], the fact that you had teachers collaborating and learning from each other."

\subsubsection{Knowledge and understanding}

A contentious issue regarding curriculum integration is the perception that the disciplines of knowledge are its rivals. James Beane (2007) has sought to remedy this, stating that "in the thoughtful pursuit of authentic curriculum integration, the disciplines of knowledge are not the enemy. Instead they are a useful and necessary ally" (p. 1). Beane asserts that trans-disciplinary integration is a means of reflecting about the sources of, and how to use, such knowledge. This was a view shared by several teachers at each school. Ralf, a teacher at Rua reflected this belief, also drawing on Young's (2009) position regarding the power of knowledge: 
The real world doesn't exist in independent silos, I do think that ... by drawing on particular disciplines we're drawing on incredibly powerful knowledge. And actually the way you think in English and in Maths and Science and Social Studies, there are differences, and I think that what curriculum integration does is that it draws on those disciplinary strengths in order to understand the world and to participate in the world better ... that's the power of the silo! Because they usually have a community and I think that curriculum integration isn't afraid of those silos, although they're afraid of them becoming sort of reified and static and sort of independent of humans.

Ralf's comment also draws attention to an unanticipated finding from all four schools. All participants placed great value on the separate subject disciplines. None of the participants advocated for the removal of the specialist subjects, but were more inclined to champion their importance in secondary education. Rua's Deputy Principal described the benefit of subject specialists as "they're being taught by an expert and someone that's passionate ... they're not getting a diluted form of English, Science or Maths, which I think happened before with other forms of integration." Russell at Pakirehua also felt that specialist knowledge was essential for guiding successful integration: "You've got to know your stuff with these guys to keep them in the right direction. Know your curriculum, know where you can, and cannot, fit things." Pakirehua's Principal explained that the original Science teacher who had initiated their programme "had some challenges ensuring that he was covering the Social Science [and] English curriculum. [So we] appointed Warren, who bought the other side of the curriculum into the mix." As mentioned in Chapter Three, a similar situation was encountered at Niu where the whole staff decided that the primary trained teachers recruited to teach Years Seven and Eight would not be able to adequately prepare students for NCEA at Years Nine and Ten, and therefore specialist teachers would be required. Niu's Deputy Principal described how "it becomes difficult in terms of staffing ... you need specialist knowledge required for that subject, but you've got the balance and the tension of them being isolated from the rest of the learning community."

However, while valuing subject knowledge, the teachers also described the advantages of learning at the intersection of bodies of knowledge. Tom, a teacher at Rua shared his thought that "all the great discoveries and progress are made in the interstices between the blocks of knowledge." This was also seen to be an advantage of 
integration by the Deputy Principal at Niu, who described "a meshing together ... a sharing of the knowledge, it's not compartmentalised and segregated." The Principal at Awa described the need to move away from subjects as silos: "Knowledge is compartmentalised, and that's kind of artificial in the way that it's acquired ... [We should] try to get away a little bit from the idea of subjects as stand-alone entities." He felt that is was "a shame to lose the bubbling enthusiasm of students on entry by compressing them into boxes - we don't need to, why would we?" Pakirehua's Principal also agreed that "the individual silos that sit with each of the different curriculums ... isn't the reality of knowledge and it's not the reality of how we problem solve and how we think."

Several participants also commented on the comprehensiveness of the students' knowledge and understanding gained through curriculum integration when compared to the more traditional delivery of teaching. Awa's Principal felt integration gave "a broader breadth of possible findings", which was echoed by Pakirehua and Niu's Principals. Warren, a teacher at Pakirehua, described how the inquiry students had felt that research assessments at NCEA Level One were quite easy: "Topics that they're doing in Chemistry or English or History or whatever, [the students] are finding they're actually at a much lower level than they've investigated at Year Ten." He added that other teachers at Pakirehua regularly commented on the advanced research, comprehension, and critical thinking skills of the students who had been through the inquiry programme, compared to the other boys in Year 11 to 13.

\subsubsection{New Zealand Curriculum}

The 2007 New Zealand Curriculum was regularly referenced as either having parallel intentions to curriculum integration or as the stimulus for adopting or extending it. Curriculum integration was cited by Rua High and Niu College as having been specifically chosen to address the philosophy of the 2007 New Zealand Curriculum. Awa High and Pakirehua College's integration programmes were established prior to 2007, and subsequently the Curriculum was not their initial inspiration. It was, however, regularly referenced by each of the schools as having strong links to their programmes. Integration was commonly noted as being a straightforward method through which to develop the Curriculum's Key Competencies, particularly thinking, managing self, and participating and contributing. Rose, a teacher at Awa, noted that integration also helped 
to "address the requirements of the front end ${ }^{1}$ of the curriculum". The fact that studentcentered curriculum integration promotes personalised learning, in order to meet students' individual learning needs, was connected to the increase in Teaching as Inquiry promoted in the Curriculum (see section 5.2.2 for further discussion).

The 2007 Curriculum was used at Awa High as the vehicle to drive change towards broadening integration, and the Principal made several references to this, particularly the Key Competencies:

If [Key Competencies] don't have to fit in a column, and they're just a wider thing, then that is much more cross-curricular teaching. Because what's feeding into those values is a cross-curricular view of, or should I say, a 'non-curricular' view of what education is, so that the knowledge is packed around as and when it fits.

Warren at Pakirehua felt that "the revised New Zealand Curriculum took an important step in identifying that the Key Competencies are as important as the content that we teach. Curriculum integration is a great way to develop students' Key Competencies." Pakirehua's Principal believed that integration "enables us to utilise those Key Competencies," as did Lily, a teacher at Awa, who considered that integration "would play a large part to develop all the Key Competencies." The Deputy Principal of Rua conveyed that "the Key Competencies ... became the center of our learning, which then made more sense for integrating something."

The Key Competency of thinking, which is also a key aspect of teaching, was mentioned by all schools as being nurtured through integration, which is in agreement with Stevens (2006) and Vars (2001), who both advocate integration as a tool to promote critical thinking in adolescents. Pakirehua's Principal described how after two years in the inquiry class "a number of teachers will comment, 'this boy keeps asking questions, except he doesn't just want to know what, he wants to know why.' So we really have turned the light on." Other participants echoed this view:

1 The front end of the Curriculum refers to the first section of the 2007 New Zealand Curriculum that includes features such as the vision, principles, values, key competences, effective pedagogy, school design and review (Rosemary Hipkins, 2010). 
Misty: "They've got the critical thinking." (Rua)

Russell: “Critical thinking skills [are developed]." (Pakirehua)

Deputy Principal "We're wanting the kids to develop their thinking through integration." (Rua)

Self-management was a competency developed through integration as perceived across all schools. Flo and Ted, from Niu, described the self-management of their students:

Flo: “Sometimes you walk in here and don't realise there's four classes ... because the kids are really engaged in what they're doing, it's very hard to find the teacher, because everybody is busy."

Ted: "And that can happen within two minutes of the start of each block. Because you do the roll, say 'is everybody clear what you need to do? Right, carry on'."

The teachers at Pakirehua provided some examples of self-management:

I get a lot of emails from boys that are away asking, 'what can I do, what do I need to do to catch up? ... the boys know what the outcome is, they know the deadline ... more often than not they're contacting us from Dunedin or Christchurch or Wellington or wherever, they want you to check their progress.

The Deputy Principal at Niu described how he had witnessed some Year Ten students applying the skills they had learnt in their integration class in a personal situation:

They spent an hour tracking this character down, using all their inquiry skills. They'd follow a lead and it would peter out and they'd think, 'How can I approach this? Who else would have information?' and eventually after about ten phone calls they tracked the character down. So confident, the persistence just impressed me, that self-management. All those skills that we try and promote and it's the Key Competencies - it was all there. I could have used that as their final assessment and they'd have passed with flying colours. It was really neat to see.

Participating and contributing was a Key Competency inadvertently addressed using curriculum integration at each school. Awa's Principal felt that integration was "a process that socialises the students while it teaches them content, rather more than other methods might be." Warren at Pakirehua reiterated this view "that they're learning to work with other people, so they're participating and contributing ... the boys 
don't accept a poor presentation, they feel like it's sort of a shared consciousness." Russell at Pakirehua described how "the boys will wander off to the computer and have a conversation with their sick colleague at home. It's nice to know that they're contributing. The boys more often than not work in pairs, and they're sharing information."

One of the participants gave another reason for teaching through curriculum integration that I felt was worth noting: "For me, I really enjoy getting out of bed and getting into school, because you never quite know what's going to crop up. It is a really interesting way to teach."

\subsection{Teachers' discussions of the theoretical foundations of curriculum integration}

It is evident that each school's programme and its implementation of curriculum integration differed in a number of ways. In this section I address the question concerning how the teachers' discussions and philosophy of curriculum integration were informed by theory. Dowden (2007) attributes the ambiguity surrounding curriculum integration to three interconnected origins, one of which is that "new models of curriculum integration were developed without sufficient reference to existing theory." As discussed in Chapter Two, there are several theories surrounding curriculum integration, including multi-disciplinary, inter-disciplinary and trans-disciplinary (see Table 2.1 for definitions). The main theorist regarding integration, referred to here as trans-disciplinary, is James Beane (1997), whose work is grounded in Dewey's organic education. Heidi Hayes-Jacobs is a theorist frequently referenced in the literature regarding inter-disciplinary integration, which is based on the conception of correlation and Susan Drake has written in depth about multi-disciplinary integration, amongst other types. Several other theorists and key authors were mentioned in the data as pivotal to the direction of each school's programme. These sources were not all specific to curriculum integration, but were aligned to the nature of the individual programmes.

I analysed the data to examine which authors and theorists were influential in shaping the nature and practice of curriculum integration. Table 4.2 , at the end of the chapter, summarises the key theorists and authors that were discussed in the focus group sessions, the interviews, and the planning documents at each school. At Rua and Awa each focus group included a founding member of their school's integration 
programme. These staff members were able to inform the rest of the group who had been the grounding theorists.

Despite the theories used by the Awa teachers not being directly related to curriculum integration, as a group they demonstrated a greater awareness of the theories used within their programme than the other three schools. Rose, one of the founding integration teachers at Awa, listed the theories that she knew had been applied when the programme was created, acknowledging that the sources weren't theorists of curriculum integration. "Kagan, Don Brown, Lottie Thomson; [the programme] was built on those cooperative learning foundations, but possibly not curriculum integration specifically." This stimulated other staff to list other theorists that they knew had been introduced to them through the programme. "We've looked at De Bono, we've looked at Bloom's”, “Gardener's Multiple Intelligences”, “Tony Ryan's Thinkers' Keys.”

Two teachers from Rua stressed the importance of staff being aware and in agreement about the theories upon which an integrated programme is embedded. Ralf shared his belief that the intention "can be lost if the way that a school or community defines curriculum integration is 'fluffy', or there's no real consensus or on-going questioning or readings about what it means." Charlie, a teacher who clearly did not embrace the concept of curriculum integration, stated that it was "important that the philosophical approach of all members is in rough alignment [in order for the programme to succeed]. Unless you nurture something in a school it falls between the cracks." Despite this belief in the worth of a shared theoretical understanding it was only Ralf at Rua who had any notion of the theories used, and the value of critiquing them:

The thing is with Beane is that we can say he's the number one guy, but there's plenty of people that critique Beane and if we're going to be intelligent about our theories, we need to know what it is people don't like about Beane.

Such critical discussions on theory were evidently rare. In many schools teachers made little or no reference to a theoretical base. For example, the other staff at Rua knew that the programme was based on specific theories but not what the theories were. Tom revealed that "I think there are theories that are in a Power Point, but I don't think it's been shared with the rest of the staff," and Vanessa stated "it's in the manual but I can't remember them." A similar comment was made by Flo at Niu: "Certainly there's a lot of research underpinning what we do ... but I don't know who the theorists 
are." The senior leadership at three of the schools showed no knowledge of the theories used when asked: “No, I don't know” (Awa Principal); “No, I don't actually” (Pakirehua Principal): "I don't think there is a particular theory" (Niu's Deputy Principal). Whereas the Deputy Principal at Rua did know some of the theorists used for their programme. The participants that weren't involved in the establishment or development of the curriculum integration programme at each school did not know what theory the programme was embedded in, which was demonstrated by Warren at Pakirehua: "It's probably based on some sound theory it's just that I didn't do the research to develop the programme."

A number of the schools went on to describe the unique blend of ideas and theories that had informed their 'own way' of doing curriculum integration. All schools recognised that multiple theories had been used to create the programmes, which could account for the staff not being able to identify them, described by Awa's Principal: "My sense is that it is rather more based on a philosophy, pulling in elements of different theories wherever they seem to fit." Flo at Niu echoed this view: "I think it's a conglomeration of people's different theories." Related to this notion of a blending of theories was a perception that the schools had developed their own theory. Flo, a teacher at Niu, shared that "it's our own way of doing inquiry that's been put together based on a variety of research." Misty, at Rua, expressed a desire that "we come up with our own theory. We've done it for long enough. What do we want to do? Make it our own model?" The Deputy Principal at Niu stated that:

The senior leadership team and a lot of the teachers have done an awful lot of research and readings before this and visited a few other schools and they'll have their own experiences from previous teaching. So I don't think it's based on any particular theory, I think it's just a Niu College theory.

The theoretical underpinning of the curriculum integration programmes was not commonly understood at any of the four schools and several of the theories identified were not specifically associated with curriculum integration.

Table 4.2 illustrates that three of the schools identified multiple theories, which corresponds with their mixed approach to curriculum integration. This is examined further in Chapter Five. It was interesting to note that Awa and Rua, two of the longer standing programmes, had more theoretical knowledge than Pakirehua and the newest 
programme at Niu. The possible reasons for this difference, and the schools' perception of developing their own theory, are both discussed further in Chapter Six.

\begin{tabular}{|l|l|c|c|c|c|}
\hline $\begin{array}{l}\text { THEORY/ APPROACH } \\
\text { CITED BY SCHOOLS }\end{array}$ & $\begin{array}{l}\text { THEORIST } \\
\text { /AUTHOR }\end{array}$ & AWA HIGH & $\begin{array}{c}\text { PAKIREHUA } \\
\text { COLLEGE }\end{array}$ & RUA HIGH & $\begin{array}{c}\text { NIU } \\
\text { COLLEGE }\end{array}$ \\
\hline Integrative model & Beane & & $\checkmark$ & $\checkmark$ & $\checkmark$ \\
\hline Inquiry learning & $\begin{array}{l}\text { Harpers \& } \\
\text { Lepstein }\end{array}$ & & $\checkmark$ & & $\checkmark$ \\
\hline $\begin{array}{l}\text { Drama-Inquiry } \\
\text { 'Mantle of the expert' }\end{array}$ & Heathcote & & & $\checkmark$ & \\
\hline Inquiry learning & Murdoch & & & $\checkmark$ & \\
\hline Cooperative learning & $\begin{array}{l}\text { Brown \& } \\
\text { Thompson }\end{array}$ & $\checkmark$ & & & \\
\hline Cooperative learning & Kagan & $\checkmark$ & & & \\
\hline Cooperative learning & No theorist & & & & $\checkmark$ \\
\hline $\begin{array}{l}\text { Building Learning } \\
\text { Power }\end{array}$ & Claxton & & & $\checkmark$ & \\
\hline Thinking Hats & De Bono & $\checkmark$ & & & \\
\hline Social constructivism & Dewey & & & $\checkmark$ & $\checkmark$ \\
\hline Multiple Intelligences & Gardener & $\checkmark$ & & $\checkmark$ & $\checkmark$ \\
\hline Constructivist & No theorist & & & & \\
\hline
\end{tabular}

Table 4.2: Summary of theorists $\&$ authors linked to curriculum integration

\subsection{Chapter conclusion}

This chapter has discussed the perceptions of teachers from four New Zealand secondary schools concerning curriculum integration. A description of each of the case study schools has provided background information regarding the history and nature of each programme's establishment. The participants' perceived benefits of utilising curriculum integration have been listed, and the final section outlines the perceived theoretical grounding of each programme, highlighting the pragmatic disposition of teachers. Chapter Five provides an analysis of teachers' practices of curriculum integration. 


\section{CHAPTER 5: SECONDARY SCHOOL TEACHERS' PRACTICES TOWARD CURRICULUM INTEGRATION}

Whatever form of curriculum integration you end up with you create your own meaning.

(Deputy Principal, Rua High)

\subsection{Chapter introduction}

The findings in Chapter Four indicate that each of the four curriculum integration programmes were established in quite different ways in terms of who created and implemented them, their scope and their nature. In this chapter I examine this in greater depth and, in particular, consider how the programmes were initiated. Each school's perception and current practice toward curriculum integration appears to have been influenced, in part, by whether the initiation was top down (led by senior management), or bottom up (led by teachers). Perceptions and practices also appear to have been shaped according to whether the programme is whole school or a specialist programme. I will examine how the historical foundations of the curriculum integration programmes (leadership and support) have influenced the nature of integration and how it is practised in each school, both of which are discussed in greater depth in Chapter Six.

\subsection{Types of curriculum integration: perceptions vs. practice}

The chapter begins with an examination of the degree to which the programme is trans-disciplinary, inter-disciplinary, or multi-disciplinary in nature. I also examine the degree to which teachers' perceptions and practices of curriculum integration were student- or subject-centered. I also draw attention to the alignment of teachers' perceptions and practices, as the need for teachers to "courageously critique their own practice to bridge the gap between rhetoric and reality" was cited as crucial by Fraser (1999, p.1), who also noted that "teachers generally did not realise that there was a mismatch between what they said they did, and what they in fact practised" (p.2).

It has been argued that one of the fundamental elements of curriculum integration is its student-centered approach to teaching and learning (Beane, 1997; Dewey, 1949; Dowden, 2007, 2012; Drake, 2007), which was reflected in the findings of Chapter Four. Yet despite this many current models are subject-centered (Fogarty, 1991; Jacobs, 1989). Student-centered curriculum integration has less regard for the delineating subject boundaries and focuses on problem solving through issues of 
significance to the students, and is linked closely to trans-disciplinary integration. Subject-centered curriculum integration links subject area content through a common skill, topic, or theme, while retaining the subject boundaries, and is linked to interdisciplinary and multi-disciplinary integration (refer to Table 2.1 for definitions). However, some of the teachers utilising a multi-disciplinary or inter-disciplinary model used student-centered pedagogies in their practice, which is why I have included an analysis of the student-centered nature in this chapter. The schools' perceptions and practices of the different types of curriculum integration are summarised in Table 5.1.

\begin{tabular}{|c|c|c|c|c|c|c|c|c|}
\hline \multirow[t]{2}{*}{ CI PROG. } & \multicolumn{2}{|c|}{$\begin{array}{l}\text { AWA } \\
\text { HIGH }\end{array}$} & \multicolumn{2}{|c|}{$\begin{array}{l}\text { PAKIREHUA } \\
\text { COLLEGE }\end{array}$} & \multicolumn{2}{|c|}{$\begin{array}{l}\text { RUA } \\
\text { HIGH }\end{array}$} & \multicolumn{2}{|c|}{$\begin{array}{c}\text { NIU } \\
\text { COLLEGE }\end{array}$} \\
\hline & Perception & Practice & Perception & Practice & Perception & Practice & Perception & Practice \\
\hline Type & $\begin{array}{l}\text { Mix trans- } \\
\text { disc. }> \\
\text { multi-disc. }\end{array}$ & $\begin{array}{l}\text { Inter- } \\
\text { disc. } \\
\text { Little } \\
\text { multi- } \\
\text { disc } \\
\end{array}$ & \begin{tabular}{|c|} 
Trans- \\
disc.
\end{tabular} & $\begin{array}{l}\text { Trans- } \\
\text { disc. }\end{array}$ & $\begin{array}{c}\text { Mix } \\
\text { multi-disc } \\
>\text { trans- } \\
\text { disc. }\end{array}$ & $\begin{array}{c}\text { Mix } \\
\text { multi- } \\
\text { disc. }> \\
\text { trans- } \\
\text { disc. } \\
\end{array}$ & $\begin{array}{c}\text { Mix } \\
\text { multi-disc. } \\
=\text { trans- } \\
\text { disc. }\end{array}$ & $\begin{array}{c}\text { Mix } \\
\text { multi- } \\
\text { disc. }> \\
\text { trans- } \\
\text { disc. } \\
\end{array}$ \\
\hline Thematic & Strong & Varied & No & Seldom & Often & Varied & Always & Mostly \\
\hline Inquiry & $\begin{array}{l}\text { Principal } \\
\text { only }\end{array}$ & No & Yes & Yes & Varied & $\begin{array}{c}\text { Small } \\
\text { amount } \\
\text { across all } \\
\text { classes, } \\
\text { varying } \\
\text { in others }\end{array}$ & \begin{tabular}{|l|} 
Regularly \\
\\
\end{tabular} & Regularly \\
\hline $\begin{array}{l}\text { Focused } \\
\text { around an } \\
\text { issue }\end{array}$ & Varied & No & Yes & Normally & $\begin{array}{l}\text { Varied, } \\
\text { less yes }\end{array}$ & $\begin{array}{c}\text { In few } \\
\text { classes }\end{array}$ & Varied & Often \\
\hline \begin{tabular}{|l|} 
Student- \\
or \\
subject- \\
centered
\end{tabular} & $\begin{array}{l}\text { Mostly } \\
\text { student }\end{array}$ & Subject & Stud & ent & $\begin{array}{l}\text { Varied, } \\
\text { mostly } \\
\text { subject }\end{array}$ & $\begin{array}{l}\text { Mostly } \\
\text { subject, } \\
\text { some } \\
\text { student }\end{array}$ & $\begin{array}{l}\text { Varied, } \\
\text { mostly } \\
\text { student }\end{array}$ & $\begin{array}{c}\text { Some } \\
\text { student, } \\
\text { some } \\
\text { subject }\end{array}$ \\
\hline
\end{tabular}

Table 5.1: Comparison of the perception and practices of the type of curriculum integration

Each school implemented curriculum integration across the learning areas of English, Maths, Science, and Social Studies. Awa, Rua, and Niu have separate lessons for each of these learning areas at years Nine and Ten, whereas Pakirehua College integrates all four for the majority of the school year. Although all four schools practice forms of curriculum integration, Awa and Rua explicitly refer to their programmes as curriculum integration, while Pakirehua and Niu refer to theirs as inquiry.

\subsubsection{Trans-disciplinary integration}

Each of the four descriptions of curriculum integration provided by the case study schools included perceptions that aligned with Beane's (1997) trans-disciplinary 
model to varying degrees. In practice, there were either small pockets, or no transdisciplinary integration, observed, at most schools.

Pakirehua College had the most trans-disciplinary view of integration which was clearly reflected in their practice. Warren, a teacher at Pakirehua, stated that curriculum integration is "the investigation into an idea, question, problem or issue... an authentic context for learning"; Russell, another teacher at Pakirehua, stated that students "choose a topic that they investigate from different angles"; and the Principal asserted that "it's not specific to one particular curriculum area". For the majority of their scheduled integration class time Pakirehua's students were carrying out work on topics they had chosen themselves. Warren at Pakirehua described an aspect of their practice that fits well with Beane's trans-disciplinary model of integration: "There is also a curriculum links section [in the student's task information] where they are identifying the curriculum areas that they'll be touching on." However, the students in the curriculum integration programme at Pakirehua are required to sit the same summative assessments as the mainstream students. The teachers explained that approximately two to three weeks a term is dedicated to preparing students for such assessment, which involves primarily subject-centered teaching.

Most of Niu College's teachers and their Deputy Principal had a clear image of integration as trans-disciplinary, using real life contexts. They described how they would take "a problem in society or globally," make "links to real issues," solve "real life problems," so that the students "can understand what's going on in their world." This was echoed in Niu's teaching and learning handbook:

The topics of learning will encourage students to learn in a context that is relevant to them... allowing students to have more choice in determining their own deep questions to answer, their own solutions to solve problems and their own specific approach to focus their learning (p. 2).

In practice, Niu College's teachers' integration was less trans-disciplinary than their perception. The timetabled inquiry slots were when this form of integration was most likely to take place, but more often than not this was directed around the whole school theme, and was therefore less student-centered than Beane's depiction of transdisciplinary integration, in which the students decide what to investigate. Niu's Deputy Principal described how they "started last year with the problem based learning model, 
where a teacher would identify a scenario and overlay that with a problem that the students would go away and solve, and they'd draw all the different curriculum areas in to that". However, the teachers at Niu do plan together regularly, to consider the specific needs of the class and its individuals. They do not follow prescribed unit plans from year to year, so in this regard it is trans-disciplinary in nature.

Awa High's teachers' and Principal's collective perception of curriculum integration varied greatly, between multi- and inter-disciplinary at the start of their coversations, and trans-disciplinary towards the end. Lily described how integration could look like with no barriers: "Projects that need all the learning areas, and a variety of skills using outdoor education. All subjects would be relevant, and connected to the real world." This description also depicts experiential learning as described by Dewey (1949). Rose talked about a recent professional development session linked to Māori student achievement, with different learning areas feeding into a central concept, which approximated trans-disciplinary integration:

We want these Maori students to design and paint a mural. We were writing a list of all the skills and things that they were going to need to do to be able to do that themselves ... to go and ask questions of all these different people ... using all the different curriculum areas, and then you're producing a final kind of project at the end of it.

Rose referred to "we" (the teachers) wanting the students to paint a mural, rather than it being something co-constructed with the students, which does not entirely align with Beane's trans-disciplinary model. Principal Awa's descriptions of curriculum integration were consistently towards the trans-disciplinary, explaining how "several subject's strands feed into the central issue."

Despite providing some clearly trans-disciplinary perceptions, there was no evidence of this form of integration in any of the practice at Awa High. The programme has become less integrated over time due to pressure from heads of department for teachers to teach within one learning area only, and to follow detailed, prescribed schemes of work, as outlined in section 4.4.1, which could explain the difference in the teachers' perceptions and practices.

Some teachers at Rua High provided trans-disciplinary views of curriculum integration, particularly Ralf, Sophie, and Tom. They described the need for "a central 
problem, issue or question", involving "co-constructing projects with students, into which individual curriculum areas would feed as the need arises", and the importance for "citizenry, for democracy, about the key issues." The Deputy Principal felt it helped to "look at big issues and think what we need to learn to be able to answer that." Ralf at Rua highlighted the disparity between Rua's teachers' perceptions and practices of integration:

It is up to the Science, Maths, and, English teacher to bring their disciplinary knowledge to the centre. If they don't do this I can still integrate curriculum, because I will always make sure I have a central question, so I integrate as much as I would like, but it would be nice if other subjects did their bit more.

At Rua two of the three teachers who had a strong trans-disciplinary view practiced in a similar vein, but not quite to the same depth as their stated perceptions. Rua's other participant teachers practised multi-disciplinary integration, to varying degrees.

\subsubsection{Inquiry learning}

Inquiry is a recurring concept in the New Zealand Curriculum, and is commonly employed with curriculum integration, particularly trans-disciplinary. Boyd \& Hipkins (2012) describe that "student inquiry and curriculum integration are becoming increasingly popular in New Zealand schools and are often-but not always-combined" (p. 16). They refer to this combination as integrated inquiry. Inquiry learning is described by Kellow (2009) as "a constructivist approach, in which students have ownership of their learning" (para. 1). Inquiry learning begins with students' exploration and questioning, leading to investigation into a question, issue, problem, or idea. Students ask questions, gather and analyse data, create solutions, support conclusions and take action, and so inquiry learning commonly integrates several learning areas. Inquiry learning was referenced in all four schools when discussing perceptions of curriculum integration, and inquiry learning was employed to implement curriculum integration at Pakirehua College, Niu College, and Rua High, but not at Awa High.

Inquiry learning was the key tool used to facilitate nearly all learning at Pakirehua, even when they have their content-based lessons, so once again their perceptions align with their practice. Pakirehua's Principal asserted that "curriculum integration is research through inquiry so that all aspects of the curriculum are 
covered", echoed by both Pakirehua's teachers. Niu also considered inquiry an integral element of integration, and had chosen it as the primary vehicle through which to operate problem-based learning. This view was reiterated by the Deputy Principal at Niu, affirming that "one of the purest forms [of curriculum integration] would be the inquiry process." Niu College dedicated substantial and regular timetabled blocks to inquiry, but also used a very thematic approach to inquiry and integration. The teachers at Niu College all use the terms curriculum integration and inquiry interchangeably, which was addressed in the focus group interview by Katy: “It's almost like there's two, like there's inquiry and then you're talking about curriculum integration, so we keep talking about inquiry, but then your study's on curriculum integration!"

At Rua High, inquiry was raised as an instrument to facilitate integration by some teachers. Rua contributed time to inquiry despite it not being linked to curriculum integration in terms of their perceptions, but the amount of inquiry used varied from teaching group to teaching group. Rua's Deputy Principal depicted how “you would find 60 kids and four teachers doing their inquiry, which they maybe did a couple of times a year, where they would have been in cross-curricular groups." Rua's original programme was set up to implement curriculum integration, but evolved to incorporate more inquiry learning. Sophie at Rua explained the need "to find some sort of project or end result that we can plan to ensure that we're actually doing integration."

At Awa High it was only the Principal that made a connection between inquiry and integration, stating that integration is "inquiry based learning, operating across several subjects feeding into the central issue with the idea that the students are investigating a wider kind of educational perspective as the outcome." Awa's teachers', however, did not utilise inquiry learning as part of their curriculum integration programme. This could be linked to the frustrations of Awa's teachers, outlined in Chapter Four, that the programme was not wholeheartedly supported by the Principal. Despite his perception of integration spanning multiple learning areas "so that the knowledge is packed around as and when it fits", he was not enabling this to happen.

\subsubsection{Multi-disciplinary and inter-disciplinary integration}

Teachers at Awa, Rua and Niu all made frequent reference to multi-disciplinary perceptions of integration, whereas Pakirehua's teachers viewed it as a less valuable form of integration. 
Although the teachers at Niu College shared mixed perceptions of integration, they practised more consistently multi-disciplinary integration than any of the other schools. All lessons observed at Niu College were linked to the term's school wide theme. All four learning areas made explicit and implicit links to this theme in all learning activities, as described by the teachers and Deputy Principal in their discussions. At Niu, multi-disciplinary integration is an integral part of the teaching and learning guidelines, which advise that "the curriculum learning areas will be covered in the context of individual units of work that relate to a school-wide theme each term" (p. 2). Each of Niu's teachers and the Deputy Principal emphasised the value of making connections from each subject to a common theme, enabling coverage of "a range of achievement objectives from different curriculum areas, through teaching in English with links to what they're learning in other areas". They were also the only school that made an attempt to link to other learning areas not included in the integrated programme, also illustrated in the guidelines: "Specialist learning programmes develop the specific knowledge and skills relevant to the specialist learning area, while still making links to the learning that occurs in the integrated learning programmes of work" (p. 3).

Rua High's teachers' perceptions of curriculum integration were divided. Several staff showed a multi-disciplinary view of integration, and others a more transdisciplinary view. The teachers at Rua that had a multi-disciplinary perception of integration made several references to the separate subject areas, with comments such as: "Making links between Science and Social Studies"; "You can use what you've learnt in Maths to do this thing in Science"; "You've got four teachers with different ways of looking at the world". Those who had a more multi-disciplinary outlook at Rua reflected this to varying degree in their practice by attempting to link their teaching to the group's agreed upon theme. Sophie described how "I will be 'dancing around the theme' for parts of our Light topic next term." However, it appeared that not all of the groups of teachers at Rua had collaborated on a theme that had links to all four learning areas. I observed little or no reference to other learning areas or a theme in some lessons, despite the teachers attesting to do so in the focus group session: "We are referring to what is being taught in other subjects, and how this fits into what we are looking at in Social Studies," (Vanessa), and "I look for links and connections with the agreed on theme/question," (Charlie). After the focus group Rua's teachers agreed with each other about how useful it had been to discuss the roots and philosophy of their programme as 
a group, which they felt had helped them to clarify what integration meant to them. However, their uncertainty surrounding the future of the programme, due to recent changes in the senior management team (discussed further in section 5.3 and Chapter Six), could explain the less integrated practice at Rua High.

Awa's perceptions of curriculum integration ranged from multi- to transdisciplinary, but their practices reflected inter-disciplinary integration. When asked to describe curriculum integration there was an initial tendency across Awa's teachers to depict a multi-disciplinary model where the content of several learning areas was linked to a context or theme, while still teaching the subjects discretely. Rose described curriculum integration as "coming up with a context and then looking at it within our subject areas. We come up with the idea and then link it." This echoed Aroha's view that, “it's about making links between curriculum areas. You're still teaching separate subjects - the skills and content of English and the skills and content of Social Studies referring to both of those subjects in the other one." The planning documents provided by Awa High reflect a multi-disciplinary model of curriculum integration, with the year's teaching mapped out on a grid, linking each of the four learning area's content to an overarching termly theme where possible. However, none of the observed teachers at Awa made reference to the other subject areas, or a theme, during the observed lessons. Awa High's teachers' perceptions of curriculum integration were more inter-disciplinary in nature than the other schools'. There was a collective belief that curriculum integration was as much concerned with how one taught as with what one taught, whereas pedagogy was not directly associated with curriculum integration by any of the other schools. Awa's teachers and Principal were in consensus that the way they teach is the key element to their integration, which was evident in all data collected. Rose, one of the longest standing members of the programme, portrayed curriculum integration at Awa as:

Integrating through pedagogy - it's the way that we teach. The way that we've used common strategies in our classrooms, has been really positive and has been a strength of [the programme] for a long time... the Maths, the English, the Science, the Social Studies teachers are all kind of [teaching] the same way. I think that's really powerful.

Lily, a teacher at Awa, described that when integration was happening in her classroom "students are using different skills and knowledge from different curriculum areas to 
accomplish a task". Angela, another teacher at Awa, explained how "the head of department of Social Studies will tell me what I am doing in my Year Nine class next year ... then I plan my Year Nine English to make the skills link to that topic.... I'm set up right before the year even starts" These examples demonstrate Awa's predominantly interdisciplinary practice. This may also reflect that despite constraints on the level to which they can teach across learning areas, the teachers are still able to integrate through pedagogy.

Pakirehua College's participants' only reference to multi-disciplinary methods were to describe them as "disconnected", "unpurposeful”, and "less cohesive".

\subsubsection{Student-centeredness}

A key reason given for why schools embraced curriculum integration was how it could enable progressive and student-centered learning. However, while all four schools referenced student-centered teaching and learning in relation to curriculum integration, this was not the case for all teachers at each of the schools. The perception of curriculum integration as student-centered was common at Pakirehua College, Niu College, and Awa High, but was less so across all teachers at Rua High. The level to which each school's practice was student-centered appeared to be linked to how trans-disciplinary their curriculum integration was. Figure 5.1 compares the schools' perceptions and practices of the student-centered nature of curriculum integration.

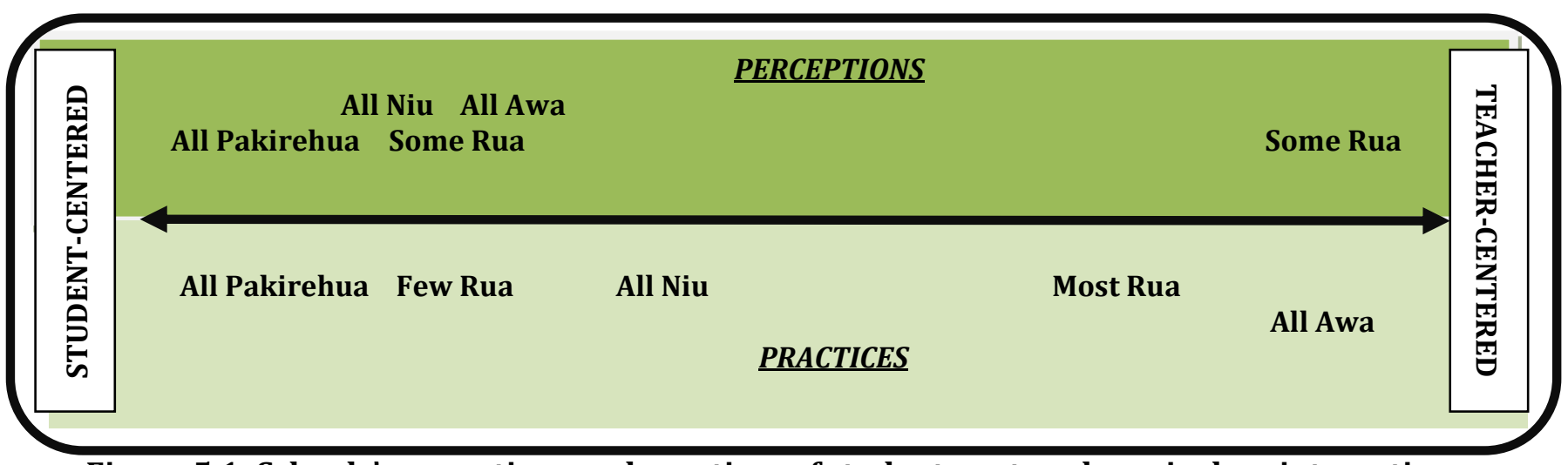

Figure 5.1: Schools' perceptions and practices of student-centered curriculum integration

Pakirehua College had a strong commitment toward a student-centered integrated curriculum, with both the teachers and Principal repeatedly highlighting the importance of student ownership. Russell, a teacher at Pakirehua, described how students "choose a topic that they take ownership of". Warren, his colleague, described how "student-centered students become responsible for their own work," and the 
Principal asserted "student choice - it's essential." Pakirehua's teachers endeavoured to make all learning student-centered, with student choice evident in all aspects of their learning; from selecting the focus of their research, to their data collection methodology; from their presentation method, to their assessment activity. Russell confirmed what I had observed, that "there's always a degree of choice ... the boys still have the ability to put their own spin on it if there's something they're particularly interested in."

At Niu College there was a shared association between curriculum integration and student-centered learning. This was evident throughout the focus group session, the interview with the Deputy Principal, and the document analysis, where the students' interests were at the centre, as expressed by Molly:

For me the key thing would be student ownership of the inquiry, if they really grasp what they're wanting to find out through their inquiry and they're really passionate about it, then you'll get that curriculum integration happening, so it's really important that the kids get and own what they're doing.

All other teachers at Niu were in agreement with this statement. The Deputy Principal endorsed that it's "ideally student-centered, choosing a context or an inquiry that they'd like to follow, then come up with a fertile question that interests them." Niu's practice was student-centered across the school, (but to a lesser extent than Pakirehua), as described by the Deputy Principal: “The student comes up with their idea, they've got their questions in place, and they've got their research plan in place."

Awa High's teachers and Principal also referenced the student-centered nature of integration:

Principal: "The fluidity to do what the kids want to do."

Aroha: "Students pursue their own subject of interest."

Rose: "Students design their own learning plan for the week."

Annabelle: "Easier to link to the students' worlds."

Lily: "Students would choose their own projects."

Angela: 'Substantially less teacher-centered work to take account of students' interests." 
At Awa there was no perceptible student choice in any of the lessons that I observed, and there was also no reference to co-construction with students in any of the planning documents at Awa.

At Rua High, the Deputy Principal and only three out of the seven teachers discussed student-centered learning in relation to curriculum integration:

Sophie: "The issue would have been co-constructed with the students."

Ralf: "Students have input into what we are learning."

Tom: "Moves the locus of power from the teacher to the student."

Deputy Principal Rua: "The kids negotiate a way that they might do something."

In two lessons at Rua, there was a considerable amount of student input, with teachers giving students the responsibility to choose that term's focus, whereas in other classrooms, student input was absent. Ralf depicted this in his comment that "the visible difference [in my classroom] is at the beginning when students have input into what we are learning about".

\subsection{Support towards curriculum integration implementation}

The level of support provided by schools for curriculum integration was raised as an important issue by all participants. There were a number of factors reported by participants related to the support afforded, that appeared to have influenced the strength of integration at each school. These factors were: timing; initial leadership; backing from senior management; cooperation of heads of department and teachers; cooperation from caregivers; and professional development. There was significant variation across schools for the level of support obtained in each of these areas.

\subsubsection{Timing}

Implementation of the curriculum integration programmes was initially through a small-scale trial approach at three of the schools, with whole school integration from the start at Niu College. Awa High trialled curriculum integration in 2000, Pakirehua College in 2006, and Rua High in 2008. At Awa and Pakirehua, the programmes remained on a small-scale, whereas at Rua, the integration programme was spread across all Year Nine and Ten classes after a year-long trial. Niu embraced curriculum integration from its outset as a new school in 2011. The time taken by the schools to take their programmes school-wide has been inverse to the length each programme has 
been running; Awa High was the first to implement their programme 12 years ago, and has still not extended it school wide; Pakirehua College is the second longest running (six years) and was in the planning stages for a whole school programme at the time of my research; Rua High started with a trial five years ago and is now a whole school programme; and Niu College started two years ago with whole school curriculum integration at Years Seven, Eight and Nine.

That curriculum integration was a founding philosophy at Niu College was evident in all data collected, which could be attributed to Niu's founding date being four years after the launch of the 2007 New Zealand Curriculum. The timing of the programmes is discussed further in Chapter Six.

\subsubsection{Leadership}

Initial leadership of the integration programmes varied between each school. At Awa, Rua and Niu the programmes were instigated by their Principals, whereas at Pakirehua College the programme was initiated and executed by a lead teacher. At Awa and Rua High the programmes were subsequently designed and implemented by lead teachers who had a desire to pursue more progressive pedagogies to increase student engagement (field notes, June 2012). Only at Niu College was the programme designed and led by senior management. The programmes at Awa, Rua and Pakirehua were established prior to the launch of the New Zealand Curriculum in 2007 and subsequently were more ad hoc in their planning, whereas Niu College was opened four years after the Curriculum's launch and the programme's planning was directed by the curriculum document itself.

\subsubsection{Support from senior management}

Senior management support for the curriculum integration programmes was perceived to be strong at each of the schools, however, to varying degrees. At Pakirehua and Niu College the teachers felt fully supported by senior management, but less so at Awa and Rua High.

Teachers at Niu, the school that reported the greatest degree of support, indicated that senior management had provided strong leadership in curriculum integration and had taken steps from the beginning to ensure that it is utilised. When asked if they support curriculum integration at Niu, the Deputy Principal's response was “more than support it, they lead it ... if the leaders of the school don't understand or buy 
into the need for cross-curricular integration then it's just not going to happen." Niu's teachers all reinforced this view when asked the same question. They felt that senior management saw integration as "important ... essential ... an expectation ... it's kind of the basis of our whole philosophy ... it's Niu College". Flo expressed how she understood this belief: "I think the difference here is that it comes from the top down, so there's an expectation that you will know what they are doing in Science and what they're doing in Maths".

At Pakirehua the Principal was fully supportive of the programme and both teachers described how they had been given as much support as they needed from senior management in terms of timetabling and resources. Warren's comments about the interest shown by the Principal and the Principal's commitment to expanding the programme, in section 4.2.3, demonstrate the support provided towards curriculum integration from senior management at Pakirehua College.

At Awa High, the teachers felt that support for curriculum integration was increasing. However, the process of curriculum integration in the school had been initiated by a small group of teachers, which had left it an isolated programme. The common feeling amongst the teachers at Awa High is that senior management is gradually starting to see the benefit of the programme, with one particular Assistant Principal being very supportive. The curriculum integration teachers commented that there had been a growing awareness to the benefit of the programme. David described how "they're waking up to it, but the wheels turn slowly." Rose shared that "it's good having [Assistant Principal] as part of [the programme]", which Lily agreed with: "She's 100 percent behind us; she really fought for us last year ... they obviously see value in it." The Principal at Awa High showed his support for the programme with the following observation:

Its philosophy very much anticipated the New Zealand Curriculum as it is now, so my expectation would be that the school would move towards more of the [programme's] styles of teaching, certainly teaching methodology. It's already shifting in theory and to some extent in practice. The rate of that shift will, I think, accelerate.

At Rua High there was some uncertainty regarding the support of senior management towards the integration programme. The senior leadership team at Rua 
had made several new management appointments in the last year (field notes, June 2012) due to the founding Principal retiring, and the Deputy Principal in charge of developing the integration programme moving schools, during the course of my research. The teachers believed that their successors had little experience with curriculum integration, leaving the staff concerned as to the future of the programme. This was evident from the teachers' comments who described the current situation as "tricky", and that "we're in unusual times". One stated that "in the past people had grown up organically with it, wholeheartedly behind it, now I'm not quite so sure about senior management's attitudes, buy in and commitment." Sophie summarised the group's feelings:

We're in a period of sort of change, transition, and flux at the moment. A DP might have had one term or half a term and that's the entire senior management's experience of it ... whereas if the person developed it, fought for it, and had seen it developed over many years then they'd have a different attitude for it.

This comment highlighted the significance of senior management's support in developing curriculum integration programmes.

\subsubsection{Support from other colleagues}

The implementation of curriculum integration was a source of contention at Awa High, Pakirehua College, and Rua High. There were four main reasons why curriculum was a source of tension in these schools, which are summarised, below.

\subsubsection{The unconventional nature of curriculum integration}

The methodologies associated with curriculum integration are different from the traditional transmissive approach to teaching still prevalent in many secondary schools (Beane, 1997; Dowden, 2010; Fraser, 1999). The pedagogies used within the integration programmes at Awa and Pakirehua have historically been perceived by the community and other teachers within the schools to be unconventional and not common practice (field notes, June 2012). Both of these school's Principals and the teachers involved in curriculum integration noted that amongst many of the mainstream staff, particularly longer standing teachers, there was an underlying fear of incorporating aspects of the programme into their practice. They surmised that this had led to a delay in implementing the desired change on a school wide level. 


\subsubsection{Structural and leadership changes}

While the senior management at most of the schools were perceived to be in support of curriculum integration, there was a sense at three of the four schools that outside of the group of enthusiasts I had interviewed for my research, individual heads of department and other teachers were less than supportive. For example, all of the teachers at Awa stated that teaching across two subjects was a fundamental characteristic of the original programme that was being removed against their wishes by dominant heads of department. They explained that a recently appointed head of department disapproved of teachers in the department teaching across subjects and had implied that teachers doing so would be less likely to teach the senior classes of their choice, as conveyed by Lily:

Ideally we would be teaching two or more subjects depending on how flexible the school is. I don't think they are necessarily supportive of teachers teaching across subject areas ... so there's not a lot of flexibility in terms of executing it properly.

The struggle for this structure to be maintained was also alluded to by the Principal:

The programme is intended to be integrated curriculum and integrated teaching in the sense that teachers teach in more than one subject. That occurs to a greater or lesser degree, depending on the availability of staff, the willingness of the staff to teach across subjects and the willingness of the HoDs to allow that to happen.

At Pakirehua the teachers also felt that they were not supported by heads of department, who insisted that the programme's students sit all formative assessments along with the non-integrated students. Warren noted that these tests were increasingly becoming recall-based and less conceptual, which was at odds with the teaching and learning in the integrated programme. Russell agreed: "Having to sit the same tests, measuring them against their peers ... they are not doing anything remotely like their peers are doing, so it really is a false measure". This is symptomatic of a high stakes testing regime emerging in New Zealand $(\mathrm{Au}, 2011)$.

\subsubsection{Imposed curricular change}

At Awa and Pakirehua, teachers had chosen to be part of their programmes due to the programmes' specialist nature, whereas at Rua High it was decided by the Principal to extend the programme school wide. Therefore, all Year Nine and Ten teachers at Rua, regardless of their experience with, or views of, curriculum integration, 
were obliged to employ it. All of the participants at Rua High implied that they had been informed that the school-wide implementation was happening, rather than via a process of consultation, which Misty described as "a sort of runaway pony that we're going with." Rua's Deputy Principal explained that "the plan was to move further, but that will only come as teacher confidence to become more student-driven happens." This division of affiliation could account for the diversity in the level of curriculum integration from class to class at Rua High, which Ralf inferred: "Maybe it's because Sophie and I have worked together for a long time [using integration], and Pete and I worked together for a long time [using integration], and we just sort of made it work." Tom's response suggested unease with the way the staff were prepared for the programme's release:

But you came up with the idea and saw it through for five years which gives you an advantage over us with all the learning and teaching you've done in the past as well as all the reading, whereas other teachers are coming in perhaps for the first time and being thrown into it.

Charlie, a teacher at Rua High, raised the need for willing and experienced colleagues to implement successful integration: "I've really enjoyed working with you two, you're obviously in a rhythm, you've got it sussed, it flows effortlessly along, it's great, but it hasn't always been like that with teams I've worked with before." This mirrors an observation of Fraser (1999) in her summary of a New Zealand Ministry of Education funded professional development contract in curriculum integration that she cofacilitated. Fraser described that "some teachers did not select to be involved in the contract but had been 'ordered' to" noting that this was "hardly an auspicious beginning for enthusiastic, growth-oriented participation" (p. 1).

\subsubsection{Difficulties of integration by individuals and subjects}

There was a perception at Rua and Awa that it was more difficult to integrate with some subjects than others, and that some individual teachers were resistant to working with them on aspects of integration. Several teachers at Rua noted that the Mathematics and Science teachers found it particularly hard to embrace the programme's philosophy and methodology, including Brendon, a Maths teacher himself: "Maths finds it very hard to integrate everything and cover all the skills we have to .... sometimes I intentionally do not plan for integration." Sophie reiterated this point: "Maths and Science teachers do struggle to cover the content and to integrate as well," as 
did the Deputy Principal of Rua: "It was really, really difficult, especially for Mathematics and Science ... some of the scientists wouldn't get rid of the content."

Teachers at Awa had also noted similar issues, such as Rose: "I've been to the Maths department and it's really hard to get a link going there". Angela reflected this observation: "Some departments are less ... you need cooperation between departments ... and if they're too fixed in the way they want to do things then it's harder to do the integration." Annabelle shared her experience that "in the last few years departments have become more insular, rather than less, and more 'you are teaching my subject, and that is what you will teach'”.

A resistance to integration from heads of department or individual teachers was absent from the data collected at Niu College. Teachers at Niu were required to show an understanding of, and willingness to teach using, curriculum integration during their interview process, as described by Ted, a teacher at Niu:

When we did our interviews last year we had to bring a short presentation - 'what do you see as the link between the process of learning through inquiry and teaching (mine was) Science. Anyone who was applying knew exactly what they were getting into.

The lack of resistance from staff at Niu towards curriculum integration, therefore, could be attributed to the fact that all staff were advised of the school-wide focus on integration before recruitment at the school.

\subsubsection{Community support}

Another group within the school community that was cited as influencing the process of integration at Awa and Pakirehua were the parents and caregivers. These two schools have 'opt-in' curriculum integration programmes, and so parents and caregivers have shown support by choosing integration for their children. However, they sometimes don't support the programmes' methods wholeheartedly. Aroha, a teacher at Awa noted that "certain things must be done so a grade can be put in a mark book for different subjects, because caregivers still want to see that ... as well as wanting to do the integration." This was reiterated by her colleague, Rose "its demand from parents. They want their students to be assessed the same way as a non-integrated classroom." Warren, a teacher at Pakirehua expressed a similar concern: 
We still sit the mainstream exams, we still have parents wanting to know how well their son is doing [in integration] compared to the mainstream and the best tool that we have at the moment is to still sit those tests.

Warren went on to justify this need: "If the majority of teachers find [integration] too foreign to touch then you can expect parents that went through a completely different school and model are sometimes just as unsure." Dowden (2007) described how in the early $20^{\text {th }}$ century the conservatism of parents delayed the widespread implementation of progressive methods being trialled at the time, and that "the ultimate goal of teachers and parents was still success in the Proficiency and Matriculation examinations" (p. 83). Beane (1993) believes this is due to the entrenched belief of parents about education, which exposes the subject-centered schooling that they themselves experienced.

The alternative merits of curriculum integration as perceived by the local community were a common theme raised at each school. At Awa and Pakirehua the programme had historically been perceived as a special programme offered as an alternative option to the mainstream, which could serve to attract students to the school. Warren, at Pakirehua, suggested that the integration programme is commonly used as a marketing tool for the school: "I think that [the Principal] loves to hold it up as an example of innovation." Similar comments were made by the teachers at Awa, suggesting that it gave the school a point of difference when competing for students. The Deputy Principal at Niu also stated that curriculum integration is "pretty much our marketing pledge really. The cross-curricular integration is really what we believe sets us apart from most of our competitors."

Interestingly this positive view of the integration programme at Awa has not always been the case. For many years it was regarded as a pathway for students with learning difficulties or behavioural issues. This misconception has been largely remedied in the wider community, which has stimulated an increase in the number of students enrolling in the programme in recent years [field notes, May 2012].

\subsubsection{Professional Development}

Professional development in curriculum integration was viewed by the teachers at each of the schools as an important aspect in showing support for integration. This is a view echoed by Dowden (2012), who asserts that to overcome the challenges associated with curriculum integration "professional development is essential, in order 
for student-centered integration, pedagogy, and practices to be implemented successfully" (p. 20). Fraser (1999) agrees with Dowden, stating that "teachers' professional development in CI therefore, is crucial" (p.1). It was not only professional development within schools that was felt to assist successful integration, but also preparation at teacher training institutions. Aligned with this perspective was a collective view across all four schools that new teachers needed just as much, if not more, professional development in integration than longer-standing teachers, due to an inferior understanding of what curriculum integration entailed.

Three of the four schools talked about having received externally facilitated curriculum integration professional development. At Niu the teachers agreed that professional development had been extensive and that they were constantly consulted on their own learning needs. Ted, a young teacher at Niu, stated that, "I think we're making it up as we go because I think we've come to the stage where a few people have gone to external professional development sessions and come back going, 'we already do this'”. The Deputy Principal at Rua signalled that the senior management was eager to send staff on curriculum integration professional development: "If there was something that I thought was appropriate to go to, I would send them and they'd come back and share their learning". Warren at Pakirehua felt that he had experienced extensive professional development surrounding curriculum integration, having been on external courses as well as facilitating curriculum integration professional development to the whole staff himself.

At all four schools, teachers described how a lot of their professional development was delivered by their own staff. Lily from Awa explained that their professional development was carried out during the integration department's regular meeting time by the head of department. Rua's Deputy Principal described their integration professional development as "a distributed model ... I appointed a leader of each group and I worked with the leaders, and we would chat about how they could help their teachers." Russell at Pakirehua shared how the best professional development he had encountered was simply working with Warren: "Spending the first term with Warren has probably taught me more [about integration] than anything else has."

Niu College appeared to have received the most professional development around integration. They described how a connection to the philosophy of the 2007 
Curriculum, underpinned by the process of teaching as inquiry, meant a constant reappraisal of ideas on the go:

On the job training or learning ... students come up with things and then you chat about it with other staff and that results in some solutions, and so we're learning as we go ... the students I feel teach us quite a bit ... I may not know the ins and outs of what they want to do, so let's look into it and read up on it. (Katy, a teacher at Niu)

The Deputy Principal also described how the physical spaces at Niu assisted continual, informal professional development:

[Having] open [teaching] spaces with four teachers in the same room... teachers can actually see other people's practice and learn from that practice ... They can modify their programmes so that theirs become more complimentary with the other teachers ... they're in the same workroom together so ... they're having professional discussions about what they're doing...we're experimenting. If something works ... we'll follow that line, if not ... we find other ways of improving.

The debate surrounding who needed the most professional development appeared to be divided according to whether integration was a whole school or a specialist programme. At Awa and Pakirehua, where the programmes were not mainstream, the teachers and Principals were in agreement that it was the 'established' teachers that required extensive professional development, which is supported by Dowden's (2012) comment, above. The Principal at Awa shared his opinion that "it is a real challenge for some staff where they've been teaching for 25, 30 years ... the issue is where teachers don't understand the process, their fear about shifts in methodology." The Principal at Pakirehua agreed that spreading the integration practice was a challenge with people that don't want to change the way they've always done things. Niu's Teaching and Learning guide acknowledged that "many staff with previous experience in the secondary sector may require some professional learning" (p. 9), however, this did not align with the overarching view at Niu (and Rua) that it was less experienced teachers that needed more professional development. Vanessa at Rua summed up this position: "It demands quite a lot of professional knowledge from a teacher about how to integrate so if you've got new staff to a school ... training needs to be embedded somehow ... to keep going." Ted, a second year teacher at Niu also noted the absence of education surrounding curriculum integration at teacher training institutions, describing how "they taught us it was a new way of doing things and that it 
was very interesting, 'but let's move on' and that was it!” Vanessa at Rua agreed with Ted, stating that at "secondary, we're not trained for it, aye?" This raises the question as to whether teacher training establishments, or the Ministry of Education, should be delivering some, or more, professional learning surrounding curriculum integration in line with the 2007 Curriculum's ethos, which is a question pursued further in Chapter Six.

\subsection{Chapter conclusion}

In summary, these findings have highlighted the varying pathways toward curriculum integration at four secondary schools, and how curriculum integration cannot be understood in isolation from contextual factors operating both within the school setting (leadership, other teachers, professional development), and outside, in the school community (parental support and pressures). The findings have shown how important support towards curriculum integration, from various groups, is vital if the integration programmes are to flourish and grow. It would appear that at Awa, Pakirehua, and Rua, the curriculum integration journey has not been smooth or steady, due in part to the perceived unconventionality of the programmes, lack of teacher consultation, and a fear of the unknown. At Niu the fact that the programme has been in place from the start, was initiated and driven by senior leadership, and made clear as an expectation to all prospective staff, has paved the way for a less bumpy ride.

There are several interesting questions raised in Chapter Four and Five's analysis, including, which factors have helped to facilitate or hinder the progress of curriculum integration, why have the teachers chosen to implement and develop curriculum integration, and, are teachers able to practice the type of integration that they described in the classroom? These questions are discussed in Chapter Six. 


\title{
CHAPTER 6: DISCUSSION
}

\author{
Curriculum integration is like being a chef, \\ using whatever ingredients you need \\ to create the overall idea you want to convey. \\ (Ted, Niu College)
}

\subsection{Chapter introduction}

Chapters Four and Five considered the perceptions and practices of secondary school teachers towards curriculum integration. The analysis illustrated that while teachers across all of the schools shared a level of commitment and enthusiasm toward curriculum integration, there were considerable differences in how participants understood, interpreted, and enacted it. These differences are worth exploring in greater depth. In this chapter I discuss in further detail a number of factors that I argue have been pivotal in shaping the nature of perceptions and consequent practices at each school. I begin by analysing the factors enhancing and impeding curriculum integration, followed by an examination of the reasons the four schools have implemented curriculum integration, considering whether their motivation was theoretically or pragmatically grounded. I reflect on how aligned teachers' perceptions were with their practice of curriculum integration, concluding with a consideration of the current status of curriculum integration in New Zealand secondary schools.

The theoretical lense of social constructivism used to guide this research has helped to shed light on the historical, cultural, political, and social contexts of schools and their communities. The following sections highlight the social construction of curriculum integration in each of the four schools, and the influence of the school's communities, leaders, and learning areas on the shape of curriculum integration at each school. The progressive nature of curriculum integration increases the degree to which it is influenced by political pressures on education, such as standardised testing.

\subsection{Factors enhancing and impeding curriculum integration}

In Chapter Five, I raised several factors that contributed to the establishment of each programme that appear to have influenced the status and development of the current programmes. The factors pointed to the significance of the historical origins of curriculum integration, school leadership and support, and the impetus provided by the 2007 New Zealand Curriculum. These factors closely align with a study conducted by 
Wallace et al. (2007) looking at the conditions enabling and inhibiting integration at the middle school level, which were categorised as shared purpose, collegial relations, norms of improvement and structure. Conditions inhibiting integration included staff turnover, teaching out of field, planning time, and discipline dominance. In the following sections I will review a number of the factors that appeared to support or impede the adoption of curriculum integration in the four schools in my study and compare these findings with Wallace et al.'s and other relevant studies.

Two of the four schools in this study had thriving and growing curriculum integration programmes (Pakirehua and Niu) and the other two schools had encountered a number of challenges that need addressing before curriculum integration could be widely embraced (Awa and Rua). At Pakirehua and Niu all of the teachers within their programmes were utilising curriculum integration willingly, and arguably the teachers' beliefs therefore aligned with the philosophy of integration from the start. There was a strong sense of support from senior management, including in terms of professional development at both of these schools, which had aided the success and evolution of their programmes. Awa and Rua had pockets of success in their programmes, but a major factor that had inhibited growth was a lack of shared purpose. This was attributed in part to the growth of both programmes resulting in the inclusion of teachers whose philosophy did not necessarily align with that of the more committed integration enthusiasts that had established the programmes. The teachers at Awa and Rua pointed to a lack of support from both senior management and heads of department, which had also contributed to the challenges they faced.

\subsubsection{Whole school or trial beginnings}

For three of the four schools, implementation has been a slow one, rather than a radical break from the past. At Awa, Rua, and Pakirehua, the integration programmes had begun from small origins, in the form of a trial, which 12 years later at Awa, and six years later at Pakirehua, still remains the case. Rua took their initial programme across the whole school after one year, and only Niu began as a whole school initiative. This is reflected in the literature pertaining to integration in New Zealand and internationally, where most of the curriculum integration programmes were trialled with a small group before being applied across the whole school (Avroti, 1992; Inman, 2011; Nolan et al., 1992; Rennie et al., 2011; Sharpe \& Breunig, 2009). Wallace et al. (2007) found that overall, the energy, and goodwill of the members in the change process, and their ability 
to translate such change into constructive classroom episodes, made the difference to successful integration, represented in the initial trial programmes at Awa and Niu, and currently at Pakirehua and Niu.

It appeared that the teachers' philosophies and beliefs towards curriculum integration were an important part of the programmes' success and were linked to how the programmes were established. Transforming methodology in education, such as developing an integrated curriculum, is difficult, due to the fact that part of the process involves changing teachers' beliefs (Brazee \& Capelluti, 1993; Drake, 1998). At Niu College, Pakirehua College, and initially at Awa High and Rua High, the teachers' beliefs were all very much in favour of integration, having chosen to be part of the integration programmes at their schools. Hipkins \& Boyd (2011) stress the importance of learning being disseminated carefully across many different interrelated components, stating that "what is true for students as learners also holds for teachers as learners, for schools, and systems in which organised professional learning occurs" (p. 72). At Niu College comprehensive research around integration was conducted preceding the launch of the whole school integration programme, with on-going reflection and review since. The whole school curriculum integration programme was well received and implemented by the staff at Niu and continues to develop.

In contrast to Niu, the whole school programme at Rua, despite being thoroughly researched prior to its whole school launch, was not so well received by Rua's staff. The discussions in Chapters Four and Five revealed a tension towards curriculum integration from some teachers. Little time was spent engaging Rua's teachers in dialogue to determine their existing views towards integration, and so the beliefs of reluctant teachers were not addressed before integration was imposed across the whole junior school.

One of the most prominent characteristics of successful integrated programmes studied by Wallace et al. (2007), was that the teachers and students belonged to a small team of multi-disciplinary teachers with shared responsibility for a small group of students. At both Awa and Rua the programmes were considered by their respective participants to have been thriving when they were also conducted on a smaller scale, as is the current practice at Pakirehua. However, in both schools, participants described the integration as less authentic as the programmes have grown. 
Isolation from the mainstream was cited as beneficial by Sharpe \& Breunig (2009). They believed that teaching in transformative and critical ways, such as with integration, are often regarded as controversial, and that separation can avoid the influence of administrators less open to alternative pedagogy allowing these programmes to develop to their full potential. This again is the case at Pakirehua College, where there are only two integrated classes. Wallace et al. (2007) also observed that effective integration was found when small learning communities were situated within larger school communities. Although conducted on a whole school scale, Niu's Commons are small learning communities within a larger one, as outlined above. Conversely, the reason that Niu's integration is not as multi-disciplinary as the senior management desire, could be because the programme is on such a large scale.

As described in Chapter Four and above, Awa High has taken the longest of all four schools to implement school wide integration, due in part to resistance from teachers not currently in the programme. Timperley et al. (2007) explain that some teachers take questioning of theory as an attack on their professionalism and previous practice. This assists in understanding why some teachers at Awa were reluctant to change and why the teachers at Rua, who had not been given the choice, were reticent to modify, or for some transform, their current practice.

\subsubsection{Leadership \& Support}

At all four schools it was apparent that support from Senior and Middle Management, other colleagues, and caregivers were integral to the success of the curriculum integration programmes. Although curriculum integration is promoted as a 'bottom-up' model of curriculum innovation, it has far more success when supported by senior administration (Fraser, 1999; Inman, 2011; Wallace et al., 2007). Several authors maintain that despite the evidence emphasising the benefits of curriculum integration it is still largely adopted as a result of individual teacher efforts, rather than via a topdown directive. Without senior management support this can lead to increased workload while setting up programmes, increased demands on lead teachers, isolation from other colleagues, a constant need to justify the programme's merits, and subsequent burnout (Sharpe \& Breunig, 2009).

That support from senior management is important to the success of curriculum integration was clear at each of the case study schools, as discussed in section 5.3.2. At Niu and Pakirehua the teachers were in no doubt that their senior management were 
fully supportive of curriculum integration at their respective schools. At Niu College, comments such as "more than support it, they lead it ... I think the difference here is that it comes from the top down" highlighted this.

Teachers from Awa High describe how their curriculum integration programme had received full support for its initial implementation from the then Principal. However, the arrival of a new Principal had made the status of the programme less prominent. The situation was similar at Rua where the founding Principal was extremely supportive and had been responsible for the programme's instigation. The fact that Rua has recently lost the two key senior managers in charge of the integration programme, including the Principal, raised concerns amongst Rua's teachers in terms of the future and direction of the programme. The lack of on-going support from senior management at both schools has led to a much less consistent application of curriculum integration and a far bumpier and more tentative ride than the smoother journeys at Niu and Pakirehua.

As well as senior management, the support of heads of department and other colleagues was a significant contributor to curriculum integration adoption. Wallace et al. (2007) found that a collaborative effort across the school was vital for successful curriculum integration. Three of the four schools experienced some resistance from heads of department and other colleagues, which had impacted on the integration programmes at their schools. Niu was the only school that felt all colleagues were on board with integration. It would be fair to say that this could largely be due to the requirement for teachers to show a commitment to integration during the recruitment process at Niu College.

The lack of a common philosophy and approach to curriculum integration also resulted in tensions around three of the integration programmes. For example, at Awa, Pakirehua, and Rua, the teachers experienced a common issue of heads of departments stipulating that all students cover identical content, and complete the same summative assessments as the rest of the school, which are at odds with the methodology of curriculum integration. This again echoes Wallace et al.'s (2007) findings that there were many difficulties incorporating an integrated component into the curriculum of a large mainstream high school. A participant of theirs reported criticisms of the thematic approach to integration, resulting in a more compartmentalised programme. Fraser (1999) also revealed that two high school teachers on their professional development 
programme had experienced criticism from their colleagues when they endeavoured to share their work on the curriculum integration contract. This draws attention to the rather fragile status of curriculum integration as a philosophy and practice, and perhaps explains why it remains so marginalised in secondary schools.

The schools that showed support in terms of flexibility with timetable and classroom structure made the process of curriculum integration much smoother. The issue of flexibility, including timing, classroom layout, traditional systems etc. is related to support from senior management (Wallace et al. 2007). To approve modification of the traditional timetabling structure and lesson duration shows a high level of support towards integration and consequently is an enabling factor.

Part of the success in curriculum integration at Niu and Pakirehua related to the timetable structures not reflecting the traditional five hour blocks a day found in most high schools. At Niu the timetable was made up of three hour-long blocks per day, allowing students' time to work on inquiry learning in each of the learning areas. Teachers felt that the longer periods of time enabled deeper integrated learning to take place. At Pakirehua the integration programme operated for an average of four hours per day, where the students worked on their inquiry research throughout this time. Without this freedom the teachers felt that they would not be able to engage the students at a level that empowered them to take whole responsibility for their own learning. In contrast, at Rua and Awa the timetable was more traditional with students moving between hour periods in each learning area. At Awa in particular it was apparent that teachers felt this hindered the depth and breadth of their integration, and that it was not something that would be changing in the near future, if at all.

Another area linked to the support of integration is that of the professional development offered by schools to teachers to expand their understanding of and develop their practice around curriculum integration (Fraser, 1999; Hipkins \& Boyd, 2011; Timperley, 2008; Wallace et al., 2007). In this study, the professional development offered varied greatly from school to school. All schools had experienced some professional development, most of which was delivered by their own staff.

Some teachers at Niu, Pakirehua, and Rua had been on externally facilitated professional development, but felt that is was often inadequate for their needs. All participants agreed that stand-alone courses were less effective, and tended to change 
practice less than on-going professional learning. Effective professional development enables teachers to base their decisions on theoretical understandings (Fraser, 1999; Timperley, 2008).

The teachers at Niu College described how their professional development was planned around their individual needs, with many sessions being opt-in, rather than compulsory, (which was the case at the other three schools). Timperley et al. (2007) found that when teachers collectively and individually identified important issues, became the drivers for acquiring the knowledge required to resolve them, examined the impact of their actions, and adjusted their practices accordingly, they were much more successful in changing student outcomes.

\subsubsection{Impetus from the 2007 New Zealand Curriculum}

Timing appears to be a significant factor aiding the success of the programs at Niu and Pakirehua. The launch of the most recent Curriculum in 2007 appears to have provided the impetus needed by these secondary schools to re-evaluate their school curriculum, particularly at the junior school level. Whilst their program started a year prior to the launch of the new Curriculum, Pakirehua felt it validated their program. As Niu College was founded four years after the launch of the Curriculum, beginning with just Year Seven to Nine students, they took advantage of the opportunity to explore the interpretation and implementation of the Curriculum at other schools, before deciding the best way forward for themselves. Niu College were also endorsed by the Curriculum for such actions, instead of taking alternative actions as was the case for earlier schools.

The emphasis on the front end of the Curriculum, and the active encouragement to employ integration, has given schools the mandate to employ progressive pedagogies, encouraging much more student-centered learning, using the Key Competencies as the vehicle through which to drive each schools' curriculum (Begg, 2008; Hipkins \& Boyd, 2011 ). Hipkins and Boyd (2011) discuss the role that Key Competencies have played as "agents of change ... and their as yet unrealised potential to stimulate further change" (p. 70). Niu College have based their whole philosophy around such progressive pedagogies, specifically curriculum integration and inquiry learning. Although the idea for Pakirehua's programme came a year before the 2007 New Zealand Curriculum was officially launched, the founding teacher noted that its immediacy had unquestionably helped to justify the programmes existence, expansion, and progress (field notes, July 2012). 
Perhaps surprisingly, the school with the most historical curriculum integration programme, Awa High, had not seen a rapid implementation change across the school. The similar philosophies of Awa's programme and the 2007 Curriculum had not until recently been recognised and acknowledged by their senior management. Although Rua's curriculum integration programme was prompted by the 2007 Curriculum, other factors contributed to it not being as readily accepted or successful as Rua's former Principal would have liked. These differences may also be due to embedded traditions as discussed earlier.

Despite advocating integration, the New Zealand Curriculum is still largely composed of learning area content, which may impact on the Curriculum's supposed impetus for change. Although the Vision, Principles, Values, and Key Competencies have been positioned at the front of the Curriculum document, they have only been granted four pages, whereas the learning areas have been awarded over 50, suggesting that they are significantly more important (Begg, 2008). Begg proposes that "with these weightings, together with the traditions of schooling ... only confident teachers are likely to significantly change the focus of their work" (p. 1).

The 10-15 yearly curriculum changes in New Zealand are only part of the real change process, argued by Begg (2008). He maintains that progressive teachers have consistently investigated and trialled new methodologies, which have eventually been adopted by other teachers if considered successful, followed by official acceptance. This insight can help to explain the state of integration at each of the schools. Niu have embraced integration, with teachers who have either had experience with it at other schools, have encountered others practising it, or were prepared to utilise it, all coming together enthusiastically to adopt integration throughout their practice. At Awa, the programme has grown from two classes to eight, and at Pakirehua there is an indication that teachers are willing to grow their programme too. In contrast, at Rua, there was no gradual observation by teachers allowing them to assume integration in their own time. As more schools trial and adopt integration there may be 'official acceptance' in most New Zealand secondary schools.

Several factors that have enabled and impeded the development of the integration programmes at all four schools have been identified and discussed. Wallace et al. (2007) found that institutional resilience was a factor that allowed schools to sustain innovative programmes. These schools "manage to hold the enabling and 
inhibiting conditions in a kind of productive tension" (p. 45). It will be interesting to see whether Niu will be able to hold the enabling and inhibiting factors in enough tension to sustain their current level of innovation in the future.

\subsection{Reasons for implementation: pragmatism or theoretical}

This section examines the possible explanations for the common lack of secondary teachers' theoretical knowledge surrounding curriculum integration. In an investigation of how educational theory is translated into practice, Prince (2010) and Schon (1987) explain that, at the beginning of their professional career, teachers attempt to implement the theories that they have studied in their training, promptly followed by a realisation that this application of theory does not always result in the desired effect, and that a more practice-focused knowledge is required. This can lead to a critique of theoretical knowledge and its disparity with classroom practice, which may explain why so many of the participants took a more pragmatic approach to curriculum integration, rather than grounding their practice in theory.

Ambiguity surrounding the theoretical grounding of the integration programmes was the case at all of the participating schools. Comments such as "it's probably based on some sound theory, it's just that I didn't do the research to develop the programme" (Warren, Pakirehua) and "I don't think there is a particular theory" (Deputy Principal, $\mathrm{Niu}$ ) illustrate this point. Only a small minority of the participants had a clear theoretical understanding of curriculum integration, as discussed in section 4.4. This is a position which is also documented in the literature (Fraser, 1999; Whyte, 1999). This perceptible deficiency in a theoretical grounding echoes Dowden's fears (2007) that the lack of historical and theoretical consultation regarding curriculum integration in recent years has led to the confusion surrounding its definition and understanding.

A commonly cited aim for employing curriculum integration was to improve students' experience at school, as described in Chapter Four. Two pragmatically grounded reasons for utilising integration were the positive relationships formed, and the ability to provide greater relevance to students' learning. This was especially the case at Awa and Rua, where several teachers felt that the positive relationships gained through the use of integration were potentially a greater benefit than the curriculum integration itself. This was a belief noted in Wallace et al.'s (2007) review of curriculum integration in Australia who found that the teachers had assumed a more pastoral focus. 
The lack of attention given to teachers' prior beliefs and values is another aspect contributing to why schools have had a more pragmatic than theoretical inclination toward curriculum integration. Timperley et al. (2007) describe how acknowledging a teacher's theories of practice (their particular beliefs and values, and the knowledge, skills, and practices that follow from them) are integral to the success of a new practice. They explain that the meaning of new practice must be negotiated, including why existing practice needs to change, in order to engage in new theories. At Rua High, the whole school implementation did not engage, or even consider, the teachers' theories of practice. Teachers were not given the time to understand the theory behind curriculum integration in order to willingly and genuinely challenge and change their practice. At Awa, the move towards whole school curriculum integration had been a long process, but one that has enabled teachers to identify their own theories of practice and why they may need to change.

Both of the teachers at Awa and Rua who displayed a greater understanding of the theories used were the founding teachers of their school's programmes. Therefore, it is likely that having carried out a comprehensive review of curriculum integration theories at the outset they would have passed this knowledge on to at least some of the other teachers. That Awa High's approach was shaped at a time when curriculum integration was less common and less supported in the previous New Zealand Curriculum, could have led to the need for a deeper justification for, and more thought around the concept of integration. Awa may have had a greater theoretical base due to extensive research into curriculum integration 12 years ago, as opposed to having the current New Zealand Curriculum as justification. At Rua, the Principal that instigated the integration programme had also conducted thorough research, ensuring that the trial year was facilitated by two of her strongest teachers, who also understood the value of educational theory to practice. At Pakirehua the founding teacher had left, and at Niu there was not a founding teacher, so the dissemination of theoretical information to other teachers was consequently absent at these two schools.

The reasons for utilising curriculum integration were not necessarily based on theory, which is not a surprising finding. Beane (1995) asserts that putting theory into practice is not an easy task: "Theoretically, defining the relations between curriculum integration and the disciplines of knowledge is easy. But that act does not resolve the tension over how those relations work in the practical context of curriculum 
integration" (p. 617). This tension between theory and practice could be why the majority of participants were not more acquainted with the theory of curriculum integration.

The absence of a theoretical underpinning has a number of implications according to researchers in this area. The necessity to maintain an understanding of the theoretical groundings of curriculum integration is raised by Fraser (1999). She believes that a challenge is to "focus on both product and process in curriculum integration - the product can lose all meaning if teachers do not understand the complexity of the processes involved" (p. 1). Timperley et al. (2007) found that the integration of theory and practice was fundamental to professional development that positively impacted outcomes for students.

Despite the longevity of curriculum integration in New Zealand, there is still little professional development surrounding it, which could contribute to the ambiguity surrounding it in the education community in general (Beane, 1997; Dowden, 2007; Drake, 1998; Wallace et al., 2007). That there is minimal reference to curriculum integration in secondary teacher training programmes (Dowden, 2007) adds to an understanding of why there was a general lack of theoretical comprehension of integration across all schools.

\subsection{How perceptions aligned with practices}

In this section I will discuss how teachers' perceptions of curriculum integration aligned with their practices. I offer some suggestions to explain why they contrasted so greatly at some schools, whereas at others they were more comparable. I conclude this section with a discussion of the importance that all participants placed on separate subject specialism.

It was apparent that while the four schools held much in common with regard to their perceptions of curriculum integration, there was also significant variation. Teachers' views of the type of curriculum integration used varied both across and within schools, with greater within-school variation in some schools than others. The information gathered indicated that teachers' perceptions were not always reflected in their practice, which was also a finding of Fraser (1999). In Figure 6.1 I have provided a continuum to compare the perceptions and practices of the type of curriculum integration at all four schools. The continuum highlights the degree of cohesiveness 
between the participants' perceptions at each school, indicated by some versus all, and their position on a trans-disciplinary to inter- and multi-disciplinary continuum.

Figure 6.1 shows that the school with the greatest trans-disciplinary view of curriculum integration was Pakirehua, who were also the only school whose perceptions and practices aligned almost completely. The only differences occurring between their perceptions and practices were due to enforced preparation for common assessment, as outlined in Chapter Five. This could in part be attributed to the size of Pakirehua's

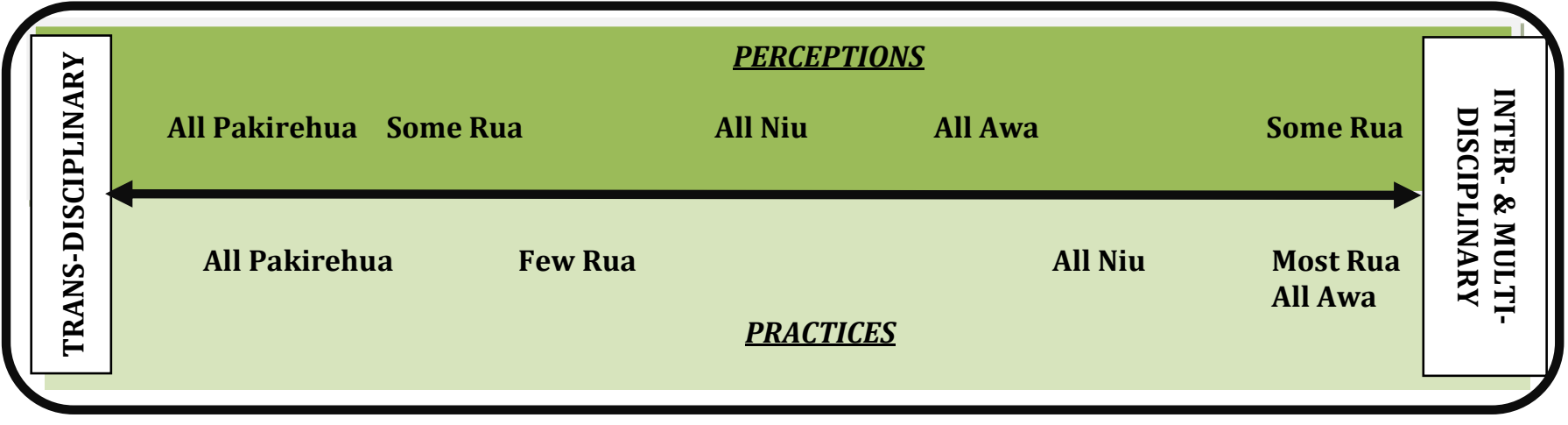

Figure 6.1: Comparison of participants' perceptions and practices towards the type of integration

integrated programme, comprising two classes and two teachers at the time of my research. Warren had been teaching in the programme for longer than Russell, who had no prior experience of integration, and so it is likely that he had assimilated Warren's perceptions of curriculum integration. Russell practised with a high degree of similarity to Warren, which Russell alluded to with his comment that "spending the first term with Warren has probably taught me more [about integration] than anything else has."

At Rua High there appeared to be a division amongst staff between both their perceptions and their practice of curriculum integration. Some of the participants at Rua had a strong trans-disciplinary perception, whereas others had a more multidisciplinary view of integration. Unlike the staff at Pakirehua, Niu, and Awa who showed a general level of collective agreement with each other, the participants at Rua demonstrated less unity in their perceptions and practices. While there was a polarity of perceptions of curriculum integration at Rua between the staff, their own perceptions of integration were reflected in their own practice.

There are several possible reasons for the division of beliefs around curriculum integration at Rua. One could be that the initiative to employ curriculum integration had come from the Principal, which the whole staff were then obliged to utilise following a 
year-long trial. Minimal whole staff discussion prior to implementation had occurred, with no agreement of a definition or methodology for integration. There also appeared to be great value placed on strong autonomy of teacher philosophy at Rua, which could similarly explain these differences of opinion. Rather than forming a collective identity and pathway toward curriculum integration, it would appear that the teachers at Rua had formed rather individualistic perceptions and practices.

Participants from Niu had a perception of curriculum integration that was partly trans-disciplinary and partly multi-disciplinary. Niu's perceptions and practices varied minimally, which may be credited to the fact that the curriculum integration programme at Niu was run as a whole school initiative, potentially leading to a more homogenous school culture. The variation between perception and practice at Niu was towards a more multi-disciplinary approach. Integration as a philosophy of the entire school was established from the beginning at Niu, meaning that the perceptions and practices were more aligned right from the start.

Awa's participants showed mixed perceptions of curriculum integration that sat somewhere between the two poles. Awa was the school that showed the greatest variation between perception and practice. Awa's teachers' perceptions varied between multi-disciplinary to trans-disciplinary during the focus group, whereas the practice of integration across the school was more inter-disciplinary. It appeared that their initial perceptions reflected what they thought their practice was like, and then they formed a new collective viewpoint upon further discussion. As a group they were united in both their perceptions of integration and their practice.

The difference between Awa's participants' perceptions and practices could be attributed to a number of tensions within the school. The teachers voiced that they did not feel completely supported from senior management, which prevented them from practising as they wished, as outlined in Chapter Five. The perceived resistance to integration from heads of department at Awa, which according to a number of teachers had placed barriers in the way of some of their key integrating practices, may also have contributed to this disengagement. Additionally, having begun integration over 12 years ago, with little evolution, many teachers at Awa may have disengaged with the practice of integration. 
At both Awa and Rua there was a sense that the programmes had diminished in enthusiasm and effectiveness over time. Wallace et al. (2007) found that "when reform does make a difference in individual classrooms, the impact erodes over time ... with participants often reverting to traditional teaching ways" (p. 30). This highlights the need to constantly reflect on practice, both at a classroom and system level, to ensure that all of the necessary and essential contributing conditions for integration are adequately maintained. Such reflective practice was not evident at Awa and Rua, but was at Niu and to some extent at Pakirehua.

While I had chosen the four schools for their commitment to curriculum integration, one quite unanticipated finding was that nearly all participants at each of the secondary schools placed great value on the separate subjects when discussing curriculum integration, as discussed in chapter Five. It would be natural to expect that a group of committed curriculum integration teachers may be lesser advocates of the separate subjects, but this was not the case. The nature of this endorsement differed between schools. Awa and Pakirehua felt that access to specialist subject knowledge was required, but that the content did not necessarily need to be taught in subject compartments by subject specialists. Rua and Niu had trialled teaching across multiple subjects and decided that at Years Nine and Ten it was necessary to deliver content through subject specialists.

It appears that in New Zealand secondary schools, the value placed on the subject specialist is still a prevailing theme (Begg, 2008), which could be attributed to a number of reasons, including subject status and high-stakes testing. Beane (1995) and Dowden (2012) both raise the notion that teachers' professional identities are built around and tied to subject area status. Heidi Hayes-Jacobs (in Brandt, 1991) describes how "in secondary schools ... teachers become identified with their subject to such a degree that it's hard for them to look over the fence" (p. 24). This has parallels with the issue raised by participants at Awa, of the agenda of heads of department reluctant to allow teachers to teach across disciplines. Wallace et al. (2007) reported that a participant of their study felt that there was a "perception that it was more prestigious to teach in the senior school" (p. 40).

There was also a strong link between the need for subject specialism and NCEA assessment raised at each school, particularly by the Principals. High academic results are a parameter by which secondary schools are (increasingly) judged and curriculum 
integration is often perceived as a threat to such results, despite evidence to the contrary (Beane, 1997). The restriction imposed on teachers by assessments in general is also an important consideration in secondary schools, which has a trickle-down effect on the junior school, as described at Pakirehua College. Au (2011) describes how highstakes testing has forced the educational process to be driven by pre-determined objectives to the point that not even the subjects are the central focus of the curriculum. $\mathrm{Au}$ asserts that teachers have been disempowered as a result and are adopting more teacher-centered pedagogies to meet the demands of testing, which is at odds with constructivist, student-centered best practises, such as curriculum integration. Apple (1995) believes that a focus on standardised testing removes the need for skills such as "curriculum deliberation and planning, designing teaching and curricular strategies for specific groups and individuals based on intimate knowledge of these people" (p. 132) which are all features of curriculum integration.

The common support for subject specialism across all participating schools could also be due to the nature of secondary schools and that nearly all of the participants come from the mostly white, upper-middle class backgrounds that Apple (2007) and Beane (1995) assert to be favoured by teaching and learning through separate subjects. Additionally, it could be that as many New Zealand secondary schools represent this socioeconomic group, there is less favour for Beane's trans-disciplinary democratic model of curriculum integration. Apple, Beane, and others surmise that the separate subjects are terrains fashioned by, and for, the interest of academics or elitists in society, providing them with a factory for high-status knowledge that can be used as their cultural capital, while marginalising non-privileged and non-dominant cultures. $\mathrm{Au}$ (2011) describes how fragments of the US New Middle Class are conflicted by the perceived benefit to their children of the separate subjects and standardised testing, and the fact that schooling constructed around such testing does not adequately prepare their children for life in the globalised economy.

Subject specialists' lack of knowledge in other learning areas could also be responsible for this affiliation to the separate disciplines. A discomfort when negotiating curriculum with students was found to be in part due to teachers feeling overwhelmed with the knowledge base required in certain topics by Fraser (1999). Julia Atkin (2011) discusses this challenge for secondary educators when talking about the implementation of the New Zealand Curriculum, describing how they think of themselves as teachers of 
subjects such as Science, Maths, or English, rather than a teacher of the person. Many of the participants of this study showed a willingness to learn what was necessary to integrate across learning areas as the need arose, whereas other teachers were less prepared to cross the subject boundaries.

\subsection{Chapter summary}

This chapter has examined three key findings of this research in to New Zealand secondary school teachers' perceptions and practices towards curriculum integration. That support from senior management was crucial to the success of integration at each school is clear, as was the timing and method of implementation, in particular concerning addressing teachers existing beliefs toward integration. The lack of a theoretical understanding of curriculum integration at all four schools has implications for the authenticity and consistency of practice at each school. Where teachers perceptions and practices were more closely aligned, there appeared to be more successful integration taking place, as was the case at Niu and Pakirehua.

In summary, the status of curriculum integration in New Zealand secondary schools is resting on shaky ground. It has been undermined by the ambiguity surrounding its definition and a lack of cohesive direction from the Ministry of Education. A persistent and growing emphasis on high stakes, standardised testing has forced secondary educators to lessen their focus on the student-centered pedagogies associated with curriculum integration. All of these factors have the potential to erode the intention of the progressive ideals of an integrated curriculum espoused in the New Zealand Curriculum, and endorsed by key authors, such as Apple (2009), Beane (1995), and Dowden (2007).

The final chapter draws conclusions from this study, looking at how it has addressed unanswered questions about curriculum integration in secondary schools, as well as other wider implications of this work. How this study can be applied in New Zealand and further afield is also addressed. 


\title{
CHAPTER 7: CONCLUSION
}

\author{
Curriculum integration is something like a can of paint \\ into which you're pouring different colours and at the center is a \\ glowing, compelling colour that everyone wants to grab. \\ (Principal, Awa High)
}

\subsection{Chapter introduction}

The aim of this research was to explore New Zealand secondary school teachers' perceptions and practices towards curriculum integration. I contended in the first chapter that this was an important area for research due to the recent renewed interest in curriculum integration, in particular in the unusual territory of secondary schools. The renewed interest in integration is, in part, a result of its promotion in the $2007 \mathrm{New}$ Zealand Curriculum document, as well as the perceived need to address other issues prevalent in education today, such as the changing nature of knowledge, the DeSeCo key competencies, and the disengagement of many of today's learners. This chapter revisits the research questions in light of the findings, from which I draw several conclusions.

\subsection{Revisiting the research questions}

At the outset of this research, I identified that:

a) Little data exists on curriculum integration in New Zealand secondary schools.

b) That there was considerable ambiguity surrounding curriculum integration and its implementation.

Leading from these two propositions, my first research question asked, what are New Zealand secondary school teachers' perceptions and practices of curriculum integration? The findings in Chapters Four and Five demonstrated that both perceptions and practices were broad and varied across and within schools. All participants showed an understanding of Beane's student-centered, trans-disciplinary integration, where the learning is centered around and constructed with the students. All participants also described types of integration that were multi-disciplinary in nature, in which learning was situated around a common theme. Two of the schools described curriculum integration in terms of inter-disciplinary integration, in which participants emphasised the development of generic skills such as critical thinking and problem solving. Yet, while all schools employed elements of these three types of curriculum integration, significant differences were notable in their emphasis. Pakirehua's teachers practised 
curriculum integration in a much more trans-disciplinary way, with students largely guiding their own learning through inquiry for the majority of their time in class. Niu's application was mainly multi-disciplinary, with small pockets of trans-disciplinary and inter-disciplinary integration. Rua's integration varied within school, with most teachers performing multi-disciplinary integration and one or two practising trans-disciplinary. Awa was the only school whose teachers predominantly carried out inter-disciplinary integration through the use of cooperative learning strategies.

One of the themes that was surprisingly universal across all schools was the fact that subject specialism remained an important concept in secondary schools, even when utilising curriculum integration. All teachers felt that disciplinary knowledge was important and powerful and that it was imperative to retain such knowledge regardless of the type of integration practised. This finding could help to ease the qualms of Wood and Sheehan (2012) and Young (1999) regarding the diminishing of powerful subject knowledge as a result of the push for integration and progressive pedagogies.

The above findings from Chapters Four and Five also address the first subquestion: are there differences between teachers' perceptions and practices of curriculum integration? That the perceptions and practices at most of the schools were common across teachers within each school draws attention to the socially constructed nature of knowledge, even within school communities. At Awa, Pakirehua and Niu there was a clear shared philosophy of curriculum integration, which could be attributed to the fact that at each of these schools the teachers had chosen to be a part of their integration programmes. I believe that this finding shows that although teachers' perceptions and practice varied somewhat from school to school, they were shaped by their personal experiences, and the creative actions of the community in which they practiced, leading to the subtle and not so subtle difference observed at each school.

The concept of a community of practice is described by Wenger (2009) who asserts that learning happens through social participation, by active participants in social communities, constructing identities in relation to these communities. Awa, Pakirehua, and Niu all displayed a collective ownership of their curriculum integration programmes. They shared common practices, a collective definition for curriculum integration, and a similar pathway in their programmes' evolution. This aligns with Wenger's four interconnected and mutually defining elements necessary for communities of practice: meaning, practice, community, and identity. The exception to 
this community of practice model was Rua College. Rua was a unique case, as the teachers had not opted into the programme, and were also proud of their high levels of teacher autonomy. Rua's teachers shared a belief in student-centered learning, but found it harder to plan across learning areas due to their apparent autonomy. This also highlights that the social constructivist theoretical paradigm and methodological approach taken in this study was a fitting one, as it allowed teachers to share their personal opinions of curriculum integration through discussion with their peers in the focus group interviews, providing rich, valuable data to explore.

The second sub-question asked: What theoretical lense do teachers describe as the basis for their curriculum integration programmes? The findings indicated that there was a significant lack of theoretical grounding in each of the case study school's integration programmes. It appeared that teachers were more likely to read contemporary populist authors, such as Claxton, than curriculum integration theorists, such as Beane. This exposes the fact that teachers had very little guidance when making decisions about curriculum integration.

Despite advocating integration, the 2007 Curriculum does not offer a definition or provide any reference to a particular theoretical standpoint. With this lack of guidance it has been left for teachers to carry out their own review into curriculum integration. It was apparent in all four case study schools that most teachers were reluctant to read theory, and were instead pragmatic in their planning. This has resulted in what Dowden (2012) argues to be a more sophisticated understanding of curriculum integration in New Zealand being gradually forgotten.

The final sub-question asked: How is the curriculum integration programme supported by the senior management? Dowden (2012) stresses that the support of senior management is vital, reasoning that Principals, with a deep knowledge of their local communities, are "best equipped to explain and extol the benefits of curriculum integration" (p. 30). However, it became apparent that support not only from the senior management was crucial to the success of the programmes. Support was necessary from many other areas, such as heads of department, colleagues, caregivers and the local community, as well as support in terms of professional development. The notion of a community of practice (Wenger, 2009) can also be linked to the need for support, as findings in this study confirm that without agreement amongst all members of the local community, curriculum integration is less likely to flourish. This indicates the need for a 
whole school community approach, in order to implement curriculum integration, rather than the ad hoc approach that was more common in the case study schools.

My second research question asked why have teachers chosen to implement curriculum integration? There were numerous justifications provided for the use of integration at each school in Chapter Four, which aligned closely with the reasons explored in Chapter Two's literature review of the changing nature of knowledge and learning in the $21^{\text {st }}$ century, a need to re-engage students from diverse backgrounds, and the advocation of curriculum integration by the 2007 Curriculum. Whether curriculum integration is addressing the motives outlined above is beyond the scope of this study, but it does illustrate that the reasons teachers have chosen to employ curriculum integration are relevant to contemporary educational issues, on a local and global scale.

\subsection{Implications for stakeholders}

One aim of my research was that the findings might inform future professional development programmes and teacher training in the area of curriculum integration. If schools continue to adopt and develop curriculum integration programmes, there is a critical need for professional development to ensure effective implementation. The issue of support raised in this study exposes the question of who should be held responsible for tackling the ambiguity surrounding curriculum integration, and for providing professional development to address this concern. Additionally, as the Ministry of Education have taken the radical stance of promoting curriculum integration in the 2007 Curriculum, then it is likely that it may become a future area of focus for the Educational Review Office (ERO).

While this study is small in scale, its findings highlight the varied interpretations of this new curriculum direction. Hipkins et al. (2008) and Wood \& Sheehan (2012) have alluded to the fact that more secondary schools are employing curriculum integration to meet the needs of the 2007 Curriculum. Whether curriculum integration will remain a growing trend in New Zealand secondary schools could be determined by the tension surrounding the competition between progressive pedagogies (such as integration) versus standardisation.

Where the responsibility lies for providing curriculum integration professional development is an important consideration. Whether it should be with individual schools or with the Ministry of Education is an area for exploration. Schultz (2009) 
states her belief that a procedural manual explaining how to integrate with integrity would be essential in providing all teachers the agency to utilise curriculum integration. This is at odds with Beane's concept of integration, but may provide a starting point for those less confident with student-centered curriculum integration pedagogy.

I believe that teacher training institutions should be investing time into teaching secondary trainee teachers about curriculum integration if there are indeed an increasing number of secondary schools adopting this methodology. Sharpe \& Breunig (2009) suggest an opportunity for teacher training institutions to counter the prevalent enculturation found in schools, so that newly trained teachers can be confident to initiate alternative or counter-hegemonic praxis, such as curriculum integration, even if they are not the norm.

\subsection{Further research in this area}

My research has looked at a small number of case study schools and so the findings are not generalisable. Due to the time limitations of a Master's thesis, I have provided insights into curriculum integration in only a handful of secondary schools in New Zealand. However, I believe that the area of curriculum integration offers huge potential for future research and so I have suggested possible areas that I think would be valuable to pursue in future research in the area of curriculum integration in New Zealand secondary schools:

1. Most of the curriculum integration studies conducted in New Zealand have been qualitative in nature and conducted in primary or intermediate schools (Dowden, 2007, 2012; Fraser, 1999; Locke, 2008; Matangi-Hulls, 2010; Whyte, 1999). This has helped to give insights into the types of curriculum integration being enacted at this level, including the factors supporting and inhibiting the success of integration, including this study. However, we still don't know fully the extent to which New Zealand secondary schools have embraced curriculum integration since the launch of the 2007 Curriculum, and therefore a larger quantitative study would support this.

2. My research has looked at teachers' perceptions and practices towards curriculum integration at four case study schools. I believe that an in-depth case study at one of the schools successfully utilising curriculum integration would provide constructive information regarding the ideal conditions for curriculum integration implementation in New Zealand secondary schools. This could be useful 
for secondary schools hoping to implement curriculum integration in the future, so that they do not have to travel down such an isolated road, as with the schools in this case study.

3. My study looked at perceptions towards integration, rather than the student outcomes of integration. As Niu College (and others) are intending to carry their curriculum integration programme into the senior school, it would be useful to follow their students' progress into Years 11, 12 and 13, to examine their NCEA data within integrated courses. The impact of curriculum integration on educational outcomes at the senior level of secondary schools would be a valuable area for future research.

4. Finally, my research looked at the perceptions toward curriculum integration of teachers who were already practising it. If ambiguity is so prevalent amongst advocates of integration, then it may also be important to examine the perceptions of teachers who do not currently utilise it, especially if the employment of integration does indeed become an emerging trend.

\subsection{Final remarks}

I began this thesis with a description of the metaphors for curriculum integration provided by the participants of this study. I refer back to these metaphors now as a tool to accentuate the varied perceptions of teachers towards curriculum integration.

Some of the metaphors were trans-disciplinary in nature, and had a largely creative, individualistic theme, which echo the philosophies of Beane (1997) and Dewey (1949):

A can of paint into which you're pouring different colours and at the center is a glowing, really compelling colour that everyone wants to grab. (Principal Awa)

It's like being a chef, using whatever ingredients you need to create the overall idea you want to convey. (Ted, teacher at Niu)

The subjects are a particular coloured pot of paint in a traditional classroom. In an integrated classroom the colours are spattered together often mixing to make another colour. (Flo, teacher at Niu) 
Most were multi-disciplinary, and conveyed a real sense of hope and vibrancy in the potential of curriculum integration:

A fern frond - all different areas of learning contributing to one beautiful understanding of the world we live in. (Lily, teacher at Awa)

Like the Olympic rings -discrete learning areas joined by a common theme or pedagogy. Some skills in the learning areas the same, some unique. (Rose, teacher at Awa)

A rowing boat with eight oars. (Principal Awa)

A piece of rope with strands at each end...the strands are together during times of Curriculum integration, otherwise the strands are separate (the ends of the rope). (Joan, teacher at Rua)

The curriculum is together white light - a combination of all the different colours of the learning spectrum. These colours are useful and have their place individually, mix a couple together to make new understanding and all together in equal parts produce the overall white light. White light is what you use to see clearly and fairly - an uneven mix will just eventually hurt your eyes. (Misty, teacher at Rua)

And one was inter-disciplinary, which mirrors the ethos of the 2007 New Zealand Curriculum:

Hau Ora-you've got a healthy individual in the center and into that center are pouring the discrete components of knowledge, attitudes, skills and experience that build the educated individual (Principal Awa)

I believe that the optimism, enthusiasm, and possibilities provided by these metaphors may not be fulfilled unless schools implement a cohesive programme of support, employ theoretically grounded intentional practice, and critically monitor their progress.

The historical and theoretical study of curriculum integration in New Zealand conducted by Dowden (2007) raised the issue of the ambiguity surrounding curriculum integration's definition, describing the literature surrounding integration as "a plethora of models" (p. ii). Dowden's research did not look at the reality of curriculum integration in New Zealand's classrooms, whereas this study has done just that, confirming that a plethora in the literature is matched by a plethora of teacher perceptions and practises. 
The Deputy Principal at Niu College offered this fitting metaphor for the implementation of curriculum integration, that highlights its unrealised potential:

It's like building aeroplanes in the sky - we're developing this whole cross-curricular inquiry model as we're flying. We're off the ground and we have to make it work and we've got kids lives or their academic future at stake so it has to work. But how it looks is evolving with time. We're sort of pulling different components in and adjusting them as we're flying along.

I stated at the beginning that while I remain an advocate of curriculum integration, I entered this research with reflexivity, open to critical debate that I was aware would add to my insight into, and potentially shift my position on curriculum integration, which is what has happened. I remain a strong advocate of curriculum integration and through the journey my knowledge and theoretical understanding of curriculum integration has evolved, which I believe will change my practice as a result. I have no doubt that there will always be multiple interpretations and types of curriculum integration, but I do hope that my research has highlighted the need for a more informed, collaborative decision making process, and the need for a greater level of support from school communities and the Ministry of Education. My greatest hope is that standardisation will not win the battle with curriculum integration in New Zealand secondary schools, which I believe has the power to unlock the unrealised potential of the New Zealand Curriculum. 


\section{REFERENCES}

Apple, M. (1995). Education and power. New York: Routledge.

Apple, M. (2007). Whose markets, whose knowledge? In A. Sadovnik (Ed.), Sociology of education: a critical reader (pp. 177-193). New York: Routledge.

Apple, M. (2009). Can critical education interrupt the right? Discourse: Studies in the Cultural Politics of Education, 30(3), 239-251. doi:10.1080/01596300903036814

Atkin, J. (2011). Expressing the essence of the NZ Curriculum. ED talks: A CORE education initiative. Retrieved December 13, 2012, from http://edtalks.org/video/dr-juliaatkin-expressing-essence-nz-curriculum\#.UMk-GKx5e74

$\mathrm{Au}, \mathrm{W}$. (2011). Teaching under the new Taylorism: High-stakes testing and the standardisation of the 21st century curriculum. Journal of Curriculum Studies, 43(1), 25-45.

Australian Curriculum, Assessment and Reporting Authority. (2008). The Australian Curriculum v 4.0. Year 12 Australian Curriculum online. Retrieved December 13, 2012, from http://www.australiancurriculum.edu.au/

Avroti, R. (1992). Comparative analysis of the traditional and the integrated curricular in Ghanaian secondary schools. Presented at the AARE/NZARE Joint Conference, Geelong. Retrieved from http://www.aare.edu.au/92pap/avotr92066.txt

Bainbridge, W. (2005). Maori Education Issues. Matipo School. Retrieved March 27, 2012, from http://matipo.school.nz/2005/01/maori-education-issues/

Barbour, R. (2008). Doing focus groups. London: SAGE.

Beane, J. (1993). A middle school curriculum: From rhetoric to reality. Columbus, OH: National Middle School Association.

Beane, J. (1995). Curriculum integration and the disciplines of knowledge. Phi Delta Kappan, 76(8), 616-622. 
Beane, J. (1997). Curriculum integration: designing the core of democratic education. New York: Teachers College Press.

Begg, A. (2008). Curriculum options: Being, knowing and exploring. Curriculum Matters, $4,1-6$.

Berg, B. (2009). Qualitative research methods for the social sciences (7th ed.). Boston: Allyn and Bacon.

Bickhard, M. (1997). Constructivisms and relativisms: A shopper's guide. Science \& Education, 6, 29-42.

Bishop, R., \& Berryman, M. (2006). Culture speaks: Cultural relationships and classroom learning. Wellington, New Zealand: Huia Publishers.

Boyd, S., \& Hipkins, R. (2012). Student inquiry and curriculum integration: Shared origins and points of difference (Part A). SET, 3, 15-23.

Brady, M. (1995). A supradisciplinary curriculum. In J. Beane (Ed.), Toward a coherent curriculum (pp. 16-25). Alexandria, VA: ASCD.

Brandt, R. (1991). On interdisciplinary curriculum: A conversation with Heidi Hayes Jacobs. Educational Leadership, 49(2), 24-26.

Brazee, E., \& Capelluti, J. (1993). Curriculum integration: Getting out of the blocks. NELMS Journal, 6(1), 25-29.

Brophy, J., \& Alleman, J. (1991). A caveat: Curriculum integration isn't always a good idea. Educational Leadership, 49(2), 66.

Brough, C. (2008). Student-centered curriculum and The New Zealand Curriculum. SET, $2,16-21$.

Bruner, J. (2009). Culture, mind, and education. In K. Illeris (Ed.), Contemporary theories of learning (pp. 159-168). Oxon, UK: Routledge. 
Burton, N., Brundrett, M., \& Jones, M. (2008). Doing your education research project. London: SAGE.

Case, R. (1991). The anatomy of curricular integration. Canadian Journal of Education, 16(2), 215-224. doi:10.2307/1494974

Chien, R. (2004). The classification and framing of the curriculum: A case of integrated studies (Ph.D. thesis). Curtin University of Technology, Perth, Australia.

Creswell, J. (2007). Qualitative inquiry \& research design: choosing among five approaches (2nd ed.). Thousand Oaks, CA: SAGE.

Davies, B., \& Bansel, P. (2007). Neoliberalism and education. International Journal of Qualitative Studies in Education, 20(3).

Dede, C. (2009). Comparing frameworks for "21st century skills". Harvard Graduate School of Education. Retrieved July 13, 2012, from http://www.watertown.k12.ma.us/dept/ed_tech/research/pdf/ChrisDede.pdf

Department for Education. (2012). The school curriculum. Department for Education. $\begin{array}{llll}\text { Retrieved } \quad \text { December } & \text { 2012, from }\end{array}$ http://www.education.gov.uk/schools/teachingandlearning/curriculum

Dewey, J. (1900). The child and the curriculum/ The school and society. Chicago: University of Chicago Press.

Dewey, J. (1916). Democracy and education. New York: The Macmillan Company.

Dewey, J. (1949). Experience and education. New York: The Macmillan Company.

Dowden, T. (2007). Curriculum integration for early adolescent schooling in Aotearoa New Zealand: Worthy of serious trial (Ph.D. thesis). Massey University, Palmerston North, New Zealand. 
Dowden, T. (2010). Curriculum integration in Aotearoa New Zealand: Rediscovering the potential of student-centered curriculum design in the middle years. Middle Years Schooling Association, 10(2), 4-10.

Dowden, T. (2012). Implementing curriculum integration: Three easy lessons from past practice. SET: Research information for teachers, 3, 25-31.

Drake, S. (1998). Creating integrated curriculum: Proven ways to increase student learning. Thousand Oaks, CA: Corwin Press.

Drake, S. (2007). Standards-based integrated curriculum (Second.). Thousand Oaks, CA: Corwin Press.

Drake, S. (n.d.). Integrated Curriculum. ASCD. Retrieved December 11, 2012, from http://www.ascd.org/publications/curriculumhandbook/425/chapters/Overview.aspx

Drake, S., \& Reid, J. (2010, September). Integrated curriculum: Increasing relevance while maintaining accountability. What Works?, 28, 1-4.

Erickson, H. (1995). Stirring the head, heart, and soul: Redifining curriculum and instruction. Thousand Oaks, CA: Corwin Press.

Field, E. (n.d.). Changing how learning takes place in secondary schools. Integrated $\begin{array}{llll}\text { Programs. } & \text { Retrieved } & \text { March } & \text { 19, }\end{array}$ http://integratedprograms.drupalgardens.com/

Fogarty, R. (1991). Ten ways to integrate curriculum. Educational Leadership, 49(2), 6165.

Fraser, D. (1999). They keep asking questions and want to know more: Enhancing students' (and teachers') learning through curriculum integration. Presented at the AARE/NZARE Joint Conference, Melbourne. 
Fraser, D, Aitken, V., Price, G., \& Whyte, B. (2012). Inquiry learning, drama and curriculum integration. SET, 3, 32-40.

Fraser, D, \& Deane, P. (2010). Making a difference: Agents of change through curriculum integration. SET, 3, 10-14.

Fraser, D, \& Paraha, H. (2002). Curriculum integration as Treaty praxis. Waikato Journal of Education, 8, 57-70.

Fraser, Deborah. (2000). Curriculum integration: what it is and what it is not. SET, 3, 3437.

Gilbert, J. (2005). Catching the knowledge wave? Wellington, New Zealand: NZCER.

Gilgun, J. (2010). Reflexivity and Qualitative Research. Current Issues in Qualitative Research, 1(2), 1-8.

Godinho, S., \& Imms, W. (2011). Voyage of the SS Discovery, and The Truman Show: Case studies of integrative approaches to bridging the disciplinary divides. Curriculum and Teaching, 26(1), 87-107.

Guba, E., \& Lincoln, Y. (2001). Competing paradigms in qualitative research. In C. Conrad, J. Grant Haworth, \& L. Lattuca (Eds.), Qualitative research in higher education: Expanding perspectives (2nd ed., pp. 57-71). Boston: Pearson Custom Publishing.

Hargreaves, A., Earl, L., \& Ryan, J. (1996). Schooling for change: Reinventing education for early adolescents. London: Falmer.

Hayes, W. (2007). The Progressive Education Movement: Is it still a factor in schools today? Lanham, MD: Rowman \& Littlefield Education.

Hipkins, R. (2008, June 20). Inquiry learning and key competencies. Perfect match or problematic partners? Presented at the CORE breakfast seminar, Wellington. Retrieved from http://nzcurriculum.tki.org.nz/Curriculum-stories/Keynotes- 
and-presentations/Inquiry-learning-and-key-competencies.-Perfect-match-orproblematic-partners

Hipkins, R. (2010). Reshaping the secondary school curriculum: Building the plane while flying it? Wellington, NZ: NZCER.

Hipkins, R, \& Boyd, S. (2011). The recursive elaboration of key competencies as agents of curriculum change. Curriculum Matters, 7, 70-86.

Hipkins, R, Cowie, B., Boyd, S., \& McGee, C. (2008). Themes from the curriculum implementation case studies (pp. 1-40). Wellington, NZ: NZCER.

Hodge, W. (n.d.). Basic education curriculum revisited: A look at the current content and reform. Singapore: Ministry of Education.

Hofstede, G. (2011). Dimensionalizing Cultures: The Hofstede Model in Context. Online Readings in Psychology and Culture, Unit 2, 2(1), 1-26.

Inman, S. (2011). Developing communities of learners. The Curriculum Journal, 22(4), 469-483.

Jacobs, H. (1989). Interdisciplinary curriculum: Design and implementation. Virginia: $\begin{array}{llll}\text { ASCD. } & \text { Retrieved } & 9 & \text { March, }\end{array}$ http://www.eric.ed.gov/ERICWebPortal/contentdelivery/servlet/ERICServlet?a ccno=ED316506

Jacobs, H. (1991). Planning for curriculum integration. Educational Leadership, 49(2), $27-28$.

James, W. (1995). Pragmatism. Mineola, NY: Dover Publications.

Johnson, B., \& Christensen, L. (2008). Educational research: quantitative, qualitative, and mixed approaches (3rd ed.). Thousand Oaks, CA: SAGE.

Kain, D. (1993). Cabbages and kings: Research directions in integrated/ interdisciplinary curriculum. The Journal of Educational Thought, 27(3), 312-331. 
Kaskey-Roush, M. (2008). How does using an integrated curriculum promote critical thinking and engagement in middle school student learning (Master's thesis). Ohio University, Ohio.

Kellow, J. (2009). What is Inquiry? Inquiring Mind. Retrieved October 15, 2012, from http://www.inquiringmind.co.nz/

Kilpatrick, W. (1926). Education for a changing civilisation. New York: MacMillan.

Kinsiz, M. (2010). Curriculum as a continuous dialogue: the integrated curriculum as a way to possibilities. Language and Dialogue, 1(2), 121-130.

Kress, G. (2007). Meaning and learning in a world of instability and multiplicity. Studies in Philosophy and Education, 27, 253-266. doi:10.1007/s11217-007-9070-2

Lave, J. (2009). The practice of learning. In K. Illeris (Ed.), Contemporary theories of learning (pp. 200-208). Oxon, UK: Routledge.

Leung, W. (2006). Teaching integrated curriculum: teachers' challenges. Pacific Asian Education, 18(1), 88-102.

Locke, J. (2008). Curriculum integration in secondary schools. Curriculum Matters, 4, 6984.

Loepp, F. (1999). Models of Curriculum Integration. Journal of Technology Studies, 25(2), para. 9.

MacMath, S., Roberts, G., Wallace, J., \& Chi, X. (2010). Curriculum integration and at-risk students: A Canadian case study examining student learning and motivation. British Journal of Special Education, 37(2), 87-94.

Matangi-Hulls, A. (2010). Enhancing student achievement through curriculum integration based on New Zealand's key competencies (Master's thesis). Massey University, Palmerston North, New Zealand. 
Merriam, S. (2001). Case studies as qualitative research. In C. Conrad, J. Haworth, \& L. Lattuca (Eds.), Qualitative research in higher education: expanding perspectives (2nd ed., pp. 191-201). Boston: Pearson Custom Publishing.

Ministry of Education. (2007). The New Zealand Curriculum. Learning Media Limited.

Ministry of Education. (n.d.). Find a School. Education Counts. Retrieved September 13, 2012, from http://www.educationcounts.govt.nz/find-a-school

Murdoch, K. (1998). Classroom connections: Strategies for integrated learning. Melbourne, Australia: Eleanor Curtain.

Mutch, C. (2010). Knowledge and the curriculum. Curriculum Matters, 6, 1-5.

N.I.U. (n.d.). Principles supporting qualitative research. Northern Illinois University. $\begin{array}{llll}\text { Retrieved } \quad \text { April } & \text { 15, } & \text { from }\end{array}$ http://www.cedu.niu.edu/ sorensen/502/powerpoint/topicD/qlnotes.htm

Nolan, C., McKinnon, H., \& Owens, L. (1992). A comparative analysis of the learning mode preferences of students in the Freyberg Integrated Studies Project with students in other secondary schools. Presented at the AARE/NZARE Joint Conference, Geelong.

OECD. (2005). The definition and selection of key competencies: Executive summary. $\begin{array}{llll}\text { Retrieved } 23 & \text { July, } & \text { 2012, }\end{array}$ http://www.pisa.oecd.org/dataoecd/47/61/35070367.pdf

Parr, B., Edwards, C., \& Leising, J. (2009). Selected effects of a curriculum integration intervention on the mathematics performance of secondary students enrolled in an agricultural power and technology course: an experimental study. Journal of Agricultural Education, 50(1), 57-69. doi:10.5032/jae.2009.01057

Peterson, R., \& Williams, D. (2000). “Gaps” between ethnic groups: Some key statistics. NZ Parliamentary Library. 
Poole, B. (n.d.). Motivational quotes. Retrieved April 4, 2012, from http://www.pitt.edu/ poole/ARCHIVE3.HTML.

Prasad, P. (2005). Critical theory: Hegemony, knowledge production, and communicative action. In Crafting qualitative research working in the postpositivist traditions (pp. 136-158). New York: Armonk.

Prince, B. (2010). Effectiveness of teacher preparation: from theory to practice (Ph.D. thesis). Capella University, Minnesota.

Reich, K. (2009). Constructivism: diversity of approaches and connections with pragmatism. In L. Hickman, S. Neubert, \& K. Reich (Eds.), John Dewey between pragmatism and constructivism (pp. 39-66). New York: Fordham University Press.

Rennie, L., Venville, G., \& Wallace, J. (2011). Learning science in an integrated classroom: Finding balance through theoretical triangulation. Journal of Curriculum Studies, 43(2), 139-162.

Russell, C., \& Burton, J. (2000). A report on Ontario secondary school integrated environmental studies programs. Canadian Journal of Environmental Education, 5, 287-304.

Samu, T. (2011). Understanding the lines in the sand: Diversity, its discourses and building a responsive education system. Curriculum Matters, 7, 175-194.

Schon, D. (1987). Educating the relective practitioner: toward a new design for teaching and learning in the professions. San Francisco, CA: Jossey-Bass.

Schultz, J. (2009). Reworking the manifesto: Social education for the twenty-first century. The Social Educator, 27(3), 27-35. 
Sharpe, E., \& Breunig, M. (2009). Sustaining environmental pedagogy in times of educational conservatism: A case study of integrated curriculum programs. Environmental Education Research, 15(3), 299-313.

Shriner, M., Schlee, B., \& Libler, R. (2010). Teachers' perceptions, attitudes and beliefs regarding curriculum integration. The Australian Educational Researcher, 37(1), $51-62$.

Stevens, R. (2006). Integrated middle school literacy instruction. Middle School Journal, $38(1), 13-20$.

Sutinen, A. (2008). Constructivism and education: Education as an interpretive transformational process. Studies in Philosophy and Education, 27, 1-14.

Taylor, P., Fraser, B., \& Fisher, D. (1997). Monitoring constructivist classroom learning environments. International Journal of Educational Research, 27(4), 293-302.

Thorburn, M., \& Collins, D. (2006). The effects of an integrated curriculum model on student learning and attainment. European Physical Education Review, 12(1), 3150. doi:10.1177/1356336X06060210

Thornley, C., \& Graham, S. (1999). Curriculum integration in the primary classroom, part one: Implicit integration. Presented at the AARE/ NZARE Joint Conference, Melbourne.

Timperley, H, Wilson, A., Barrar, H., \& Fung, I. (2007). Teacher professional learning and development. Ministry of Education. Retrieved 30 October, 2012, from http://www.educationcounts.govt.nz/_data/assets/pdf_file/0017/16901/TPLa ndDBESentire.pdf

Timperley, H. (2008). Teacher professional learning and development. International Academy of Education. $\quad$ Retrieved 
http://www.ibe.unesco.org/fileadmin/user_upload/Publications/Educational_Pr actices/EdPractices_18.pdf

Vars, G. (1997). Effects of integrative curriculum and instruction. In J. Irvin (Ed.), What current research says to the middle level practitioner (pp. 179-186). Columbus, OH: National Middle School Association.

Vars, G. (1991). Integrating curriculum in historical perspective. Educational Leadership, 49(2), 14-15.

Vars, G. (2001). Can curriculum integration survive in an era of high-stakes testing? Middle School Journal, 33(2), 7-17.

Wallace, J., Sheffield, R., Rennie, L., \& Venville, G. (2007). Looking back, looking forward: re-searching the conditions for curriculum integration in the middle years of schooling. Australian Educational Researcher, 34(2), 29-49.

Ward, L., \& Henderson, A. (2011). An evaluation of network learning communities. New Zealand: Ministry of Education.

Wenger, E. (2009). A social theory of learning. In K. Illeris (Ed.), Contemporary Theories of Learning (pp. 207-218). Oxon, UK: Routledge.

Whyte, B. (1999). I eat, breathe and sleep curriculum integration: Enhancing teachers' learning through curriculum integration. Presented at the AARE/NZARE Joint Conference, Melboure.

Wood, B., \& Sheehan, M. (2012). Dislodging knowlege? The New Zealand Curriculum in the 21st century. Pacific-Asian Education, 24(1), 17-30.

Yin, R. (2002). Case study research: Design and methods, 3rd edition (3rd ed.). Thousand Oaks, CA: SAGE.

Young, M. (1999). Knowledge, learning and the curriculum. British Educational Research Journal, 25(4), 463-477. 
Young, M. (2009). What are schools for? In H. Daniels, H. Lauder, \& J. Porter (Eds.), Knowledge, Values and Educational Policy: A Critical Perspective (pp. 10-18). Oxon, UK: Routledge.

Young, M., \& Muller, J. (2010). Three educational scenarios for the future: Lessons from the sociology of knowledge. European Journal of Education, 45(1), 11-27. 


\section{APPENDICES \\ Appendix 1: Information sheet for schools

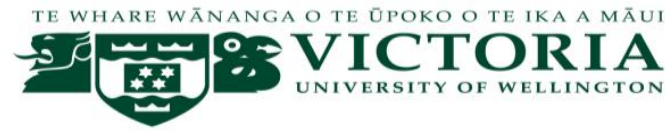 \\ Dear [Principalipal] \\ Title of research: Curriculum integration in NZ secondary schools: \\ Teachers' perceptions \& practice \\ Researcher: Susan Larkins, Faculty of Education, Victoria University of Wellington \\ RESEARCH INFORMATION SHEET: SCHOOL PRINCIPALS}

I am a Master in Education student at Victoria University of Wellington. As part of this degree I am conducting research into the perceptions and practices of NZ secondary school teachers regarding curriculum integration. My Master's research is supervised my Dr Bronwyn Wood, in the School of Education, Policy and Implementation. This research is approved by Victoria University Faculty of Education Ethics Committee Application Number 19339.

The research aims to provide an insight into New Zealand secondary school teachers' perceptions and practices regarding curriculum integration. The latest New Zealand curriculum endorses integration and there has consequently been a renewed interest in this area. The current literature suggests that there is broad variation of how curriculum integration is perceived, and that there is little research surrounding curriculum integration in New Zealand secondary schools, particularly considering how teachers' perceptions and practices have been formed.

The study aims to inform future professional development in the area of curriculum integration for secondary schools and teacher training establishments. The study may also be of interest to schools and the Ministry of Education in terms of updating them as to how aspects of the revised New Zealand curriculum are being interpreted and implemented.

I would like to invite your school, as one of six case study schools in New Zealand to participate in this research. Your school has been selected as you are a secondary school that is currently employing curriculum integration. Victoria University requires that ethics approval is obtained for research involving human participants. I would appreciate your consideration in consenting to the research being carried out in your school after reading the information outlining the research below.

\section{What is involved with the research?}

If you accept the invitation to partake in the research I would request that you nominate a member of staff as a point of contact to liaise with. I would visit the school to conduct four methods of data collection as follows:

Focus group interview - I would like to carry out a focus group session with six to eight teachers currently utilising curriculum integration. The teachers will be nominated by the 
liaison teacher. The interview would be arranged at a convenient time and will take approximately one hour, possibly during scheduled department meeting time. Each of the teachers will be given a copy of example questions prior to the focus group interview in order to introduce them to the topic of the interview and to help them reflect. This would require informed consent from the participating teachers. The interview will be audio taped.

Interview with the Principal - I will also interview you (or a delegate if you feel that would be more appropriate). This interview will be conducted using semi-structured questions similar to those used in the focus group interview and will take approximately 30 minutes. You will also receive example questions for reflection prior to the interview. The interview will be scheduled at your convenience. This would require informed consent from the Principal or delegate. The interview will also be audio taped.

Classroom observation - I will invite the focus group teachers to volunteer to have an observation take place in one of their curriculum integration lessons. I will ideally observe two or three teachers for one lesson each. Teachers will indicate on their consent form whether they would be willing to be observed.

Analysis of curriculum planning documents - I would also like to examine the school's curriculum integration planning documents, which will either be done at the school, or if electronic access is possible, this will be carried out off site.

\section{Privacy and confidentiality}

The names of all teachers the Principal (or delegates) and the school will remain confidential to the researcher and her supervisor. I will use pseudonyms for all individuals and the school in each write up stage of the research, including the final thesis.

All data collected will be stored in a locked filing cabinet and all electronic information will be password protected. Information from this research will be published in my thesis and some articles will be submitted for publication in academic journals and conferences. The thesis will be stored in the Victoria University library, where it will be accessible to staff, students and other library users. All data will be destroyed five years after completion of the research.

Teachers will be fully informed about the nature and requirements of the research and participation is voluntary. I will send the school a copy of the initial data analysis so that the teachers and Principal may provide clarification and feedback. I will also offer the opportunity to have audiofiles returned or wiped following analysis.

Please feel free to contact me with any questions that you may have regarding the research.

Thank you in anticipation of your contribution to this study.

Kind regards,

Susan Larkins

Contact details: [supplied] 


\section{Appendix 2: Consent to participation in research - schools}

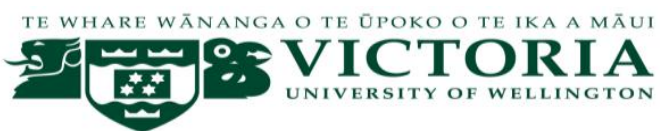

Title of research: Curriculum integration in NZ secondary schools:

Teachers' perceptions \& practice

Researcher: Susan Larkins, Faculty of Education, Victoria University of Wellington

I have read the enclosed letter outlining the purpose and structure of the research and I give consent for Susan Larkins, Mater's student at Victoria University of Wellington, Faculty of Education, to invite teachers to participate in her research project.

Signed (Principal): Date:

Name of Principal:

I am happy for the name of the school to be used in the research write up

I would prefer that a pseudonym is used in the thesis write up for the school name

OR $(\sqrt{ })$ I have emailed my consent

\section{School name:}

Nominated liaison teacher:

Liaison teacher email:

Contact number: 


\title{
Appendix 3: Information sheet for teachers
}

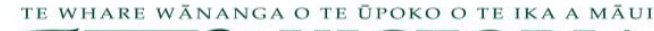 \\ Date......

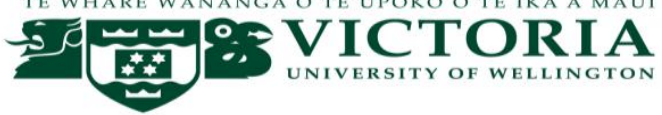 \\ Dear [teacherer]. \\ Title of research: Curriculum integration in NZ secondary schools: Teachers' perceptions \& \\ practice
}

Researcher: Susan Larkins, Faculty of Education, Victoria University of Wellington

\section{RESEARCH INFORMATION SHEET: CURRICULUM INTEGRATION TEACHERS}

I am a Master in Education student at Victoria University of Wellington. As part of this degree I am conducting research into the perceptions and practices of New Zealand secondary school teachers regarding curriculum integration. My Master's research is supervised my Dr Bronwyn Wood, in the School of Education, Policy and Implementation. [The Victoria University Research and Human Ethics Committees have approved my research].

The research aims to provide an insight into New Zealand secondary school teachers' perceptions and practices regarding curriculum integration. The latest New Zealand curriculum endorses integration and there has consequently been a renewed interest in this area. The current literature suggests that there is broad variation of how curriculum integration is perceived, and that there is little research surrounding curriculum integration in NZ secondary schools, particularly considering how teachers' perceptions and practices have been formed.

The study aims to inform future professional development in the area of curriculum integration for secondary schools and teacher training establishments. The study may also be of interest to schools and the Ministry of Education in terms of updating them as to how aspects of the revised New Zealand curriculum are being interpreted and implemented.

\section{What is involved with the research?}

I am inviting teachers who employ curriculum integration from your school to participate voluntarily in this research. If you accept the invitation to partake in this study you would join a focus group interview. The interview would take place at school and will be conducted during normal school hours (e.g. department meeting or professional learning time). The interview will last approximately one hour and will involve a group discussion about your perceptions of curriculum integration. An example of some of the questions that will be asked in the interview can be found below. The interview will be audio taped and the data transcribed at a later date.

Victoria University requires that ethics approval for research involving human participants is obtained. If you would like to accept the invitation to participate in this research, could you please sign the form below and return it to me at the time of our focus group interview or email your consent to me prior to the interview. 
I will also be conducting classroom observations of two to three of the focus group teachers. This will be during one lesson using curriculum integration. If you would be happy to be observed then you can indicate this on the consent form.

\section{Example of interview questions}

1. How would you describe curriculum integration?

2. What do you think are the key themes of curriculum integration?

3. What do you think are the advantages and disadvantages of curriculum integration?

4. Do you explicitly plan for curriculum integration in your lessons, and if so, how?

5. Do you base your curriculum integration on a specific theory, and if so, which?

6. Describe what it looks like when curriculum integration is happening in your classroom.

\section{Privacy and confidentiality}

The names of all teachers, the Principal (or delegate) and the school will remain confidential to the researcher and her supervisor. I will use pseudonyms for all individuals and the school in each write up stage of the research, including the final thesis.

All data collected will be stored in a locked filing cabinet and all electronic information will be password protected. Information from this research will be published in my thesis and some articles will be submitted for publication in academic journals and conferences. The thesis will be stored in the Victoria University library, where it will be accessible to staff, students and other library users. All data will be destroyed five years after completion of the research.

I will send the school a copy of the initial data analysis so that you and the Principal may provide clarification and feedback. I will also offer the opportunity to have audiotapes returned or wiped following analysis. You may indicate your preference on the consent form.

Please feel free to contact me with any questions that you may have regarding the research.

Thank you in anticipation of your contribution to this study.

Kind regards,

Susan Larkins

Contact details: [supplied] 


\section{Appendix 4: Consent to participation in research: teachers}

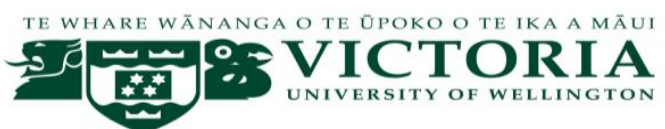

Title of research: Curriculum integration in NZ secondary schools:

\section{Teachers' perceptions \& practice}

Researcher: Susan Larkins, Faculty of Education, Victoria University of Wellington

I have been given and understand the information about this research project. I have had an opportunity to ask questions and have them answered to my satisfaction.

I consent to taking part in a semi-structured interview and to the interview being audio recorded and transcribed.

I understand that I may withdraw myself (or any information I have provided) from this project (before data collection and analysis is complete) without having to give reasons or without penalty of any sort.

I understand that any information I provide will be kept confidential to the researcher, the supervisor, the published results will not use my name, and that no opinions will be attributed to me in any way that will identify me.

I understand that the tape recording of the interview will be electronically wiped at the end of the project unless I indicate that I would like them returned to me.

I would like my audiotape interview electronically wiped / returned/ (delete one) at the conclusion of the research.

I consent to the interview data, including relevant quotes, being included in the completed thesis, educational publications and conferences, once names and other identifying details have been altered and I am aware that the completed thesis will be stored in the Victoria University library and may be accessed by staff, students and other library users.

I would like to receive feedback on the findings of this research (if yes, please provide email below)

I would be happy to be observed teaching CI in my classroom.

I would prefer not to be observed teaching CI in my classroom.
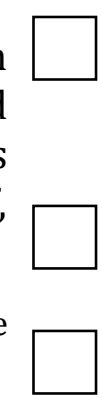

$$
\text { I would prefer not to be observed teaching Cl in my classroom. }
$$

\begin{tabular}{|l|c|}
\hline Signed: & \\
\hline Name: & Dmail: \\
\hline School: & \\
\hline
\end{tabular}




\section{Appendix 5: Information sheet for Principals \& nominees}

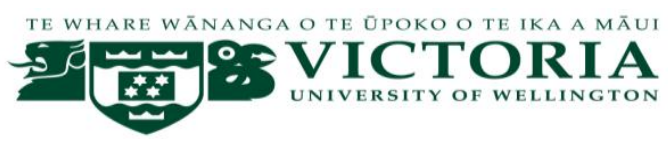

Date......

Dear [Princincipal]

Title of research: Curriculum integration in NZ secondary schools: Teachers' perceptions \& practice

Researcher: Susan Larkins, Faculty of Education, Victoria University of Wellington

\section{RESEARCH INFORMATION SHEET: PARTICIPANT PRINCIPAL (OR NOMINEE)}

I am a Master in Education student at Victoria University of Wellington. As part of this degree I am conducting research into the perceptions and practices of New Zealand secondary school teachers regarding curriculum integration. My Master's research is supervised my Dr Bronwyn Wood, in the School of Education, Policy and Implementation. [The Victoria University Research and Human Ethics Committees have approved my research].

The research aims to provide an insight into New Zealand secondary school teachers' perceptions and practices regarding curriculum integration. The latest New Zealand curriculum endorses integration and there has consequently been a renewed interest in this area. The current literature suggests that there is broad variation of how curriculum integration is perceived, and that there is little research surrounding curriculum integration in NZ secondary schools, particularly considering how teachers' perceptions and practices have been formed.

The study aims to inform future professional development in the area of curriculum integration for secondary schools and teacher training establishments. The study may also be of interest to schools and the Ministry of Education in terms of updating them as to how aspects of the revised New Zealand curriculum are being interpreted and implemented.

\section{What is involved with the research?}

I am inviting Principals or a chosen nominee from schools currently employing curriculum integration to participate voluntarily in this research. If you accept the invitation to partake in this study you would be interviewed by the researcher. The interview would take place at school and will be conducted as a time convenient to you. The interview will last approximately 30 minutes and will involve questions regarding your perceptions of curriculum integration. An example of some of the questions that will be asked in the interview can be found below. The interview will be audio taped and the data transcribed at a later date.

Victoria University requires that ethics approval for research involving human participants is obtained. If you would like to accept the invitation to participate in this research, could you please sign the form below and return it to me at the time of our focus group interview or email your consent to me prior to the interview. 


\section{Example of interview questions}

1. How would you describe curriculum integration?

2. What do you think are the key themes of curriculum integration?

3. What do you think are the advantages and disadvantages of curriculum integration?

4. Is curriculum integration at your school based on a specific theory, and if so, which?

5. Describe what it looks like when curriculum integration is happening.

\section{Privacy and confidentiality}

The names of all teachers, the Principal (or delegate) and the school will remain confidential to the researcher and her supervisor. I will use pseudonyms for all individuals and the school in each write up stage of the research, including the final thesis.

All data collected will be stored in a locked filing cabinet and all electronic information will be password protected. Information from this research will be published in my thesis and some articles will be submitted for publication in academic journals and conferences. The thesis will be stored in the Victoria University library, where it will be accessible to staff, students and other library users. All data will be destroyed five years after completion of the research.

I will send the school a copy of the initial data analysis so that you and the Principal may provide clarification and feedback. I will also offer the opportunity to have audiotapes returned or wiped following analysis. You may indicate your preference on the consent form.

Please feel free to contact me with any questions that you may have regarding the research.

Thank you in anticipation of your contribution to this study.

Kind regards,

Susan Larkins

Contact details: [supplied] 


\title{
Appendix 6: Consent to participation in research: Principals
}

\author{
TE WHARE WĀNANGA O TE ŨPOKO O TE IKA A MĀUI \\ ST VICTORIA \\ * UNIVERSITY OF WELLINGTON \\ CONSENT TO PARTICIPATION IN RESEARCH: PRINCIPAL INTERVIEW
}

Title of research: Curriculum integration in NZ secondary schools:

\section{Teachers' perceptions \& practice}

Researcher: Susan Larkins, Faculty of Education, Victoria University of Wellington

I have been given and understand the information about this research project. I have had an opportunity to ask questions and have them answered to my satisfaction.

I consent to taking part in a semi-structured interview and to the interview being audio recorded and transcribed.

I understand that I may withdraw myself (or any information I have provided) from this project (before data collection and analysis is complete) without having to give reasons or without penalty of any sort.

I understand that any information I provide will be kept confidential to the researcher, the supervisor, the published results will not use my name, and that no opinions will be attributed to me in any way that will identify me.

I would like an opportunity to check the interview transcript after initial data analysis.

I understand that the tape recording of the interview will be electronically wiped at the end of the project unless I indicate that I would like them returned to me.

I would like my audiotape interview electronically wiped / returned/ (delete one) at the conclusion of the research.

I consent to the interview data, including relevant quotes, being included in the completed thesis, educational publications and conferences, once names and other identifying details have been altered and I am aware that the completed thesis will be stored in the Victoria University library and may be accessed by staff, students and other library users.

I would like to receive feedback on the findings of this research
Signed:
Date:

Name:

School:

Please feel free to contact me with any questions that you may have regarding the research. 


\section{Appendix 7: Demographic information}

\begin{tabular}{|l|l|}
\hline School: & \\
\hline Name: & \\
\hline $\begin{array}{l}\text { Pseudonym: (you may } \\
\text { choose or the researcher can } \\
\text { choose for you) }\end{array}$ & \\
\hline Age: & \\
\hline Ethnicity: & \\
\hline $\begin{array}{l}\text { Teaching } \\
\text { qualifications: }\end{array}$ & \\
\hline $\begin{array}{l}\text { Subject specialism(s): } \\
\text { Number of years } \\
\text { teaching: }\end{array}$ & \\
\hline $\begin{array}{l}\text { Number of years } \\
\text { teaching curriculum } \\
\text { integration: }\end{array}$ & \\
\hline
\end{tabular}

\section{Questions for focus group and semi-structured interview}

1. How would you describe curriculum integration (CI)?

2. What do you think are the key themes of CI?

3. What do you think are the advantages of CI?

4. What do you think are the disadvantages of CI?

5. Do you explicitly plan for $\mathrm{CI}$ in your lessons, and if so, how?

6. Do you base your CI on a specific theory, and if so, which?

7. Have you received any professional development focused on CI?

8. How do you feel that $\mathrm{CI}$ is perceived by your senior leadership team?

9. Are you are able to integrate as much as you would like in your lessons? Please explain.

10. How would you describe your approach to CI has changed over time, if at all?

11. Describe what it looks like when $\mathrm{CI}$ is happening in your classroom.

12. What metaphor or analogy would you use to describe CI? 
Appendix 8: Observation protocol

\begin{tabular}{|l|l|l|l|}
\hline $\begin{array}{l}\text { Teacher } \\
\text { pseudonym: }\end{array}$ & Date: & Subject: & Topic: \\
\hline Descriptive notes: & Reflective notes: \\
\hline $\begin{array}{l}\text { Questions } \\
\text { relating to } \\
\text { students' } \\
\text { interest? }\end{array}$ & & & \\
\hline & & & \\
\hline $\begin{array}{l}\text { Building on } \\
\text { students' prior } \\
\text { knowledge \& } \\
\text { understanding? }\end{array}$ & & & \\
\hline $\begin{array}{l}\text { Reference to } \\
\text { explicit } \\
\text { discipline } \\
\text { knowledge? }\end{array}$ & & Seating: & Rows \\
\hline & & & \\
\hline $\begin{array}{l}\text { Context given } \\
\text { for content } \\
\text { learning? }\end{array}$ & & & \\
\hline $\begin{array}{l}\text { Linking of } \\
\text { content to } \\
\text { ather subject }\end{array}$ & & & \\
\hline & & & \\
\hline
\end{tabular}

